\title{
Guidelines for the diagnosis and treatment of pulmonary hypertension
}

The Task Force for the Diagnosis and Treatment of Pulmonary Hypertension of the European Society of Cardiology (ESC) and the European Respiratory Society (ERS) endorsed by the International Society of Heart and Lung Transplantation (ISHLT)
N. Galiè, M.M. Hoeper, M. Humbert, A. Torbicki, J-L. Vachiery, J.A. Barbera, M. Beghetti, P. Corris, S. Gaine, J.S. Gibbs, M.A. Gomez-Sanchez, G. Jondeau, W. Klepetko, C. Opitz, A. Peacock, L. Rubin, M. Zellweger and G. Simonneau

\section{CONTENTS}

Preamble

1. Introduction

2. Definitions

3. Clinical classification of pulmonary hypertension

4. Pathology of pulmonary hypertension

5. Pathobiology of pulmonary hypertension

6. Genetics, epidemiology and risk factors of pulmonary hypertension

7. Pulmonary arterial hypertension (group 1)

7.1 Diagnosis

7.1.1 Clinical presentation

7.1.2 Electrocardiogram

7.1.3 Chest radiograph

7.1.4 Pulmonary function tests and arterial blood gases

7.1.5 Echocardiography

7.1.6 Ventilation/perfusion lung scan

7.1.7 High-resolution computed tomography, contrast-enhanced computed tomography and pulmonary angiography

7.1.8 Cardiac magnetic resonance imaging

7.1.9 Blood tests and immunology

7.1.10 Abdominal ultrasound scan

7.1.11 Right heart catheterisation and vasoreactivity

7.1.12 Diagnostic algorithm

7.2 Evaluation of severity

7.2.1 Clinical, echocardiographic and haemodynamic parameters

7.2.2 Exercise capacity

7.2.3 Biochemical markers

7.2.4 Comprehensive prognostic evaluation

7.2.5 Definition of patient status

7.2.6 Treatment goals and follow-up strategy (see also section 7.3.7 and table 22)

7.3 Therapy

7.3.1 General measures

Physical activity and supervised rehabilitation

Pregnancy, birth control and post-menopausal hormonal therapy
AFFILIATIONS

Affiliation details for the authors/Task Force members are given in the Acknowledgements section. Full details of members of the ESC Committee Practice Guidelines, and the document reviewers are also provided in the Acknowledgements.

CORRESPONDENCE

N. Galiè

Institute of Cardiology

Bologna University Hospital

Via Massarenti 9

40138 Bologna

Italy

E-mail: nazzareno.galie@unibo.it

Received:

Sept 022009

Accepted after revision:

Sept 022009

First published online:

Sept 242009 


\begin{tabular}{|c|c|c|}
\hline & & \\
\hline & Psychosocial support. & 1237 \\
\hline & Infection prevention . . & 1237 \\
\hline & Elective surgery & \\
\hline $7.3 .2 \varsigma$ & Supportive therapy & \\
\hline & Oral anticoagulants & \\
\hline & Diuretics $\ldots \ldots \ldots \ldots \ldots \ldots$ & \\
\hline & Oxygen $\ldots \ldots \ldots \ldots \ldots \ldots \ldots$ & \\
\hline & $\ldots \ldots \ldots \ldots$ & \\
\hline $7.3 .3 \varsigma$ & Specific drug therapy . & \\
\hline & Calcium channel blockers . . . . . . . . . . . . . & \\
\hline & Prostanoids . . . . . . . . . . . . . . . & \\
\hline & Endothelin receptor antagonists . . . . . . . . . . & \\
\hline & Phosphodiesterase type-5 inhibitors . . . . . . . . & \\
\hline & $\begin{array}{l}\text { Experimental compounds and alternative medica } \\
\text { strategies } \ldots \ldots \ldots \ldots \ldots \ldots \ldots \ldots \ldots\end{array}$ & \\
\hline & Combination therapy . . . . . . . . . . . . . . . & \\
\hline & $\ldots \ldots \ldots \ldots$ & \\
\hline 7.3.4 T & Treatment of arrhythmias ... . & \\
\hline $7.3 .5 \mathrm{E}$ & Balloon atrial septostomy $\ldots . . . . . . .$. & \\
\hline 7.3.6 T & antation . . . . . . . . . . . . . . & \\
\hline 7.3.7 T & ent algorithm . . . . . . . . . . & \\
\hline 7.3.8 E & e care and ethical issues & \\
\hline 7.4 Spec & cific pulmonary arterial hypertension subsets & \\
\hline 7.4.1 $\mathrm{P}$ & Paediatric pulmonary arterial hypertension ... & \\
\hline & Diagnosis & \\
\hline & $\ldots \ldots \ldots \ldots \ldots \ldots$ & \\
\hline 7.4.2 F & $\begin{array}{l}\text { Pulmonary arterial hypertension associated } \\
\text { with congenital cardiac shunts . . . . . . . . }\end{array}$ & \\
\hline & Diagnosis & \\
\hline & $\ldots \ldots \ldots \ldots \ldots \ldots \ldots \ldots$ & \\
\hline 7.4.3 P & Pulmonary arterial hypertension associated & \\
\hline
\end{tabular}

\section{PREAMBLE}

Guidelines and Expert Consensus Documents summarise and evaluate all currently available evidence on a particular issue with the aim to assist physicians in selecting the best management strategies for a typical patient, suffering from a given condition, taking into account the impact on outcome, as well as the risk/benefit ratio of particular diagnostic or therapeutic means. Guidelines are no substitutes for textbooks. The legal implications of medical guidelines have been discussed previously.

A great number of Guidelines and Expert Consensus Documents have been issued in recent years by the European Society of Cardiology (ESC) as well as by other societies and organisations. Because of the impact on clinical practice, quality criteria for development of guidelines have been established in order to make all decisions transparent to the user. The recommendations for formulating and issuing ESC Guidelines and Expert Consensus Documents can be found on the ESC website (http://www.escardio.org/knowledge/ guidelines).
Diagnosis . . . . . . . . . . . . . . . . . . . . 1248

Therapy . . . . . . . . . . . . . . . . . . . . . . . . . 1249

7.4.4 Pulmonary arterial hypertension associated with portal hypertension . . . . . . . . . . . . . . 1249

Diagnosis . . . . . . . . . . . . . . . . . . . . . 1249

Therapy . . . . . . . . . . . . . . . . . . . . . . . 1250

7.4.5 Pulmonary arterial hypertension associated with HIV infection . . . . . . . . . . . . . . . 1250

Diagnosis . . . . . . . . . . . . . . . . . . . 1250

Therapy . . . . . . . . . . . . . . . . . . . . . . . 1250

8. Pulmonary veno-occlusive disease and pulmonary capillary haemangiomatosis (group 1') . . . . . . . 1251

8.1 Pulmonary veno-occlusive disease . . . . . . . . . . 1251

8.1.1 Diagnosis . . . . . . . . . . . . . . . . . . . 1251

8.1.2 Therapy . . . . . . . . . . . . . . . . . . . . . . . 1251

8.2 Pulmonary capillary haemangiomatosis ... . . . . 1252

9. Pulmonary hypertension due to left heart disease

(group 2) . . . . . . . . . . . . . . . . . . . . . . . 1252

9.1 Diagnosis . . . . . . . . . . . . . . . . . . 1252

9.2 Therapy . . . . . . . . . . . . . . . . . . . . . . . . . 1253

10. Pulmonary hypertension due to lung diseases and/or hypoxia (group 3) . . . . . . . . . . . . . 1253

10.1 Diagnosis . . . . . . . . . . . . . . . . . . 1253

10.2 Therapy ... . . . . . . . . . . . . . . . . . . . . 1254

11. Chronic thromboembolic pulmonary

hypertension (group 4) . . . . . . . . . . . . . . . . 1254

11.1 Diagnosis . . . . . . . . . . . . . . . . . . . . . 1254

11.2 Therapy . . . . . . . . . . . . . . . . . . . . 1255

12. Definition of a pulmonary arterial hypertension

referral centre ...................... 1255

Statement of interest . . . . . . . . . . . . . . 1256

Acknowledgements . . . . . . . . . . . . . . . . 1256

References . . . . . . . . . . . . . . . . . . 1257

In brief, experts in the field are selected and undertake a comprehensive review of the published evidence for management and/or prevention of a given condition.

Unpublished clinical trial results are not taken into account. A critical evaluation of diagnostic and therapeutic procedures is performed including assessment of the risk/benefit ratio. Estimates of expected health outcomes for larger societies are included, where data exist. The level of evidence and the strength of recommendation of particular treatment options are weighed and graded according to predefined scales, as outlined in tables 1 and 2.

The experts of the writing panels have provided disclosure statements of all relationships they may have which might be perceived as real or potential sources of conflicts of interest. These disclosure forms are kept on file at the European Heart House, headquarters of the ESC. Any changes in conflict of interest that arise during the writing period must be notified to the ESC. The Task force report was jointly and entirely supported financially by the ESC and the European Respiratory Society (ERS) and was developed without any involvement of the industry. 
The ESC Committee for Practice Guidelines (CPG) supervises and coordinates the preparation of new Guidelines and Expert Consensus Documents produced by Task Forces, expert groups, or consensus panels. The Committee is also responsible for the endorsement process of these Guidelines and Expert Consensus Documents or statements. Once the document has been finalised and approved by all the experts involved in the Task Force, it is submitted to outside specialists for review. The document is revised, and finally approved by the CPG and subsequently published. The Guidelines on the diagnosis and treatment of pulmonary hypertension have been developed by a joint Task Force of the ESC and of the ERS and the document has been approved by the ESC CPG and the ERS Scientific Committee.

After publication, dissemination of the message is of paramount importance. Pocket-sized versions and personal digital assistant (PDA)-downloadable versions are useful at the point of care. Some surveys have shown that the intended end-users are sometimes not aware of the existence of guidelines, or simply do not translate them into practice. So this is why implementation programmes for new guidelines form an important component of the dissemination of knowledge. Meetings are organised by the ESC, and directed towards its member National Societies and key opinion leaders in Europe. Implementation meetings can also be undertaken at national levels, once the guidelines have been endorsed by the ESC member societies, and translated into the national language. Implementation programmes are needed because it has been shown that the outcome of disease may be favourably influenced by the thorough application of clinical recommendations.

Thus, the task of writing Guidelines or Expert Consensus documents covers not only the integration of the most recent research, but also the creation of educational tools and implementation programmes for the recommendations. The loop between clinical research, writing of guidelines, and implementing them into clinical practice can then only be completed if surveys and registries are performed to verify

\section{TABLE 1 Classes of recommendations}

\begin{tabular}{l}
$\begin{array}{l}\text { Classes of } \\
\text { recommendations }\end{array}$ \\
\hline $\begin{array}{c}\text { Definition } \\
\text { Class I } \\
\text { given treatment or procedure is } \\
\text { beneficial, useful, effective. } \\
\text { Conflicting evidence and/or a divergence of } \\
\text { opinion about the usefulness/efficacy of } \\
\text { the given treatment or procedure. } \\
\text { Weight of evidence/opinion is in favour of } \\
\text { usefulness/efficacy. }\end{array}$ \\
Class IIa \\
Class IIb \\
Usefulness/efficacy is less well established \\
by evidence/opinion. \\
Evidence or general agreement that the \\
given treatment or procedure is not \\
useful/effective, and in some cases may \\
be harmful.
\end{tabular}

that real-life daily practice is in keeping with what is recommended in the guidelines. Such surveys and registries also make it possible to evaluate the impact of implementation of the guidelines on patient outcomes. Guidelines and recommendations should help the physicians to make decisions in their daily practice; however, the ultimate judgement regarding the care of an individual patient must be made by the physician in charge of his/her care.

\section{INTRODUCTION}

The Guidelines on the diagnosis and treatment of pulmonary hypertension $(\mathrm{PH})$ are intended to provide the medical community with updated theoretical and practical information on the management of patients with $\mathrm{PH}$. As multiple medical specialties are involved with this topic and different levels of insight may be needed by diverse physicians, these Guidelines should be considered as a compromise between heterogeneous requirements. The new features of this Guidelines document are:

- A joint Task Force of the ESC and of the ERS has developed these Guidelines. In addition, members of the International Society for Heart and Lung Transplantation and of the Association for European Paediatric Cardiology have been included.

- $\mathrm{PH}$ is a haemodynamic and pathophysiological state (table 3) that can be found in multiple clinical conditions. These have been classified into six clinical groups with specific characteristics (table 4) [1-6]. To highlight the remarkable differences between these clinical groups, a comparative description of pathology, pathobiology, genetics, epidemiology and risk factors is detailed in the first part. More practical information related to clinical presentation, diagnostic features and treatment are described in the second part for each individual group.

- As the diagnostic strategy in patients with suspected PH is of utmost importance, a new diagnostic algorithm has been provided in the section dedicated to pulmonary arterial hypertension (PAH, group 1). In this case the diagnosis requires the exclusion of all other groups of $\mathrm{PH}$.

- PAH (tables 4 and 5) represents the condition described more extensively due to the availability of specific treatments. Based on the publication of recent randomised controlled trials (RCTs) a new treatment algorithm with updated levels of evidence and grades of recommendation and the current approval status in different geographic

\section{TABLE 2 Levels of evidence}

Level of evidence $\mathbf{A}$

Level of evidence B

Level of evidence $C$
Data derived from multiple randomised clinical trials" ${ }^{\#}$ or meta-analyses. Data derived from a single randomised clinical trial ${ }^{\#}$ or large nonrandomised studies.

Consensus of opinion of the experts and/or small studies, retrospective studies, registries.

\#: or large accuracy or outcome trial(s) in the case of diagnostic tests or strategies. 


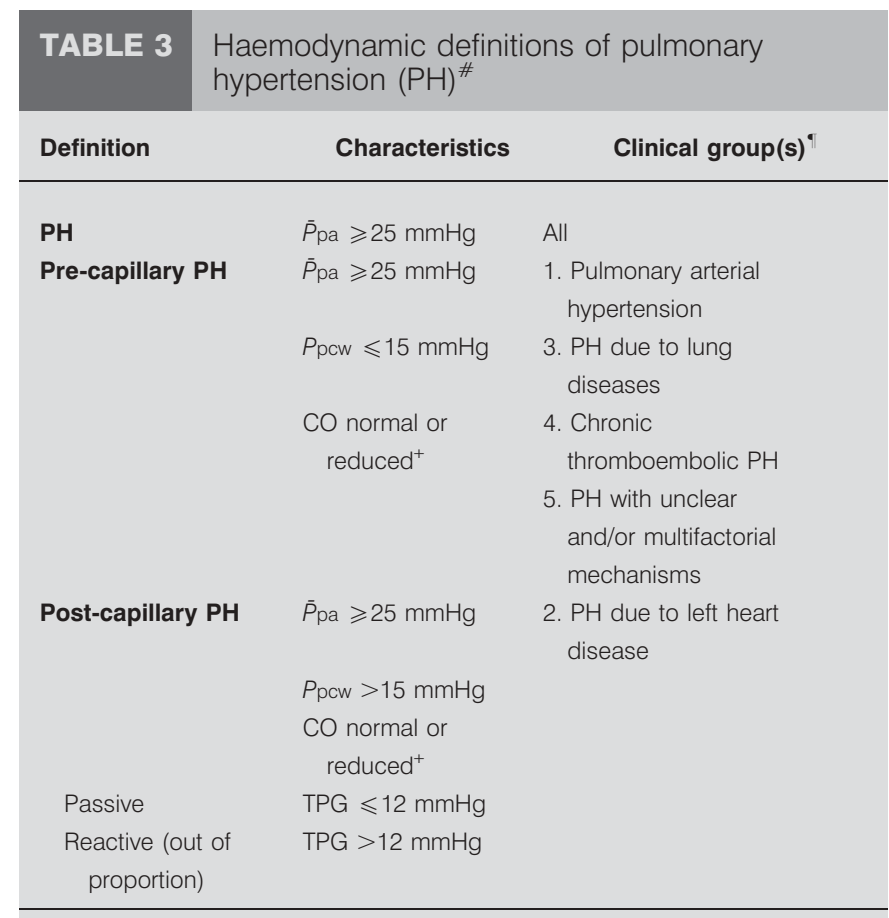

$\bar{P}_{\text {pa: }}$ mean pulmonary arterial pressure; Ppcw: pulmonary capillary wedge pressure; CO: cardiac output; TPG: transpulmonary pressure gradient $(\bar{P}$ pa$\bar{P}$ pcw). ${ }^{\# \text { : }}$ all values measured at rest; " ${ }^{\prime}$ : according to table 4 ; $^{+}$: high $\mathrm{CO}$ can be present in cases of hyperkinetic conditions such as systemic-to-pulmonary shunts (only in the pulmonary circulation), anaemia, hyperthyroidism, etc.

areas have been provided. Definitions for the evaluation of a patient's severity, treatment goals and follow-up strategy have been also included. The specific characteristics of the different types of $\mathrm{PAH}$ including paediatric $\mathrm{PAH}$ have been highlighted.

- The other four main clinical groups of $\mathrm{PH}$, i.e. pulmonary veno-occlusive disease (PVOD, group 1'), $\mathrm{PH}$ due to left heart disease (group 2), PH due to lung diseases (group 3) and chronic thromboembolic pulmonary hypertension (CTEPH, group 4) have been discussed individually while the heterogeneity and rarity of the conditions included in group 5 (table 4) prevent an appropriate description in these guidelines.

\section{DEFINITIONS}

$\mathrm{PH}$ has been defined as an increase in mean pulmonary arterial pressure $\left(\bar{P}_{\mathrm{pa}}\right) \geqslant 25 \mathrm{mmHg}$ at rest as assessed by right heart catheterisation (RHC; tables 3 and 5) [7,8]. This value has been used for selecting patients in all RCTs and registries of PAH [3, $4,8]$. Recent re-evaluation of available data has shown that the normal $\bar{P}_{\text {pa }}$ at rest is $14 \pm 3 \mathrm{mmHg}$, with an upper limit of normal of $\sim 20 \mathrm{mmHg}[9,10]$. The significance of a $\bar{P}_{\mathrm{pa}}$ between 21 and $24 \mathrm{mmHg}$ is unclear. Patients presenting with $\mathrm{PAP}$ in this range need further evaluation in epidemiological studies.

The definition of $\mathrm{PH}$ on exercise as a $\bar{P}_{\mathrm{pa}}>30 \mathrm{mmHg}$ as assessed by RHC is not supported by published data and healthy individuals can reach much higher values $[9,11]$. Thus

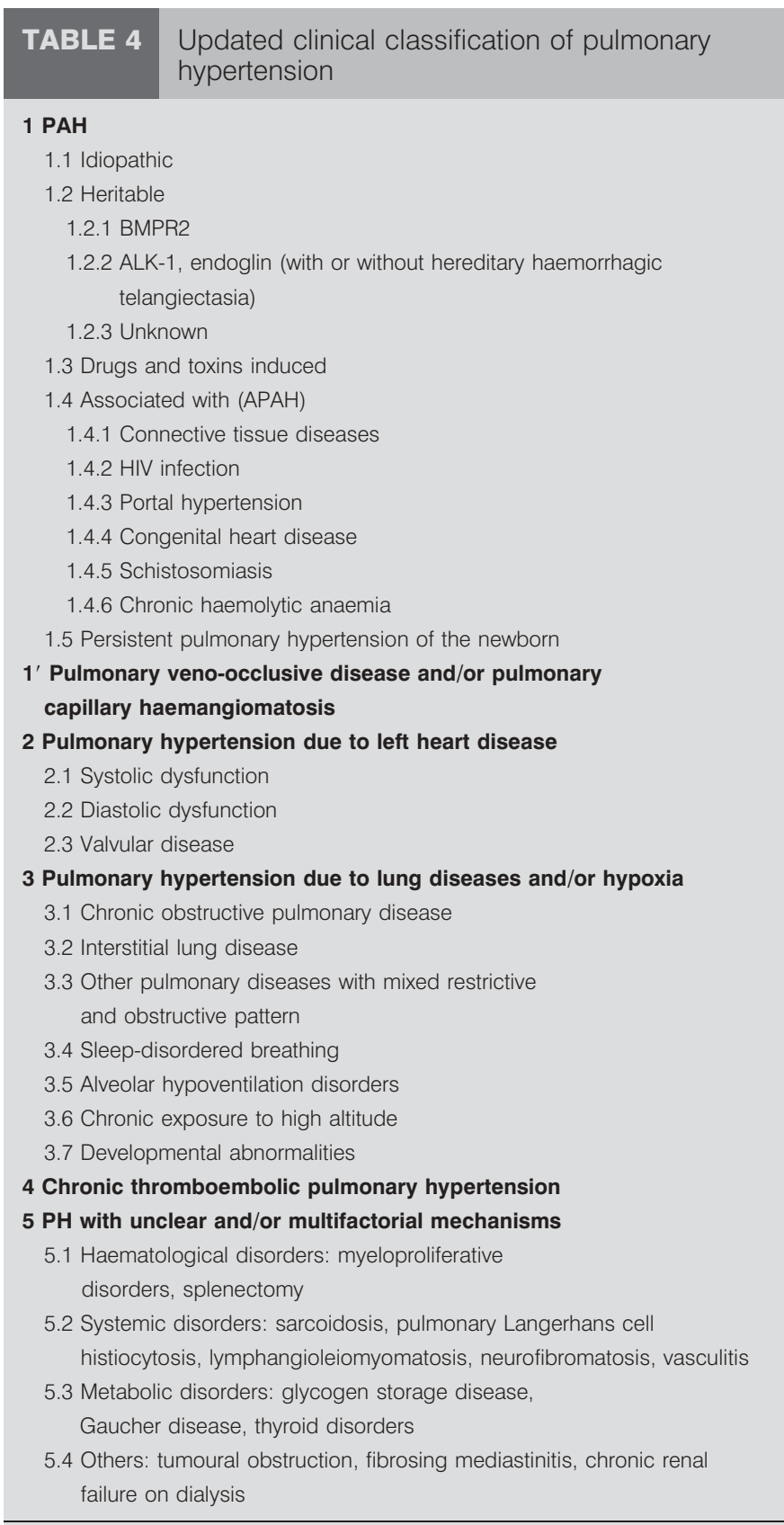

BMPR2: bone morphogenetic protein receptor, type 2; ALK-1: activin receptorlike kinase 1 gene; APAH: associated pulmonary arterial hypertension; PAH: pulmonary arterial hypertension. Reproduced from Dana Point [1], with permission from the publisher.

no definition for $\mathrm{PH}$ on exercise as assessed by RHC can be provided at the present time.

According to various combinations of values of pulmonary capillary wedge pressure $(P \mathrm{pcw})$, pulmonary vascular resistance (PVR) and cardiac output (CO), different haemodynamic definitions of $\mathrm{PH}$ are shown in table 3. Pre-capillary $\mathrm{PH}$ includes the clinical groups 1, 3, 4 and 5 while post-capillary $\mathrm{PH}$ includes the clinical group 2 (table 4) [12]. The features of each group will be discussed in specific sections. 


\section{TABLE 5 Important definitions}

\section{$\mathrm{PH}$ is a haemodynamic and pathophysiological}

condition defined as an increase in $\bar{P}$ pa $\geqslant 25 \mathrm{mmHg}$ at rest as assessed by right heart catheterisation (table 3). $\mathrm{PH}$ can be found in multiple clinical conditions (table 4).

The definition of $\mathrm{PH}$ on exercise as a $\bar{P}$ pa $>\mathbf{3 0} \mathbf{~ m m H g}$ as assessed by right heart catheterisation is not supported by published data.

PAH (group 1) is a clinical condition characterised by the presence of pre-capillary $\mathrm{PH}$ (table 3 ) in the absence of other causes of pre-capillary $\mathrm{PH}$ such as $\mathrm{PH}$ due to lung diseases, chronic thromboembolic $\mathrm{PH}$, or other rare diseases (table 4). PAH includes different forms that share a similar clinical picture and virtually identical pathological changes of the lung microcirculation (table 4).

PH: pulmonary hypertension; $\bar{P}$ pa: mean pulmonary arterial pressure; $\mathrm{PAH}$ pulmonary arterial hypertension.

\section{CLINICAL CLASSIFICATION OF PULMONARY HYPERTENSION}

The clinical classification of $\mathrm{PH}$ has gone through a series of changes since the first version was proposed in 1973 at the first international conference on primary pulmonary hypertension endorsed by the World Health Organization [7]. The previous version of the ESC-PAH guidelines adopted the Evian-Venice classification proposed at the second and third world meetings on PAH in 1998 and 2003, respectively [13]. In these classifications, clinical conditions with $\mathrm{PH}$ are classified into five groups according to pathological, pathophysiological and therapeutic characteristics. Despite comparable elevations of PAP and PVR in the different clinical groups, the underlying mechanisms, the diagnostic approaches, and the prognostic and therapeutic implications are completely different. During the fourth World Symposium on PH held in 2008 in Dana Point, CA, USA, the consensus agreement of experts worldwide was to maintain the general philosophy and organisation of the Evian-Venice classifications while amending some specific points to improve clarity and to take into account new information.

The new clinical classification (derived from the Dana Point meeting) is shown in table 4 [1]. To avoid possible confusion among the terms $\mathrm{PH}$ and $\mathrm{PAH}$, the specific definitions have been included in table 5 . Compared with the previous version of the clinical classification the changes are as follows:

- Group 1, PAH (tables 4, 6 and 7): the term familial PAH has been replaced by heritable PAH because specific gene mutations have been identified in sporadic cases with no family history. Heritable forms of PAH include clinically sporadic idiopathic PAH (IPAH) with germline mutations (mainly of the bone morphogenetic protein receptor 2 gene as well as the activin receptor-like kinase type- 1 gene or the endoglin gene) and clinical familial cases with or without identified germline mutations [14, 15]. This new category of heritable $\mathrm{PAH}$ does not mandate genetic
TABLE 6 Clinical classification of congenital, systemic-topulmonary shunts associated with pulmonary arterial hypertension (PAH)

\section{A. Eisenmenger's syndrome}

Eisenmenger's syndrome includes all systemic-to-pulmonary shunts due to large defects leading to a severe increase in PVR and resulting in a reversed (pulmonary-to-systemic) or bidirectional shunt. Cyanosis, erythrocytosis and

multiple organ involvement are present.

B. PAH associated with systemic-to-pulmonary shunts

In these patients with moderate-to-large defects, the

increase in PVR is mild to moderate, systemic-to-pulmonary shunt is still largely present, and no cyanosis is present at rest.

\section{PAH with small ${ }^{\#}$ defects}

In cases with small defects (usually ventricular septal defects $<1 \mathrm{~cm}$ and atrial septal defects $<2 \mathrm{~cm}$ of effective diameter assessed by echocardiography) the clinical picture is very similar to idiopathic PAH

\section{PAH after corrective cardiac surgery}

In these cases, congenital heart disease has been corrected but PAH is either still present immediately after surgery or has recurred several months or years after surgery in the absence of significant post-operative residual congenital lesions or defects that originate as a sequela to previous surgery

PVR: pulmonary vascular resistance. ${ }^{\#}$ : the size applies to adult patients.

testing in any patient with IPAH or in familial cases of PAH because this would not change the clinical management. The classification of congenital heart disease (CHD) causing PAH has been updated to include a clinical (table 6) and an anatomical-pathophysiological version (table 7) in order to better define each individual patient [16]. Associated PAH (APAH, table 4) includes conditions which can have a similar clinical presentation to that seen in IPAH with identical histological findings including the development of plexiform lesions [13]. APAH accounts for approximately half of the PAH patients followed at specialised centres [3]. Schistosomiasis has been included among the APAH forms because recent publications show that patients with schistosomiasis and PAH can have the required specific clinical and pathological characteristics [17]. The mechanism of PAH in patients with schistosomiasis is probably multifactorial, and includes portal hypertension, a frequent complication of this disease, and local vascular inflammation caused by schistosoma eggs. Chronic haemolytic anaemia such as sickle cell disease [18], thalassaemia, hereditary spherocytosis, stomatocytosis and microangiopathic haemolytic anaemia may result in $\mathrm{PAH}$ and are included in the APAH forms. The mechanism of PAH in chronic haemolysis is related to a high rate of nitric oxide (NO) consumption leading to a state of resistance to NO bioactivity. Smooth muscle cyclic guanosine monophosphate, a potent vasodilator/antiproliferative mediator and second messenger of $\mathrm{NO}$, is not activated in chronic haemolytic anaemia [19].

- Group 1' PVOD and pulmonary capillary haemangiomatosis remain difficult disorders to classify since they share 


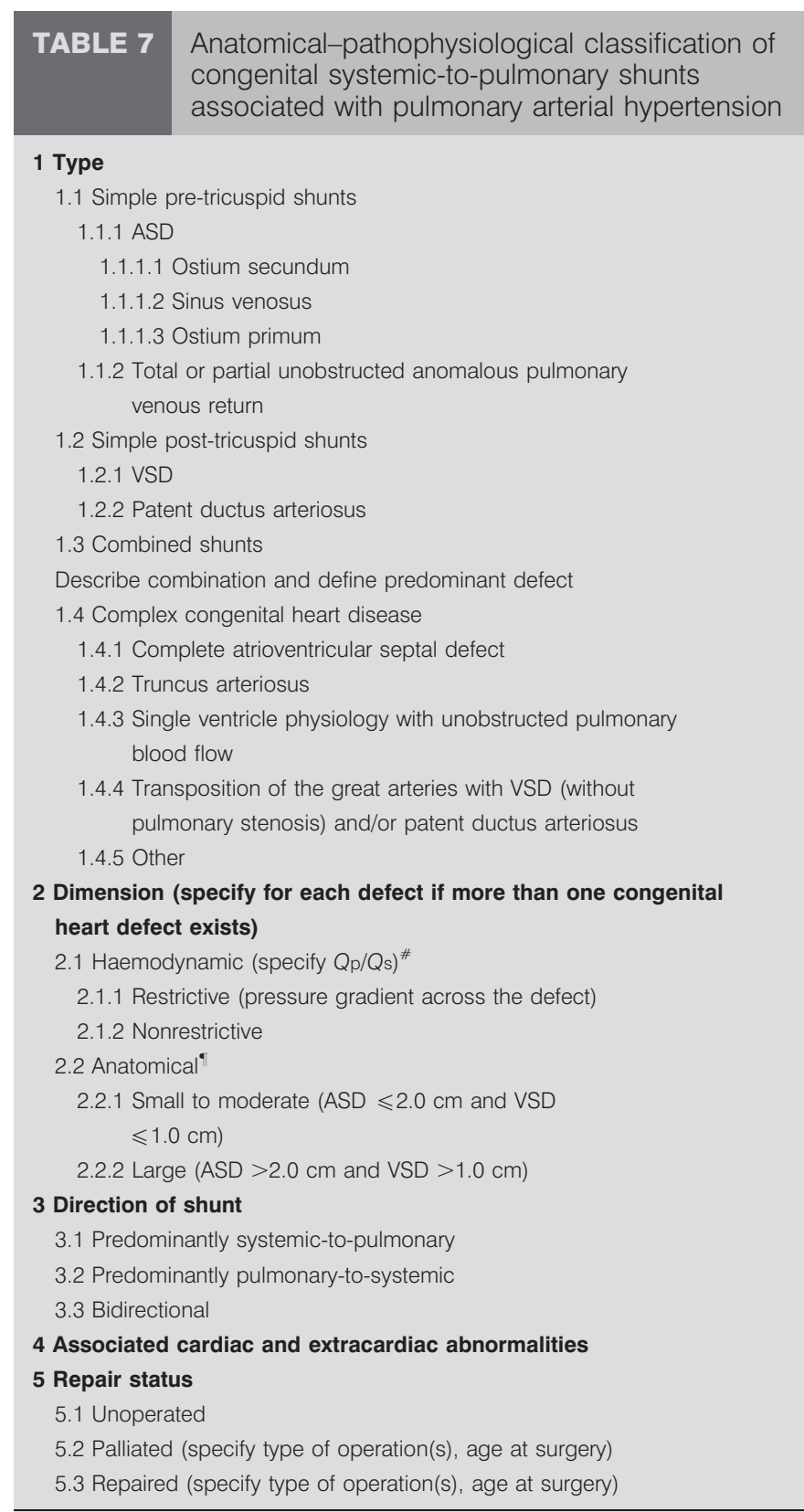

ASD: atrial septal defect; VSD: ventricular septal defect. *: ratio of pulmonary $(Q p)$ to systemic $(Q s)$ blood flow; " : the size applies to adult patients. Modified from the Evian-Venice classification 2003 [13], with permission from the publisher.

some characteristics with IPAH but also demonstrate a number of differences. Given the current evidence, it was felt that these conditions should be a distinct category but not completely separated from $\mathrm{PAH}$, and have been designated as clinical group $1^{\prime}$.

- Group 2, PH due to left heart disease, and group 3, PH due to lung diseases and hypoxia, are not substantially changed.

- Group 4, CTEPH: as there are no well-defined criteria to discriminate proximal from distal CTEPH obstructive lesions, it was decided to maintain only a single category of CTEPH without attempting to distinguish between proximal and distal forms.

- Group 5, PH with unclear and/or multifactorial mechanisms: this group comprises a heterogeneous collection of diseases with uncertain pathogenetic mechanisms leading to $\mathrm{PH}$ including haematological, systemic, metabolic and other rare disorders.

\section{PATHOLOGY OF PULMONARY HYPERTENSION}

Different pathological $[20,21]$ features characterise the diverse clinical PH groups.

- Group 1, PAH: pathological lesions affect the distal pulmonary arteries $(<500 \mu \mathrm{m}$ of diameter $)$ in particular. They are characterised by medial hypertrophy, intimal proliferative and fibrotic changes (concentric, eccentric), adventitial thickening with moderate perivascular inflammatory infiltrates, complex lesions (plexiform, dilated lesions) and thrombotic lesions. Pulmonary veins are classically unaffected.

- Group 1': includes mainly PVOD which involves septal veins and pre-septal venules (constant involvement) with occlusive fibrotic lesions, venous muscularisation, frequent capillary proliferation (patchy), pulmonary oedema, occult alveolar haemorrhage, lymphatic dilatation and lymph node enlargement (vascular transformation of the sinus), and inflammatory infiltrates. Distal pulmonary arteries are affected by medial hypertrophy, intimal fibrosis and uncommon complex lesions.

- Group 2, PH due to left heart disease: pathological changes in this group are characterised by enlarged and thickened pulmonary veins, pulmonary capillary dilatation, interstitial oedema, alveolar haemorrhage, and lymphatic vessel and lymph node enlargement. Distal pulmonary arteries may be affected by medial hypertrophy and intimal fibrosis.

- Group 3, PH due to lung diseases and/or hypoxia: pathological changes in these cases include medial hypertrophy and intimal obstructive proliferation of the distal pulmonary arteries. A variable degree of destruction of the vascular bed in emphysematous or fibrotic areas may also be present.

- Group 4, CTEPH: pathological lesions are characterised by organised thrombi tightly attached to the pulmonary arterial medial layer in the elastic pulmonary arteries, replacing the normal intima. These may completely occlude the lumen or form different grades of stenosis, webs and bands [22]. Interestingly, in the nonoccluded areas, a pulmonary arteriopathy indistinguishable from that of PAH (including plexiform lesions) can develop [23]. Collateral vessels from the systemic circulation (from bronchial, costal, diaphragmatic and coronary arteries) can grow to reperfuse at least partially the areas distal to complete obstructions.

- Group 5, PH with unclear and/or multifactorial mechanisms: this group includes heterogeneous conditions with different pathological pictures for which the aetiology is unclear or multifactorial. 


\section{PATHOBIOLOGY OF PULMONARY HYPERTENSION}

Different pathobiological features [24-26] characterise the diverse clinical PH groups.

- Group 1, PAH: the exact processes that initiate the pathological changes seen in $\mathrm{PAH}$ are still unknown even if it is recognised that PAH has a multifactorial pathobiology that involves various biochemical pathways and cell types. The increase in PVR is related to different mechanisms, including vasoconstriction, proliferative and obstructive remodelling of the pulmonary vessel wall, inflammation and thrombosis. Excessive vasoconstriction has been related to abnormal function or expression of potassium channels in the smooth muscle cells and to endothelial dysfunction. Endothelial dysfunction leads to chronically impaired production of vasodilator and antiproliferative agents, such as $\mathrm{NO}$ and prostacyclin, along with overexpression of vasoconstrictor and proliferative substances such as thromboxane $\mathrm{A}_{2}$ and endothelin-1. Reduced plasma levels of other vasodilator and antiproliferative substances such as vasoactive intestinal peptide have also been demonstrated in patients with PAH. Many of these abnormalities both elevate vascular tone and promote vascular remodelling by proliferative changes that involve several cell types, including endothelial and smooth muscle cells as well as fibroblasts. In addition, in the adventitia there is increased production of extracellular matrix including collagen, elastin, fibronectin and tenascin. Inflammatory cells and platelets (through the serotonin pathway) may also play a significant role in $\mathrm{PAH}$. Prothrombotic abnormalities have been demonstrated in PAH patients, and thrombi are present in both the small distal pulmonary arteries and the proximal elastic pulmonary arteries.

- Group 2, PH due to left heart disease: the mechanisms responsible for the increase in PAP are multiple and include the passive backward transmission of the pressure elevation (post-capillary passive $\mathrm{PH}$, table 3 ). In these cases the transpulmonary pressure gradient $\left(\mathrm{TPG}=\bar{P}_{\mathrm{pa}}-\bar{P}_{\mathrm{pcw}}\right)$ and PVR are within the normal range. In other circumstances the elevation of PAP is greater than that of Ppw (increased TPG) and an increase in PVR is also observed (post-capillary reactive or "out of proportion" $\mathrm{PH}$, table 3). The elevation of PVR is due to an increase in the vasomotor tone of the pulmonary arteries and/or to fixed structural obstructive remodelling of the pulmonary artery resistance vessels [27]: the former component of reactive $\mathrm{PH}$ is reversible under acute pharmacological testing while the latter, characterised by medial hypertrophy and intimal proliferation of the pulmonary arteriole, does not respond to the acute challenge [12]. Which factors lead to reactive (out of proportion) $\mathrm{PH}$ and why some patients develop the acutely reversible vasoconstrictive or the fixed obstructive components or both is poorly understood. Pathophysiological mechanisms may include vasoconstrictive reflexes arising from stretch receptors localised in the left atrium and pulmonary veins, and endothelial dysfunction of pulmonary arteries that may favour vasoconstriction and proliferation of vessel wall cells.
- Group 3, PH due to lung diseases and/or hypoxia: the pathobiological and pathophysiological mechanisms involved in this setting are multiple and include hypoxic vasoconstriction, mechanical stress of hyperinflated lungs, loss of capillaries, inflammation and toxic effects of cigarette smoke. There are also data supporting an endotheliumderived vasoconstrictor-vasodilator imbalance.

- Group 4, CTEPH: nonresolution of acute embolic masses which later undergo fibrosis leading to mechanical obstruction of pulmonary arteries is the most important pathobiological process in CTEPH. Pulmonary thromboembolism or in situ thrombosis may be initiated or aggravated by abnormalities in either the clotting cascade, endothelial cells, or platelets, all of which interact in the coagulation process [28]. Platelet abnormalities and biochemical features of a procoagulant environment within the pulmonary vasculature support a potential role for local thrombosis in initiating the disease in some patients. In most cases, it remains unclear whether thrombosis and platelet dysfunction are a cause or consequence of the disease. Inflammatory infiltrates are commonly detected in the pulmonary endarterectomy (PEA) specimens. Thrombophilia studies have shown that lupus anticoagulant may be found in $\sim 10 \%$ of such patients, and $20 \%$ carry antiphospholipid antibodies, lupus anticoagulant, or both. A recent study has demonstrated that the plasma level of factor VIII, a protein associated with both primary and recurrent venous thromboembolism, is elevated in 39\% of patients with CTEPH. No abnormalities of fibrinolysis have been identified. The obstructive lesions observed in the distal pulmonary arteries of nonobstructed areas (virtually identical to those observed in $\mathrm{PAH}$ ) may be related to a variety of factors, such as shear stress, pressure, inflammation and the release of cytokines and vasculotrophic mediators.

- Group 5, PH with unclear and/or multifactorial mechanisms: the pathobiology in this group is unclear or multifactorial.

\section{GENETICS, EPIDEMIOLOGY AND RISK FACTORS OF PULMONARY HYPERTENSION}

Comparative epidemiological data on the prevalence of the different groups of $\mathrm{PH}$ are not available. In a survey performed in an echocardiography laboratory [29], the prevalence of $\mathrm{PH}$ (defined as a pulmonary artery (PA) systolic pressure $>40 \mathrm{mmHg}$ ) among 4579 patients was $10.5 \%$. Among the 483 cases with PH 78.7\% had left heart disease (group 2), 9.7\% had lung diseases and hypoxia (group 3), 4.2\% had PAH (group 1), $0.6 \%$ had CTEPH (group 4 ) and in $6.8 \%$ it was not possible to define a diagnosis.

- Group 1, PAH: recent registries have described the epidemiology of PAH [3, 4]. The lowest estimates of the prevalence of PAH and IPAH are 15 cases and 5.9 cases per million adult population, respectively. The lowest estimate of PAH incidence is 2.4 cases per million adult population. $\mathrm{yr}^{-1}$. Recent data from Scotland and other countries have confirmed that PAH prevalence is in the range 15-50 subjects per million population in Europe [4]. In the French 
registry, 39.2\% of patients had IPAH and 3.9\% had family history of PAH. In the subgroup of $\mathrm{APAH}, 15.3 \%$ had connective tissue diseases (CTDs; mainly systemic sclerosis), $11.3 \%$ had $\mathrm{CHD}, 10.4 \%$ had portal hypertension, $9.5 \%$ had anorexigen-associated PAH and $6.2 \%$ had HIV infection [3].

PAH may occur in different settings depending on associated clinical conditions [1]. IPAH corresponds to sporadic disease, without any familial history of $\mathrm{PAH}$ or known triggering factor. When PAH occurs in a familial context, germline mutations in the bone morphogenetic protein receptor 2 gene are detected in at least $70 \%$ of cases [14, 15]. Mutations of this gene can also be detected in $11-40 \%$ of apparently sporadic cases, thus representing the major genetic predisposing factor for PAH [30]. The bone morphogenetic protein receptor 2 gene encodes a type 2 receptor for bone morphogenetic proteins, which belong to the transforming growth factor- $\beta$ superfamily. Among several biological functions, these polypeptides are involved in the control of vascular cell proliferation. Mutations of other receptors for these substances, such as activin receptor-like kinase 1 and endoglin, have been identified mostly in PAH patients with a personal or family history of hereditary haemorrhagic telangiectasia (Osler-Weber-Rendu syndrome) [31]. A number of risk factors for the development of PAH have been identified and are defined as any factor or condition that is suspected to play a predisposing or facilitating role in the development of the disease. Risk factors were classified as definite, likely, possible, or unlikely based on the strength of their association with $\mathrm{PH}$ and their probable causal role [1]. A definite association is acknowledged in the case of an epidemic such as occurred with appetite suppressants in the 1960s or if large, multicentre epidemiological studies demonstrated an association between the clinical condition or drug and PAH. A likely association is acknowledged if a single centre case-control study or multiple case series demonstrated an association. A possible association can be suspected, for example, for drugs with similar mechanisms of action to those in the definite or likely category but which have not been studied yet, such as drugs used to treat attention deficit disorder. Lastly, an unlikely association is defined as one in which a suspected factor has been studied in epidemiological studies and an association with PAH has not been demonstrated. Definite clinical associations are listed among APAH conditions (table 4) while the risk level of different drugs and toxins are listed in table 8.

- Group 2, PH due to left heart disease: even if constitutional factors may play a role in the development of $\mathrm{PH}$ in this group, no specific genetic linkages have been identified [12]. The prevalence of $\mathrm{PH}$ in patients with chronic heart failure increases with the progression of functional class impairment. Up to $60 \%$ of patients with severe left ventricular (LV) systolic dysfunction and up to $70 \%$ of patients with isolated LV diastolic dysfunction may present with $\mathrm{PH}$ [32]. In left-sided valvular diseases, the prevalence of $\mathrm{PH}$ increases with the severity of the defect and of the symptoms. PH can be found in virtually all patients with severe symptomatic mitral valve disease and in up to $65 \%$ of those with symptomatic aortic stenosis [10, 12, 33].

\begin{tabular}{ll} 
TABLE 8 & $\begin{array}{l}\text { Updated risk level of drugs and toxins known to } \\
\text { induce pulmonary arterial hypertension }\end{array}$ \\
\hline Definite & Possible \\
Aminorex & Cocaine \\
Fenfluramine & Phenylpropanolamine \\
Dexfenfluramine & St John's Wort \\
Toxic rapeseed oil & Chemotherapeutic agents \\
Benfluorex & Selective serotonin reuptake inhibitors \\
& Pergolide \\
Likely & Unlikely \\
Amphetamines & Oral contraceptives \\
L-tryptophan & Oestrogen \\
Methamphetamines & Cigarette smoking \\
\hline &
\end{tabular}

- Group 3, PH due to lung diseases and/or hypoxia: one study has shown that serotonin gene polymorphism appears to determine the severity of $\mathrm{PH}$ in hypoxaemic patients with chronic obstructive pulmonary disease (COPD) [34]. Based on published series, the incidence of significant $\mathrm{PH}$ in COPD patients with at least one previous hospitalisation for exacerbation of respiratory failure is $20 \%$. In advanced COPD, $\mathrm{PH}$ is highly prevalent $(>50 \%)[35,36]$. although in general it is of only mild severity. In interstitial lung disease, the prevalence of $\mathrm{PH}$ is between 32 and 39\% [37]. The combination of lung fibrosis with emphysema is associated with a higher prevalence of $\mathrm{PH}$ [38].

- Group 4, CTEPH: no specific genetic mutations have been linked to the development of CTEPH. Even if more recent papers suggest that the prevalence of CTEPH is up to $3.8 \%$ in survivors of acute pulmonary embolism [39], most experts believe that the true incidence of CTEPH after acute pulmonary embolism is $0.5-2 \%$. CTEPH can be found in patients without any previous clinical episode of acute pulmonary embolism or deep venous thrombosis (up to $50 \%$ in different series) [40].

- Group 5, PH with unclear and/or multifactorial mechanisms: the heterogeneity of this group prevents an appropriate description of genetics, epidemiology and risk factors in these guidelines.

\section{PULMONARY ARTERIAL HYPERTENSION (GROUP 1)}

$\mathrm{PAH}$ (see table 5 for definition) represents the type of $\mathrm{PH}$ in which the most important advances in the understanding and treatment have been achieved in the past decade. It is also the group in which $\mathrm{PH}$ is the "core" of the clinical problems and may be treated by specific drug therapy.

PAH comprises apparently heterogeneous conditions (table 4) that share comparable clinical and haemodynamic pictures and virtually identical pathological changes of the lung microcirculation.

Even if many pathobiological mechanisms have been identified in the cells and tissues of patients with $\mathrm{PAH}$, the exact interactions between them in the initiation and progression of the pathological processes are not well understood. The consequent increase in PVR leads to right ventricular (RV) overload, hypertrophy and dilatation, and eventually to RV 
failure and death. The importance of the progression of RV failure on the outcome of IPAH patients is confirmed by the prognostic impact of right atrial pressure, cardiac index $(\mathrm{CI})$ and PAP [8], the three main parameters of RV pump function. The inadequate adaptation of myocardial contractility seems to be one of the primary events in the progression of heart failure in a chronically overloaded RV. Changes in the adrenergic pathways of RV myocytes leading to reduced contractility have been shown in IPAH patients [41]. Afterload mismatch remains the leading determinant of heart failure in patients with PAH and CTEPH because its removal, as follows successful PEA or lung transplantation [42], leads almost invariably to sustained recovery of RV function. The haemodynamic changes and the prognosis of patients with $\mathrm{PAH}$ are related to the complex pathophysiological interactions between the rate of progression (or regression) of the obstructive changes in the pulmonary microcirculation and the response of the overloaded RV, which may also be influenced by genetic determinants [43].

\subsection{Diagnosis}

The evaluation process of a patient with suspected $\mathrm{PH}$ requires a series of investigations intended to confirm the diagnosis, clarify the clinical group of $\mathrm{PH}$ and the specific aetiology within the PAH group, and evaluate the functional and haemodynamic impairment. After the description of each examination, an integrated diagnostic algorithm is shown (fig. 1). Since PAH, and particularly IPAH, is a diagnosis of exclusion, this algorithm may be useful as a starting point in any case of suspected $\mathrm{PH}$.

\subsubsection{Clinical presentation}

The symptoms of PAH are nonspecific and include breathlessness, fatigue, weakness, angina, syncope and abdominal distension [44]. Symptoms at rest are reported only in very advanced cases. The physical signs of PAH include left parasternal lift, an accentuated pulmonary component of second heart sound, a pansystolic murmur of tricuspid regurgitation, a diastolic murmur of pulmonary insufficiency and an RV third sound. Jugular vein distension, hepatomegaly, peripheral oedema, ascites and cool extremities characterise patients in a more advanced state. Lung sounds are usually normal. The examination may also provide clues as to the cause of PH. Telangiectasia, digital ulceration and sclerodactyly are seen in scleroderma, while inspiratory crackles may point towards interstitial lung disease [45]. The stigmata of liver disease such as spider naevi, testicular atrophy and palmar erythema should be considered. If digital clubbing is encountered in "IPAH", an alternative diagnosis such as CHD or PVOD should be sought.

\subsubsection{Electrocardiogram}

The ECG may provide suggestive or supportive evidence of $\mathrm{PH}$ by demonstrating RV hypertrophy and strain, and right atrial dilatation. RV hypertrophy on ECG is present in $87 \%$ and right axis deviation in $79 \%$ of patients with IPAH [44]. The absence of these findings does not exclude the presence of $\mathrm{PH}$ nor does it exclude severe haemodynamic abnormalities. The ECG has insufficient sensitivity (55\%) and specificity $(70 \%)$ to be a screening tool for detecting significant $\mathrm{PH}$. Ventricular arrhythmias are rare. Supraventricular arrhythmias may be present in advanced stages, in particular atrial flutter, but also atrial fibrillation, which almost invariably leads to further clinical deterioration [46].

\subsubsection{Chest radiograph}

In $90 \%$ of patients with IPAH the chest radiograph is abnormal at the time of diagnosis [44]. Findings include central pulmonary arterial dilatation, which contrasts with "pruning" (loss) of the peripheral blood vessels. Right atrium and RV enlargement may be seen in more advanced cases. The chest radiograph allows associated moderate-to-severe lung diseases (group 3, table 4) or pulmonary venous hypertension due to left heart disease (group 2, table 4) to be reasonably excluded. Overall, the degree of $\mathrm{PH}$ in any given patient does not correlate with the extent of radiographic abnormalities.

\subsubsection{Pulmonary function tests and arterial blood gases}

Pulmonary function tests and arterial blood gases will identify the contribution of underlying airway or parenchymal lung disease. Patients with PAH usually have decreased lung diffusion capacity for carbon monoxide (typically in the range of $40-80 \%$ predicted) and mild to moderate reduction of lung volumes. Peripheral airway obstruction can also be detected. Arterial oxygen tension is normal or only slightly lower than normal at rest and arterial carbon dioxide tension is decreased because of alveolar hyperventilation. COPD as a cause of hypoxic $\mathrm{PH}$ is diagnosed on the evidence of irreversible airflow obstruction together with increased residual volumes and reduced diffusion capacity for carbon monoxide and normal or increased carbon dioxide tension. A decrease in lung volume together with a decrease in diffusion capacity for carbon monoxide may indicate a diagnosis of interstitial lung disease. The severity of emphysema and of interstitial lung disease can be diagnosed using high-resolution computed tomography (CT). If clinically suspected, screening overnight oximetry or polysomnography will exclude significant obstructive sleep apnoea/hypopnoea.

\subsubsection{Echocardiography}

Transthoracic echocardiography provides several variables which correlate with right heart haemodynamics including PAP, and should always be performed in the case of suspected $\mathrm{PH}$.

The estimation of PAP is based on the peak velocity of the jet of tricuspid regurgitation. The simplified Bernoulli equation describes the relationship of tricuspid regurgitation velocity and the peak pressure gradient of tricuspid regurgitation $=4 \times(\text { tricuspid regurgitation velocity })^{2}$. This equation allows for estimation of PA systolic pressure taking into account right atrial pressure: PA systolic pressure $=$ tricuspid regurgitation pressure gradient + estimated right atrial pressure. Right atrial pressure can be estimated based on the diameter and respiratory variation of the inferior vena cava although often a fixed value of 5 or $10 \mathrm{mmHg}$ is assumed. When peak tricuspid regurgitation velocity is difficult to measure (trivial/mild tricuspid regurgitation), use of contrast echocardiography (e.g. agitated saline) significantly increases the Doppler signal, allowing proper measurement of peak tricuspid regurgitation velocity. Also, potential systolic gradients between the RV and PA should be considered. 


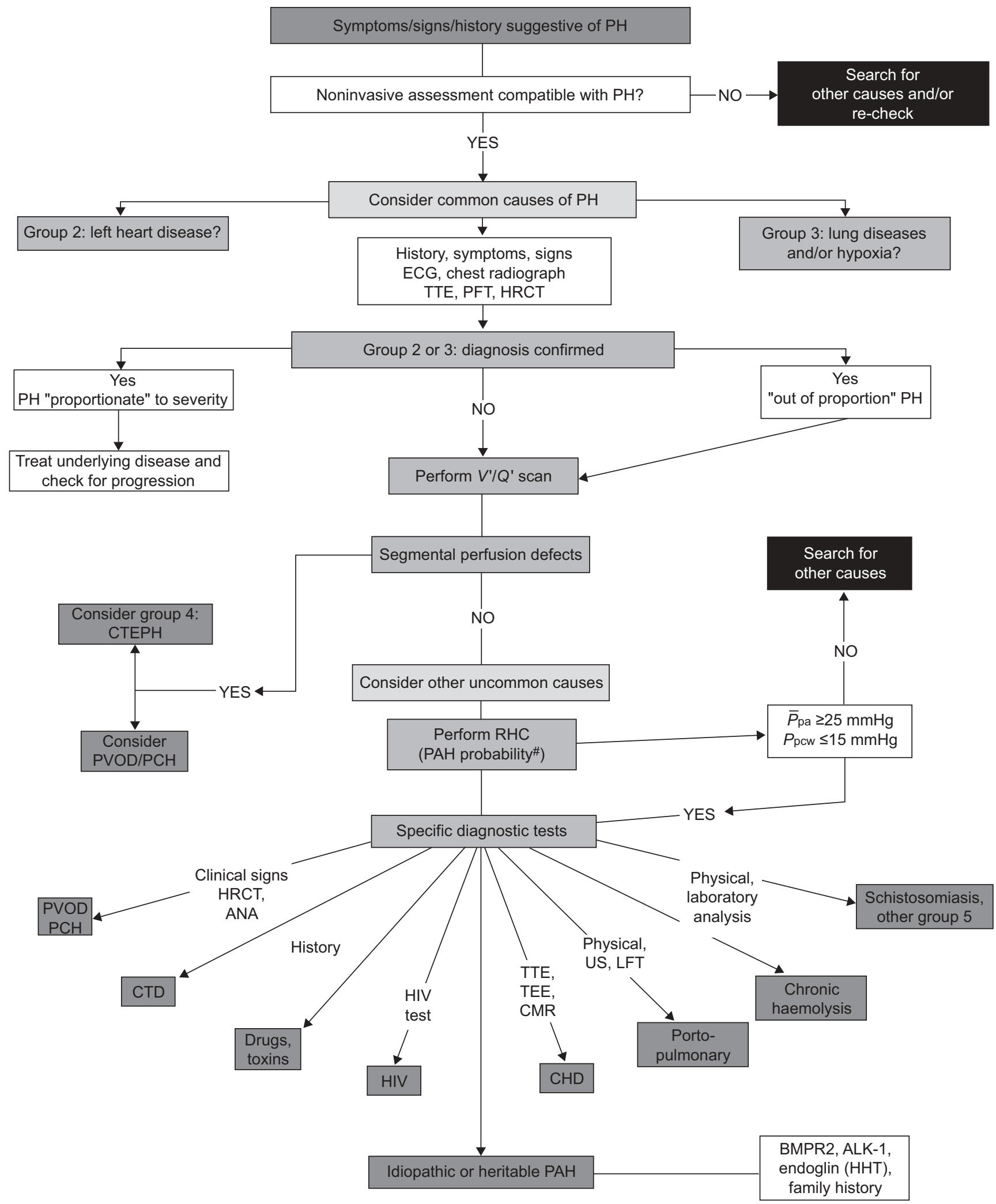

FIGURE 1. Diagnostic algorithm. ALK-1: activin-receptor-like kinase; ANA: anti-nuclear antibodies; BMPR2: bone morphogenetic protein receptor 2; CHD: congenital heart disease; CMR: cardiac magnetic resonance; CTD: connective tissue disease; CTEPH: chronic thromboembolic pulmonary hypertension; Group: clinical group (table 4); HHT: hereditary haemorrhagic telangiectasia; HRCT: high-resolution computed tomography; LFT: liver function tests; $\bar{P}$ pa: mean pulmonary arterial pressure; PAH: pulmonary arterial hypertension; PCH: pulmonary capillary haemangiomatosis; Ppcw: pulmonary capillary wedge pressure; PFT: pulmonary function test; PH: pulmonary hypertension; PVOD: pulmonary veno-occlusive disease; RHC: right heart catheterisation; TEE: transoesophageal echocardiography; TTE: transthoracic echocardiography; US: ultrasonography; $V^{\prime} / Q^{\prime}$ : ventilation/perfusion lung scan. ${ }^{*}$ : refer also to table 12. 
Theoretically, calculation of $\bar{P}_{\text {pa }}$ from PA systolic pressure is possible $\left(\bar{P}_{\text {pa }}=0.61 \times\right.$ PA systolic pressure $\left.+2 \mathrm{mmHg}\right)$ [47]. This could allow the use of Doppler measurements, applying an accepted definition of $\mathrm{PH}$ as $\bar{P}$ pa $\geqslant 25 \mathrm{mmHg}$. Unfortunately, despite the strong correlation of the tricuspid regurgitation velocity and tricuspid regurgitation pressure gradient, Doppler-derived pressure estimation may be inaccurate in the individual patient. In patients with severe tricuspid regurgitation use of the simplified form of the Bernoulli equation may lead to underestimation of PA systolic pressure. Also overestimations by $>10 \mathrm{mmHg}$ for PA systolic pressure are common [47]. Therefore, $\mathrm{PH}$ cannot be reliably defined by a cut-off value of Doppler-derived PA systolic pressure.

Consequently, estimation of PAP based on Doppler transthoracic echocardiography measurements is not suitable for screening for mild, asymptomatic $\mathrm{PH}$.

An alternative approach to echocardiographic diagnosis of $\mathrm{PH}$ is based on comparison of tricuspid regurgitation velocity with values reported in a healthy population. Ideally, the influence of age, sex and body mass should be taken into consideration [48]. This method avoids cumulative error but is less directly linked to the accepted haemodynamic definition of $\mathrm{PH}$ as a $\bar{P}$ pa $\geqslant 25 \mathrm{mmHg}$.

The reliability of several tricuspid regurgitation velocity cut-off values, using RHC as reference, has been assessed in two large screening studies. A trial evaluating the reliability of prospective screening of patients with scleroderma based on tricuspid regurgitation velocity $>2.5 \mathrm{~m} \cdot \mathrm{s}^{-1}$ in symptomatic patients or $>3.0 \mathrm{~m} \cdot \mathrm{s}^{-1}$ irrespective of symptoms, found that $45 \%$ of cases of echocardiographic diagnoses of $\mathrm{PH}$ were falsely positive [49]. In symptomatic (dyspnoea) patients with HIV infection a $\mathrm{PH}$ criterion based on tricuspid regurgitation velocity $>2.5$ and $2.8 \mathrm{~m} \cdot \mathrm{s}^{-1}$ was found to be a false positive in $72 \%$ and $29 \%$, respectively [49].

Another trial selected a tricuspid regurgitation pressure gradient $>40 \mathrm{mmHg}$ (tricuspid regurgitation velocity $>3.2 \mathrm{~m} \cdot \mathrm{s}^{-1}$ ) with an assumed right atrial pressure of $10 \mathrm{mmHg}$ (thus corresponding to a systolic PAP of $>50 \mathrm{mmHg}$ ) as the cut-off value for diagnosis of $\mathrm{PH}$ [50]. Those criteria were recently prospectively applied in systemic sclerosis patients [51]. The Doppler diagnosis was confirmed in all 32 patients who were submitted to RHC. Like previous trials, the number of false-negative cases could not be assessed.

Other echocardiographic variables that might raise or reinforce suspicion of $\mathrm{PH}$ independently of tricuspid regurgitation velocity should always be considered. They include an increased velocity of pulmonary valve regurgitation and a short acceleration time of RV ejection into the PA. Increased dimensions of right heart chambers, abnormal shape and function of the interventricular septum, increased RV wall thickness and dilated main PA are also suggestive of $\mathrm{PH}$, but tend to occur later in the course of the disease. Their sensitivity is questionable.

In table 9 this Task Force suggests arbitrary criteria for detecting the presence of $\mathrm{PH}$ based on tricuspid regurgitation peak velocity and Doppler-calculated PA systolic pressure at rest (assuming a normal right atrial pressure of $5 \mathrm{mmHg}$ ) and additional echocardiographic variables suggestive of $\mathrm{PH}$.

\begin{tabular}{|c|c|c|c|}
\hline \multirow[t]{2}{*}{ TABLE 9} & \multicolumn{3}{|c|}{$\begin{array}{l}\text { Arbitrary criteria for estimating the presence of } \\
\text { pulmonary hypertension (PH) based on tricuspid } \\
\text { regurgitation peak velocity and Doppler- } \\
\text { calculated pulmonary arterial (PA) systolic } \\
\text { pressure at rest (assuming a normal right atrial } \\
\text { pressure of } 5 \mathrm{mmHg} \text { ) and on additional } \\
\text { echocardiographic variables suggestive of } \mathrm{PH}\end{array}$} \\
\hline & & Class $^{\#}$ & Level \\
\hline \multicolumn{4}{|c|}{ Echocardiographic diagnosis: PH unlikely } \\
\hline \multicolumn{2}{|c|}{$\begin{array}{l}\text { Tricuspid regurgitation velocity } \leqslant 2.8 \mathrm{~m} \cdot \mathrm{s}^{-1} \text {, } \\
\text { PA systolic pressure } \leqslant 36 \mathrm{mmHg} \text { and no additional } \\
\text { echocardiographic variables suggestive } \\
\text { of } \mathrm{PH}\end{array}$} & 1 & B \\
\hline \multicolumn{4}{|c|}{ Echocardiographic diagnosis: PH possible } \\
\hline \multicolumn{2}{|c|}{$\begin{array}{l}\text { Tricuspid regurgitation velocity } \leqslant 2.8 \mathrm{~m} \cdot \mathrm{s}^{-1} \text {, PA } \\
\text { systolic pressure } \leqslant 36 \mathrm{mmHg} \text {, but presence } \\
\text { of additional echocardiographic variables } \\
\text { suggestive of } \mathrm{PH}\end{array}$} & Ila & C \\
\hline \multicolumn{2}{|c|}{$\begin{array}{l}\text { Tricuspid regurgitation velocity } 2.9-3.4 \mathrm{~m} \cdot \mathrm{s}^{-1} \text {, PA } \\
\text { systolic pressure } 37-50 \mathrm{mmHg} \text { with/without } \\
\text { additional echocardiographic variables } \\
\text { suggestive of } \mathrm{PH}\end{array}$} & Ila & C \\
\hline \multicolumn{4}{|c|}{ Echocardiographic diagnosis: PH likely } \\
\hline \multicolumn{2}{|c|}{$\begin{array}{l}\text { Tricuspid regurgitation velocity }>3.4 \mathrm{~m} \cdot \mathrm{s}^{-1} \text {, PA } \\
\text { systolic pressure }>50 \mathrm{mmHg} \text {, with/without } \\
\text { additional echocardiographic variables } \\
\text { suggestive of } \mathrm{PH}\end{array}$} & । & B \\
\hline \multicolumn{2}{|c|}{$\begin{array}{l}\text { Exercise Doppler echocardiography is not } \\
\text { recommended for screening of } \mathrm{PH}\end{array}$} & III & C \\
\hline
\end{tabular}

Echocardiography can be helpful in detecting the cause of suspected or confirmed PH. Two-dimensional, Doppler and contrast examinations can be used to identify CHD. High pulmonary blood flow found at pulsed wave Doppler in the absence of detectable shunt, or significant dilatation of proximal PA despite only moderate $\mathrm{PH}$, may warrant transoesophageal examination with contrast or cardiac magnetic resonance imaging to exclude sinus venosus-type atrial septal defect or anomalous pulmonary venous return. In cases of suspicion of LV diastolic dysfunction, typical Dopplerechocardiographic signs should be assessed even if their reliability is considered low and a RHC may be required in specific circumstances (see section 9.1).

The practical clinical usefulness of exercise Doppler-echocardiography in the identification of cases with $\mathrm{PH}$ only on exercise is uncertain because of the lack of prospective confirmatory data [52].

\subsubsection{Ventilation/perfusion lung scan}

The ventilation/perfusion lung scan should be performed in patients with $\mathrm{PH}$ to look for potentially treatable CTEPH. The ventilation/perfusion scan remains the screening method of choice for CTEPH because of its higher sensitivity than CT [53]. A normal- or low-probability ventilation/ perfusion scan effectively excludes CTEPH with a sensitivity of $90-100 \%$ 
and a specificity of $94-100 \%$. While in PAH the ventilation/ perfusion lung scan may be normal, it may also show small peripheral unmatched and nonsegmental defects in perfusion. Contrast-enhanced CT may be used as a complementary investigation but does not replace the ventilation/perfusion scan or traditional pulmonary angiogram. A caveat is that unmatched perfusion defects are also seen in PVOD.

\subsubsection{High-resolution computed tomography, contrast-enhanced computed tomography and pulmonary angiography}

High-resolution CT provides detailed views of the lung parenchyma and facilitates the diagnosis of interstitial lung disease and emphysema. High-resolution CT may be very helpful where there is a clinical suspicion of PVOD. Characteristic changes of interstitial oedema with diffuse central ground-glass opacification and thickening of interlobular septa suggest PVOD; additional findings may include lymphadenopathy and pleural effusion [54]. Pulmonary capillary haemangiomatosis is suggested by diffuse bilateral thickening of the interlobular septa and the presence of small, centrilobular, poorly circumscribed nodular opacities.

Contrast CT angiography of the PA is helpful in determining whether there is evidence of surgically accessible CTEPH. It can delineate the typical angiographic findings in CTEPH such as complete obstruction, bands and webs, and intimal irregularities as accurately and reliably as digital subtraction angiography $[55,56]$. With this technique, collaterals from bronchial arteries can be identified.

Traditional pulmonary angiography is still required in many centres for the work-up of CTEPH to identify patients who may benefit from PEA [22]. Angiography can be performed safely by experienced staff in patients with severe $\mathrm{PH}$ using modern contrast media and selective injections. Angiography may also be useful in the evaluation of possible vasculitis or pulmonary arteriovenous malformations.

\subsubsection{Cardiac magnetic resonance imaging}

Cardiac magnetic resonance imaging provides a direct evaluation of RV size, morphology and function, and allows noninvasive assessment of blood flow including stroke volume, CO, distensibility of PA, and RV mass [57]. Cardiac magnetic resonance data may be used to evaluate right heart haemodynamics particularly for follow-up purposes. A decreased stroke volume, an increased RV end-diastolic volume, and a decreased LV end-diastolic volume measured at baseline are associated with a poor prognosis. Among the triad of prognostic signs, increased RV end-diastolic volume may be the most appropriate marker of progressive RV failure in the follow-up [58].

\subsubsection{Blood tests and immunology}

Routine biochemistry, haematology and thyroid function tests are required in all patients, as well as a number of other essential blood tests. Serological testing is important to detect underlying CTD, HIV and hepatitis. Up to $40 \%$ of patients with IPAH have elevated anti-nuclear antibodies, usually in low titre (1:80) [59]. Systemic sclerosis is the most important CTD to exclude because this condition has a high prevalence of PAH. Anti-centromere antibodies are typically positive in limited scleroderma as are other anti-nuclear antibodies including
dsDNA, anti-Ro, U3-RNP, B23, Th/To and U1-RNP. In the diffuse variety of scleroderma, U3-RNP is typically positive. In individuals with systemic lupus erythematosus, anti-cardiolipin antibodies may be found. Thrombophilia screening including anti-phospholipid antibodies, lupus anticoagulant and anti-cardiolipin antibodies should be performed in CTEPH. HIV testing is mandatory. Up to $2 \%$ of individuals with liver disease will manifest $\mathrm{PAH}$ and therefore liver function tests and hepatitis serology should be examined if clinical abnormalities are noted. Thyroid disease is commonly seen in PAH and should always be considered, especially if abrupt changes in the clinical course occur [60].

\subsubsection{Abdominal ultrasound scan}

Liver cirrhosis and/or portal hypertension can be reliably excluded by the use of abdominal ultrasound. The use of contrast agents and the addition of a colour-Doppler examination may improve the accuracy of the diagnosis [61]. Portal hypertension can be confirmed by the detection of an increased gradient between free and occluded (wedge) hepatic vein pressure at the time of RHC [62].

\subsubsection{Right heart catheterisation and vasoreactivity}

$\mathrm{RHC}$ is required to confirm the diagnosis of PAH, to assess the severity of the haemodynamic impairment and to test the vasoreactivity of the pulmonary circulation. When performed at experienced centres, RHC procedures have low morbidity $(1.1 \%)$ and mortality $(0.055 \%)$ rates [63]. The following variables must be recorded during RHC: PAP (systolic, diastolic and mean), right atrial pressure, $P_{\mathrm{pcw}}$ and $\mathrm{RV}$ pressure. $\mathrm{CO}$ must be measured in triplicate preferably by thermodilution or by the Fick method, if oxygen consumption is assessed. The Fick method is mandatory in the presence of a systemic-to-pulmonary shunt. Superior vena cava, PA and systemic arterial blood oxygen saturations should also be determined. These measurements are needed for the calculation of PVR Adequate recording of $P$ pcw is required for the differential diagnosis of $\mathrm{PH}$ due to left heart disease. In rare cases, left heart catheterisation may be required for direct assessment of $\mathrm{LV}$ end-diastolic pressure. A $P_{\mathrm{pcw}}>15 \mathrm{mmHg}$ excludes the diagnosis of pre-capillary PAH. One of the most challenging differential diagnoses of $\mathrm{PAH}$ is heart failure with normal LV ejection fraction and diastolic dysfunction (see also section 9.1) [64]. In this population, $P$ pcw may be mildly elevated or at the higher end of the normal range at rest. Exercise haemodynamics or volume challenge can show a disproportionate increase in $P$ pcw, although the relevance of this finding remains to be established. Coronary angiography may be required in the case of the presence of risk factors for coronary artery diseases and angina or in case of listing for double lung transplantation or PEA in patients with CTEPH.

In $\mathrm{PAH}$, vasoreactivity testing should be performed at the time of diagnostic RHC to identify patients who may benefit from long-term therapy with calcium channel blockers (CCBs) (see also section 7.3 .3$)[65,66]$. Acute vasodilator challenge should only be performed with short-acting, safe and easy to administer drugs with no or limited systemic effects. Currently the agent most used in acute testing is NO (table 9) [66]; based on previous experience $[65,67,68]$ i.v. epoprostenol or i.v. adenosine may also be used as an alternative (but with a risk of systemic vasodilator effects) (table 10). 
TABLE 10 Route of administration, half-life, dose ranges, increments and duration of administration of the most commonly used agents for pulmonary vasoreactivity tests

\begin{tabular}{|c|c|c|c|c|c|}
\hline Drug & Route & Half-life & Dose range ${ }^{\#}$ & Increments & Duration $^{+}$ \\
\hline Epoprostenol & Intravenous & $3 \mathrm{~min}$ & $2-12 \mathrm{ng} \cdot \mathrm{kg}^{-1} \cdot \mathrm{min}^{-1}$ & $2 \mathrm{ng} \cdot \mathrm{kg}^{-1} \cdot \mathrm{min}^{-1}$ & $10 \mathrm{~min}$ \\
\hline Nitric oxide & Inhaled & $15-30 \mathrm{~s}$ & 10-20 p.p.m. & & $5 \min ^{\S}$ \\
\hline
\end{tabular}

\#: initial dose and maximal tolerated dose suggested (maximal dose limited by side-effects such as hypotension, headache, flushing, etc.); ": increments of dose by each step; ${ }^{+}$: duration of administration on each step; ${ }^{\text {s. }}$ for $\mathrm{NO}$, a single step within the dose range is suggested

Inhaled iloprost and oral sildenafil may be associated with significant vasodilator effects. Their role in the prediction of the response to CCB therapy has not yet been demonstrated. Due to the risk of potentially life-threatening complications, the use of CCBs given orally or i.v. as an acute test is discouraged. A positive acute response (positive acute responder) is defined as a reduction of $\bar{P}_{\mathrm{pa}} \geqslant 10 \mathrm{mmHg}$ to reach an absolute value of $\bar{P}_{\mathrm{pa}} \leqslant 40 \mathrm{mmHg}$ with an increased or unchanged CO [66]. Only $\sim 10 \%$ of patients with IPAH will meet these criteria. Positive acute responders are most likely to show a sustained response to long-term treatment with high doses of CCBs and they are the only patients that can safely be treated with this type of therapy. About half of IPAH-positive acute responders are also positive long-term responders to CCBs [66] and only in these cases is the continuation of a CCB as a single treatment warranted. The usefulness of acute vasoreactivity tests and long-term treatment with CCBs in patients with other PAH types, such as heritable PAH, CTD and HIV patients is less clear than in IPAH. Nevertheless, experts recommend performing acute vasoreactivity studies in these patients and to look for a long-term response to CCBs in those in which the test is positive. No data are available on the usefulness of long-term CCB therapy in patients with $\mathrm{PH}$ associated with $\mathrm{CHD}$ and therefore the value of performing a vasoreactivity test in this setting is controversial. Acute vasoreactivity studies to identify patients with a long-term favourable response to CCBs is not recommended in clinical groups 2, 3, 4 and 5 (table 4).

Recommendations for RHC and vasoreactivity test are summarised in table 11.

\subsubsection{Diagnostic algorithm}

The diagnostic algorithm is shown in figure 1: the diagnostic process starts with the identification of the more common clinical groups of PH (group 2-left heart disease and group 3lung diseases), then distinguishes group 4-CTEPH and finally makes the diagnosis and recognises the different types in group 1-PAH and the rarer conditions in group 5.

PAH should be considered in the differential diagnosis of exertional dyspnoea, syncope, angina and/or progressive limitation of exercise capacity, particularly in patients without apparent risk factors, symptoms or signs of common cardiovascular and respiratory disorders. Special awareness should be directed towards patients with associated conditions and/ or risk factors for development of $\mathrm{PAH}$, such as family history, CTD, CHD, HIV infection, portal hypertension, haemolytic
TABLE 11 Recommendations for right heart catheterisation (RHC; $\mathrm{A}$ ) and vasoreactivity testing $(\mathrm{B})$

\section{Class $^{\# \quad \text { Level }}$}

A.

$\mathrm{RHC}$ is indicated in all patients with PAH to

confirm the diagnosis, to evaluate the severity

and when PAH specific drug therapy is

considered

$\mathrm{RHC}$ should be performed for confirmation of

efficacy of PAH-specific drug therapy

RHC should be performed for confirmation of

clinical deterioration and as baseline for the

evaluation of the effect of treatment escalation

and/or combination therapy

B.

Vasoreactivity testing is indicated in patients with IPAH, heritable PAH and PAH associated with anorexigen use to detect patients who can be treated with high doses of a $\mathrm{CCB}$

A positive response to vasoreactivity testing is defined as a reduction of $\bar{P}$ pa $\geqslant 10 \mathrm{mmHg}$ to reach an absolute value of $\bar{P}_{\text {pa }} \leqslant 40 \mathrm{mmHg}$ with an increased or unchanged $\mathrm{CO}$

Vasoreactivity testing should be performed only in referral centres

Vasoreactivity testing should be performed using nitric oxide as vasodilator

Vasoreactivity testing may be performed in other types of PAH

Vasoreactivity testing may be performed using i.v. epoprostenol or i.v. adenosine

The use of an oral or i.v. CCB in acute vasoreactivity testing is not recommended

Vasoreactivity testing to detect patients who can be safely treated with high doses of a $\mathrm{CCB}$ is not recommended in patients with other $\mathrm{PH}$ groups (groups 2, 3, 4 and 5)

PAH: pulmonary arterial hypertension; IPAH: idiopathic PAH; CCB: calcium channel blocker; $\bar{P}$ pa: mean pulmonary arterial pressure; $\mathrm{CO}$ : cardiac output; $\mathrm{PH}$ : pulmonary hypertension. \#: class of recommendation; ': level of evidence. 
anaemia, or a history of intake of drugs and toxins known to induce PAH (table 8). In everyday clinical practice such awareness may be low. More often $\mathrm{PH}$ is found unexpectedly on transthoracic echocardiography requested for another indication.

If noninvasive assessment is compatible with $\mathrm{PH}$, clinical history, symptoms, signs, ECG, chest radiograph, transthoracic echocardiogram, pulmonary function tests (including nocturnal oximetry, if required) and high-resolution CT of the chest are requested to identify the presence of group 2-left heart disease or group 3-lung diseases. If these are not found or if $\mathrm{PH}$ seems "out of proportion" to their severity, less common causes of PH should be looked for. Ventilation/perfusion lung scan should be considered. If a ventilation/perfusion scan shows multiple segmental perfusion defects, a diagnosis of group 4-CTEPH should be suspected. The final diagnosis of CTEPH (and the assessment of suitability for PEA) will require CT pulmonary angiography, RHC and selective pulmonary angiography. The CT scan may also show signs suggestive of group $1^{\prime}-$ PVOD. If a ventilation/perfusion scan is normal or shows only subsegmental "patchy" perfusion defects, a tentative diagnosis of group 1-PAH or the rarer conditions of group 5 is made. In table 12 the further management according to the likelihood of $\mathrm{PAH}$ is given including indications for RHC. Additional specific diagnostic tests including haematology, biochemistry, immunology, serology and ultrasonography will allow the final diagnosis to be refined. Open or thoracoscopic lung biopsy entails substantial risk of morbidity and mortality. Because of the low likelihood of altering the diagnosis and treatment, routine biopsy is discouraged in PAH patients.

Recommendations for diagnostic strategy are summarised in table 13 .

\subsection{Evaluation of severity}

The evaluation of severity of patients with PAH takes place between the diagnostic process and the therapeutic decision making. The clinical assessment of the patient has a pivotal role in the choice of the initial treatment, the evaluation of the response to therapy and the possible escalation of therapy if needed.

\subsubsection{Clinical, echocardiographic and haemodynamic parameters} Both clinical and haemodynamic assessments yield important prognostic information which may guide clinical management. These data have been derived from cohorts of patients and may not accurately reflect the prognosis of individuals. Prognosis is significantly affected by the aetiology of PAH [69].

Despite large interobserver variation in the measurement, World Health Organization functional class (WHO-FC) (table 14) remains a powerful predictor of survival. In untreated patients with IPAH or heritable $\mathrm{PAH}$, historical data showed a median survival of 6 months for WHO-FC IV, 2.5 yrs for WHO-FC III, and 6 yrs for WHO-FC I and II [8]. Extremes of age ( $<14$ yrs or $>65$ yrs), falling exercise capacity, syncope, haemoptysis and signs of RV failure also carry a poor prognosis in IPAH.

Echocardiography generates many indices, and those with the best prognostic value identified by multivariate analysis are

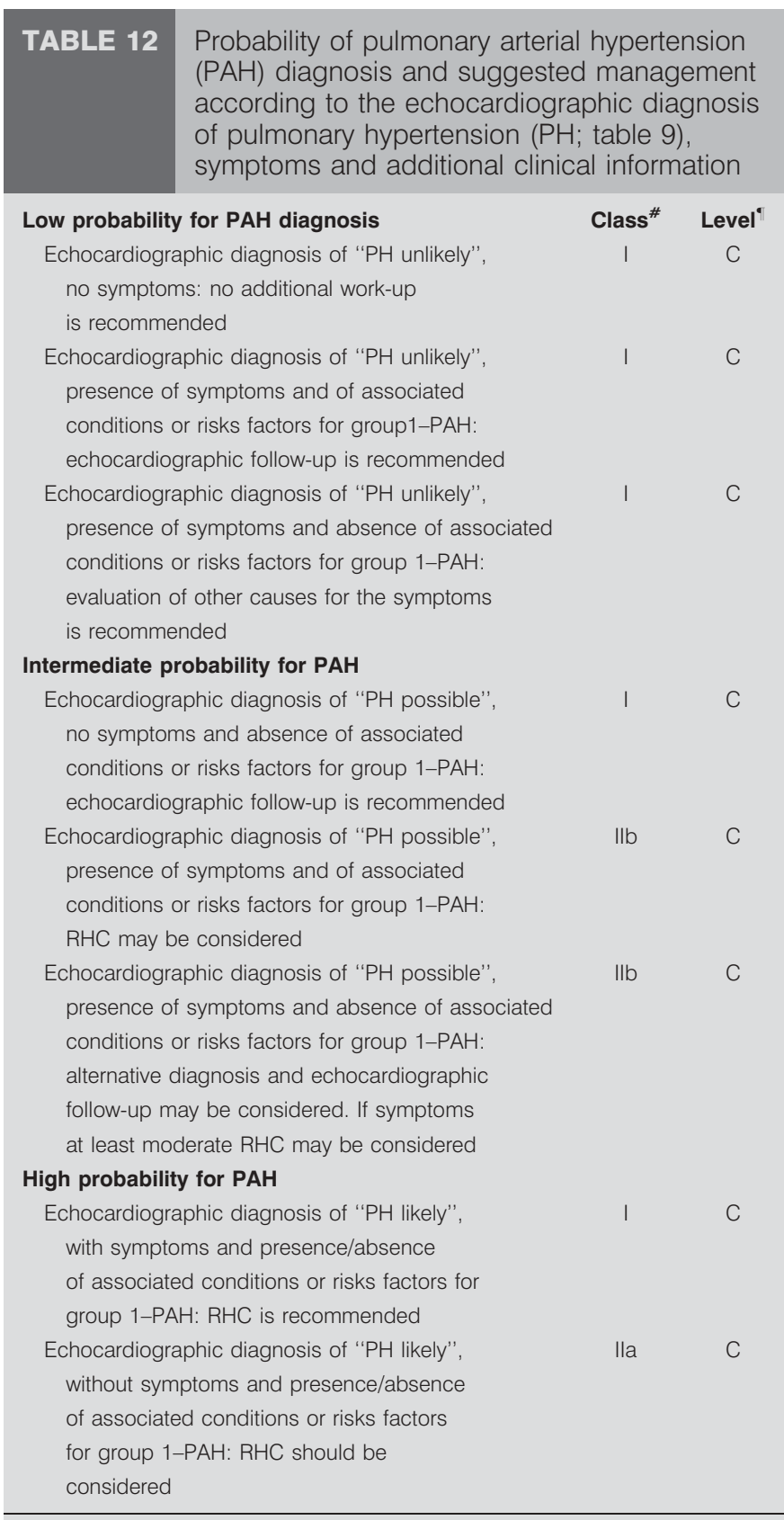

RHC: right heart catheterisation. *: class of recommendation; ": level of evidence.

pericardial effusion [70, 71], indexed right atrium area [71], LV eccentricity index [71] and the RV Doppler index [72, 73]. Estimated systolic PAP derived from tricuspid regurgitant jet velocity is not prognostic [71]. The tricuspid annular plane systolic excursion (TAPSE) has been reported to be of prognostic value [74].

Resting haemodynamics measured at RHC predict prognosis [8]. These include PA oxygen saturation, right atrial pressure, CO, PVR and a marked vasoreactivity response. PAP is also prognostic but less reliable as it may fall towards the end stage of the disease as the RV fails. Some studies suggest that 
TABLE 13 Recommendations for diagnostic strategy

\begin{tabular}{|c|c|c|}
\hline Statement & Class $^{\#}$ & Level" \\
\hline $\begin{array}{l}\text { Ventilation/perfusion lung scan is } \\
\text { recommended in patients with unexplained } \\
\mathrm{PH} \text { to exclude CTEPH }\end{array}$ & । & C \\
\hline $\begin{array}{l}\text { Contrast CT angiography of the PA is } \\
\text { indicated in the work-up of patients with } \\
\text { CTEPH }\end{array}$ & I & C \\
\hline $\begin{array}{l}\text { Routine biochemistry, haematology, } \\
\text { immunology and thyroid function tests are } \\
\text { indicated in all patients with PAH, to } \\
\text { identify the specific associated condition }\end{array}$ & 1 & C \\
\hline $\begin{array}{l}\text { Abdominal ultrasound is indicated for the } \\
\text { screening of portal hypertension }\end{array}$ & I & C \\
\hline $\begin{array}{l}\text { High-resolution CT should be considered in } \\
\text { all patients with } \mathrm{PH}\end{array}$ & Ila & C \\
\hline $\begin{array}{l}\text { Conventional pulmonary angiography } \\
\text { should be considered in the work-up of } \\
\text { patients with CTEPH }\end{array}$ & Ila & C \\
\hline $\begin{array}{l}\text { Open or thoracoscopic lung biopsy is not } \\
\text { recommended in patients with PAH }\end{array}$ & III & C \\
\hline
\end{tabular}

$\mathrm{PH}$ : pulmonary hypertension; CTEPH: chronic thromboembolic pulmonary hypertension; CT: computed tomography; PA: pulmonary artery; PAH: pulmonary arterial hypertension. ${ }^{*}$ : class of recommendation; ': level of evidence.

reduced arterial $\mathrm{O}_{2}$ saturation, low systolic blood pressure and increased heart rate carry a worse prognosis [75].

Right atrial pressure, $\mathrm{CI}$ and $\bar{P}_{\text {pa }}$ have been incorporated in a formula to predict prognosis [8]. It is unclear whether this formula is applicable to current clinical practice.

\subsubsection{Exercise capacity}

For objective assessment of exercise capacity, the 6-minute walking test (6-MWT) and cardiopulmonary exercise testing are commonly used in patients with $\mathrm{PAH}$.

The 6-MWT is technically simple, inexpensive, reproducible and well standardised [77]. In addition to distance walked, dyspnoea on exertion (Borg scale) and finger $\mathrm{O}_{2}$ saturation are recorded. Walking distances $<332 \mathrm{~m}$ [78] or $<250 \mathrm{~m}$ [79] and $\mathrm{O}_{2}$ desaturation $>10 \%$ [80] indicate impaired prognosis in PAH. With respect to treatment effects, absolute values $>380 \mathrm{~m}$ following 3 months of i.v. epoprostenol correlated with improved survival in IPAH patients while the increase from baseline did not [79]. The increase in 6-MWT distance has remained the primary end-point in most pivotal PAH RCTs. The test is not sufficiently validated in PAH subgroups and is influenced by (but not corrected for) body weight, sex, height, age and patient motivation [77].

With cardiopulmonary exercise testing gas exchange and ventilation are continuously recorded throughout incremental exercise. In $\mathrm{PAH}, \mathrm{O}_{2}$ uptake at the anaerobic threshold and peak exercise are reduced in relation to disease severity, as are peak work rate, peak heart rate, $\mathrm{O}_{2}$ pulse and ventilatory

\begin{tabular}{|c|c|}
\hline TABLE 14 & $\begin{array}{l}\text { Functional classification of pulmonary } \\
\text { hypertension modified after the New York Heart } \\
\text { Association functional classification according } \\
\text { to the World Health Organization }\end{array}$ \\
\hline Class I & $\begin{array}{l}\text { Patients with pulmonary hypertension but without } \\
\text { resulting limitation of physical activity. } \\
\text { Ordinary physical activity does not cause undue } \\
\text { dyspnoea or fatigue, chest pain, or near syncope. }\end{array}$ \\
\hline Class II & $\begin{array}{l}\text { Patients with pulmonary hypertension resulting in } \\
\text { slight limitation of physical activity. They are } \\
\text { comfortable at rest. Ordinary physical activity causes } \\
\text { undue dyspnoea or fatigue, chest pain, or near syncope. }\end{array}$ \\
\hline Class III & $\begin{array}{l}\text { Patients with pulmonary hypertension resulting in } \\
\text { marked limitation of physical activity. They are } \\
\text { comfortable at rest. Less than ordinary activity causes } \\
\text { undue dyspnoea or fatigue, chest pain, or near syncope. }\end{array}$ \\
\hline Class IV & $\begin{array}{l}\text { Patients with pulmonary hypertension with inability to } \\
\text { carry out any physical activity without symptoms. } \\
\text { These patients manifest signs of right heart failure. } \\
\text { Dyspnoea and/or fatigue may even be present at rest. } \\
\text { Discomfort is increased by any physical activity. }\end{array}$ \\
\hline
\end{tabular}

Reproduced from [76], with permission from the publishers

efficiency [81]. Following multivariate analysis of clinical, haemodynamic and exercise parameters peak $\mathrm{O}_{2}$ uptake $\left(<10.4 \mathrm{~mL} \mathrm{O}{ }_{2} \cdot \mathrm{kg}^{-1} \cdot \mathrm{min}^{-1}\right)$ and peak systolic arterial pressure during exercise $(<120 \mathrm{mmHg})$ independently predicted a worse prognosis in IPAH patients [75].

While the results of both methods do correlate in $\mathrm{PAH}$, cardiopulmonary exercise testing failed to confirm improvements observed with 6-MWT in RCTs [82, 83]. Although lack of standardisation and insufficient expertise in performing cardiopulmonary exercise testing were identified as the main reasons explaining this discrepancy [81], the 6-MWT remains until now the only Food and Drug Administration- and European Agency for the Evaluation of Medicinal Productsaccepted exercise end-point for studies evaluating treatment effects in PAH. Despite detailed recommendations [84, 85], a generally accepted standardisation of cardiopulmonary exercise testing with respect to data acquisition and analysis in $\mathrm{PAH}$ is lacking.

\subsubsection{Biochemical markers}

Biochemical markers emerged within the last decade as an attractive noninvasive tool for assessment and monitoring of RV dysfunction in patients with $\mathrm{PH}$.

Serum uric acid is a marker of impaired oxidative metabolism of ischaemic peripheral tissue. High uric acid levels were found to relate to poor survival in patients with IPAH [86]. However, allopurinol is often prescribed to patients with $\mathrm{PAH}$, and hyperuricaemia and diuretics influence its plasma levels, impairing the value of clinical monitoring based on uric acid levels.

Atrial natriuretic peptide and brain natriuretic peptide (BNP) share similar physiological properties. Both induce vasodilatation and natriuresis and are released from myocardium in 
response to wall stress. Interest in the clinical application of natriuretic peptides in monitoring RV failure due to chronic $\mathrm{PH}$ has focused on BNP.

The final step of BNP synthesis consists of a high molecular weight precursor, proBNP cleaved into biologically inactive $\mathrm{N}$-terminal segment (NT-proBNP) and the proper low molecular weight BNP. NT-proBNP has a longer half-life and a better stability both in circulating blood and after sampling. RV failure is the main cause of death in PAH, and BNP/NTproBNP levels reflect the severity of RV dysfunction. NAGAYA et al. [87]. showed that the baseline median value of BNP $\left(150 \mathrm{pg} \cdot \mathrm{mL}^{-1}\right)$ distinguished patients with a good or bad prognosis. In 49 out of 60 patients, BNP measurement was repeated after 3 months of targeted therapy and again the supramedian level $\left(>180 \mathrm{pg} \cdot \mathrm{mL}^{-1}\right)$ was related to worse longterm outcome. Plasma BNP significantly decreased in survivors but increased in nonsurvivors despite treatment. In a trial involving 68 patients with $\mathrm{PAH}$ associated with scleroderma, NT-proBNP below a median of $553 \mathrm{pg} \cdot \mathrm{mL}^{-1}$ was related to better 6-month and 1-yr survival [88]. Using receiver operating characteristic (ROC) analysis, an NT-proBNP cut-off point at $1400 \mathrm{pg} \cdot \mathrm{mL}^{-1}$ was predictive of a 3-yr outcome in 55 patients with severe pre-capillary PH [89]. Serum NT-proBNP below $1,400 \mathrm{pg} \cdot \mathrm{mL}^{-1}$ seemed particularly useful for identification of patients with good prognosis, who would not need escalation of treatment in the immediate future, and this has been independently confirmed [90]. Larger outcome trials are still required to verify the suggested cut-off levels for NT-proBNP.

Increases in NT-proBNP plasma levels on follow-up have been associated with worse prognosis [88]. Several recent trials assessing new drugs in PAH or CTEPH reported a significant decrease in NT-proBNP in the actively treated versus placebo patients.

Elevated plasma levels of cardiac troponin $\mathrm{T}$ and troponin I are established specific markers of myocardial damage and are prognostic indicators in acute coronary syndromes and acute pulmonary embolism. Elevated cardiac troponin $\mathrm{T}$ was an independent predictor of fatal outcome during 2-yr follow-up in a single trial on 51 patients with PAH and five with CTEPH [91]. In some patients cardiac troponin $\mathrm{T}$ disappeared from plasma either temporarily or permanently after introduction of treatment. The value of monitoring of the cardiac troponin $\mathrm{T}$ level in patients with $\mathrm{PH}$ still requires confirmation in future studies. Other biomarkers are currently under investigation $[92,93]$.

In conclusion, several circulating biomarkers convey prognostic information in patients with $\mathrm{PAH}$, but their value in everyday clinical practice is still not established.

BNP/NT-proBNP plasma levels should be recommended for initial risk stratification and may be considered for monitoring the effects of treatment, in view of their prognostic implications. Low and stable or decreasing BNP/NT-proBNP may be a useful marker of successful disease control in PAH.

\subsubsection{Comprehensive prognostic evaluation}

Regular evaluation of patients with PAH should focus on variables with established prognostic importance as outlined above. Treatment decisions should be based on parameters that reflect symptoms and exercise capacity and that are relevant in terms of predicting outcome. Not all parameters obtained repeatedly in PAH patients are equally well suited to assess disease severity. For example, PAP is measured on a regular basis, either by RHC or by echocardiography. The magnitude of the PAP correlates poorly with symptoms and outcome as it is determined not only by the degree of PVR increase but also by the performance of the RV. Thus, the PAP alone should not be used for therapeutic decision making. Table 15 lists several parameters of known prognostic importance that are widely used as follow-up tools. Not all parameters need to be assessed at every visit (table 16), but in order to obtain a clear picture it is important to look at a panel of data derived from clinical evaluation, exercise tests, biochemical markers, and echocardiographic and haemodynamic assessments. It is crucial not to rely just on a single parameter as several assessments may provide divergent results. In addition, no clear-cut thresholds for any single parameters can be identified to separate patients with good prognosis from those with a poor one. In table 15, patients with better or worse prognosis are separated by an intermediate group for which prognostication is more difficult. In these cases, additional factors not included in table 15 should be considered such as age, aetiology and comorbidities.

\subsubsection{Definition of patient status}

Based on the clinical, noninvasive and invasive findings the clinical condition of a patient can be defined as stable and satisfactory, stable but not satisfactory, unstable and deteriorating:

\section{Stable and satisfactory}

Patients in this condition should fulfil the majority of the findings listed in the "better prognosis" column of table 15. In particular, the patient is characterised by absence of clinical signs of RV failure [79], stable WHO-FC I or II without syncope, a 6-min walk distance $>500 \mathrm{~m}[79,95]$ depending on the individual patient, a peak oxygen uptake $\left(V^{\prime} \mathrm{O}_{2}\right)$ $>15 \mathrm{~mL} \cdot \mathrm{min}^{-1} \cdot \mathrm{kg}^{-1}[75,96]$, normal or near-normal BNP/NTproBNP plasma levels [87, 89], no pericardial effusion [71], TAPSE $>2.0 \mathrm{~cm}$ [74], right atrial pressure, $8 \mathrm{mmHg}$ and a CI $\geqslant 2.5 \mathrm{~L} \cdot \mathrm{min}^{-1} \cdot \mathrm{m}^{-2}[8,79,95,97,98]$.

\section{Stable and not satisfactory}

This is a patient who although stable has not achieved the status which patient and treating physician would consider desirable. Some of the limits described above for a stable and satisfactory condition and included in the first column of table 15 are not fulfilled. These patients require re-evaluation and consideration for additional or different treatment following full assessment in the referral centre (see specific paragraph for definition).

\section{Unstable and deteriorating}

Patients in this condition fulfil the majority of the findings listed in the "worse prognosis" column of table 15. In particular, the patient is characterised by evidence of progression of RV failure symptoms and signs, worsening WHO-FC, i.e. from II to III or from III to IV, a 6-min walk distance of $<300 \mathrm{~m}[79,95]$, a peak $V^{\prime} \mathrm{O}_{2}<12 \mathrm{~mL} \cdot \mathrm{min}^{-1} \cdot \mathrm{kg}^{-1}$ [75], rising BNP/NT-proBNP plasma levels [87, 89], evidence of pericardial effusion [71], TAPSE 


\begin{tabular}{|c|c|c|c|}
\hline \multirow[t]{2}{*}{ TABLE 15} & \multicolumn{3}{|c|}{$\begin{array}{l}\text { Parameters with established importance for assessing disease severity, stability and prognosis in pulmonary arterial } \\
\text { hypertension }\end{array}$} \\
\hline & Better prognosis & Determinants of prognosis & Worse prognosis \\
\hline & No & Clinical evidence of RV failure & Yes \\
\hline & Slow & Rate of progression of symptoms & Rapid \\
\hline & No & Syncope & Yes \\
\hline & Longer $(>500 \mathrm{~m})^{\#}$ & 6-MWT & Shorter $(<300 \mathrm{~m})$ \\
\hline Peak $\mathrm{O}_{2}$ & consumption $>15 \mathrm{~mL} \cdot \mathrm{min}^{-1} \cdot \mathrm{kg}^{-1}$ & Cardiopulmonary exercise testing & Peak $\mathrm{O}_{2}$ consumption $<12 \mathrm{~mL} \cdot \mathrm{min}^{-1} \cdot \mathrm{kg}^{-1}$ \\
\hline & Normal or near-normal & BNP/NT-proBNP plasma levels & Very elevated and rising \\
\hline No peric & ardial effusion TAPSE* $>2.0 \mathrm{~cm}$ & Echocardiographic findings & Pericardial effusion TAPSE ${ }^{*}<1.5 \mathrm{~cm}$ \\
\hline $\operatorname{RAP}<8$ & $\mathrm{nmHg}$ and $\mathrm{Cl} \geqslant 2.5 \mathrm{~L} \cdot \mathrm{min}^{-1} \cdot \mathrm{m}^{-2}$ & Haemodynamics & $\mathrm{RAP}>15 \mathrm{mmHg}$ or $\mathrm{Cl} \leqslant 2.0 \mathrm{~L} \cdot \mathrm{min}^{-1} \cdot \mathrm{m}^{-2}$ \\
\hline
\end{tabular}

RV: right ventricular; WHO-FC: World Health Organization functional class; 6-MWT: 6-min walking test; BNP: brain natriuretic peptide; NT-proBNP: N-terminal proBNP TAPSE: tricuspid annular plane systolic excursion; RAP: right atrial pressure; Cl: cardiac index. ${ }^{\#}$ : depending on age; ": TAPSE and pericardial effusion have been selected because they can be measured in the majority of the patients. Reproduced from MCLAUGHLIN and McGoon [94], with permission from the publisher

$<1.5 \mathrm{~cm}$ [74], right atrial pressure $>15 \mathrm{mmHg}$ and rising, or a CI that is $\leqslant 2.0 \mathrm{~L} \cdot \mathrm{min}^{-1} \cdot \mathrm{m}^{-2}$ and falling $[8,79,95,97,98]$. Clinical warning signs are increasing oedema and/or the need to escalate diuretic therapy, new onset or increasing frequency/ severity of angina which can be a sign of deteriorating RV function, and the onset or increasing frequency of syncope, which is often a grim prognostic sign and requires immediate attention as it heralds low output heart failure. Supraventricular arrhythmias may be seen in this condition and contribute to clinical deterioration.

\subsubsection{Treatment goals and follow-up strategy (see also section 7.3.7 and table 22)}

Treatment goals for PAH patients which may be considered are those listed in the "stable and satisfactory definition" and in the "better prognosis" column of table 15.

Target values and treatment goals should be adjusted to the individual patient. For example, a 6-MWT $>400 \mathrm{~m}$ is usually considered acceptable in $\mathrm{PAH}$ patients. Younger patients are often capable of walking $500 \mathrm{~m}$ or more despite the presence of severe $\mathrm{PH}$ and RV dysfunction. In these patients, additional exercise testing with cardiopulmonary exercise test and/or RHC is particularly useful in order to obtain a more reliable assessment of RV function. Peak $V^{\prime} \mathrm{O}_{2}, \mathrm{O}_{2}$ pulse, peak systolic blood pressure during exercise and the minute ventilation/ carbon dioxide production slope (ventilator efficacy) provide important information about RV function during exercise [75, 96]. Biomarkers, echocardiography and RHC are useful additional tools to decide whether or not the patient can be considered stable. Suggested follow-up strategies for patients with PAH are reported in table 16.

There is no universally accepted consensus about when and how often to perform follow-up RHC. Some, but not all, expert centres perform RHC regularly, for example, once a year. Some centres use RHC whenever a change in treatment is considered, while others regularly perform RHC 3-6 months after new treatments have been instituted to ensure that haemodynamics are in the desired range. In terms of prognostic importance, the most relevant haemodynamic variables are cardiac output, right atrial pressure (RAP) and mixed-venous oxygen saturation, i.e. those variables that reflect RV function. Recommendations for the use of RHC in PAH patients are provided in table 11 .

Recommendations for evaluation of severity and follow-up are summarised in table 17.

\subsection{Therapy}

In the past few years, treatment of $\mathrm{PAH}$ has undergone an extraordinary evolution, which has led to the current approval by regulatory agencies of eight drugs with different routes of administration. Additional drugs are expected in the near future. Modern drug therapy leads to a significant improvement in patients' symptomatic status and a slower rate of clinical deterioration. In addition, a meta-analysis performed on 23 RCTs in PAH patients (published prior to October 2008) reports a $43 \%$ decrease in mortality and a $61 \%$ reduction in hospitalisations in patients treated with specific drug therapies versus patients randomised to placebo [99]. These results, achieved after an average treatment period of 14.3 weeks, support the efficacy of the currently approved PAH treatments. Despite this finding, $\mathrm{PAH}$ remains a chronic disease without a cure. In addition, the medical and interventional treatments for more advanced cases are still invasive and prone to significant side-effects.

The therapy of PAH patients cannot be considered as a mere prescription of drugs but is characterised by a complex strategy which includes the evaluation of severity, supportive and general measures, the assessment of vasoreactivity, the estimation of efficacy and combination of different drugs plus interventions. In any of these steps, the knowledge and experience of the responsible physician are critical to optimise the available resources.

\subsubsection{General measures}

Patients with $\mathrm{PAH}$ require sensible advice about general activities of daily living and need to adapt to the uncertainty associated with a serious chronic life-threatening disease. The diagnosis usually confers a degree of social isolation [100]. 
TABLE 16 Suggested assessments and timing for the follow-up of patients with pulmonary arterial hypertension

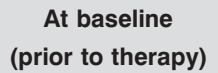

(prior to therapy)

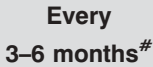

3-6 months after

initiation or changes

in therapy
In case of clinical worsening

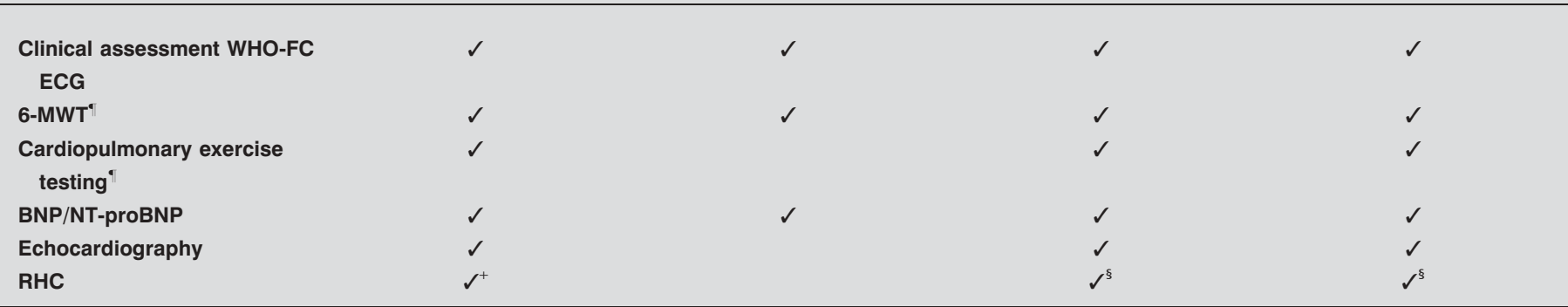

WHO-FC: World Health Organization functional class; $\checkmark$ : assessment is suggested; 6-MWT: 6-min walking test; BNP: brain natriuretic peptide; NT-proBNP: N-terminal proBNP; RHC: right heart catheterisation. ${ }^{\#}$ : intervals should to be adjusted to individual patients needs; ${ }^{\bullet}$ : usually one of the two exercise tests is performed; ${ }^{+}$: is recommended (table 11A); ${ }^{\text {: }}$ should be performed (table $\left.11 \mathrm{~A}\right)$.

Encouraging patients and their family members to join patient support groups can have positive effects on coping, confidence and outlook.

\section{Physical activity and supervised rehabilitation}

Patients should be encouraged to be active within symptom limits. Mild breathlessness is acceptable but patients should avoid exertion that leads to severe breathlessness, exertional dizziness, or chest pain. A recent study has shown the value of a training programme in improving exercise performance [101]. Patients should therefore avoid excessive physical activity that leads to distressing symptoms, but when physically deconditioned may undertake supervised exercise rehabilitation.

One recent study has demonstrated an improvement in exercise capacity in patients with $\mathrm{PAH}$ who took part in a training programme [101]. More data are required before appropriate recommendations can be made. There is growing evidence supporting loss of peripheral muscle mass in patients

\begin{tabular}{|c|c|c|c|}
\hline TABLE 17 & \multicolumn{3}{|c|}{$\begin{array}{l}\text { Recommendations for evaluation of severity } \\
\text { and follow-up }\end{array}$} \\
\hline Statement & & Class $^{\#}$ & Level" \\
\hline \multicolumn{2}{|c|}{$\begin{array}{l}\text { It is recommended to evaluate the severity of PAH } \\
\text { patients with a panel of data derived from clinical } \\
\text { evaluation, exercise tests, biochemical } \\
\text { markers, and echocardiographic and haemodynamic } \\
\text { assessments (table 15) }\end{array}$} & I & C \\
\hline \multicolumn{2}{|c|}{$\begin{array}{l}\text { It is recommended to perform regular follow-up every } \\
3-6 \text { months (table 16) also in stable patients } \\
\text { with PAH }\end{array}$} & 1 & C \\
\hline \multicolumn{2}{|c|}{$\begin{array}{l}\text { A goal-oriented treatment strategy is recommended } \\
\text { in patients with PAH }\end{array}$} & 1 & C \\
\hline
\end{tabular}

PAH: pulmonary arterial hypertension. ${ }^{*}$ : class of recommendation; " level of evidence. with advanced $\mathrm{PAH}$, and this may be corrected by a defined rehabilitation programme.

Pregnancy, birth control and post-menopausal hormonal therapy There is consistency from the $\mathrm{WHO}$, existing guidelines and the Expert Consensus Document of the ESC [102] that pregnancy is associated with $30-50 \%$ mortality in patients with PAH [103], and as a consequence PAH is a contraindication to pregnancy. There is less consensus relating to the most appropriate methods of birth control. Barrier contraceptive methods are safe for the patient but with an unpredictable effect. Progesterone-only preparations such as medroxyprogesterone acetate and etonogestrel are effective approaches to contraception and avoid potential issues of oestrogens as those included in the old generation mini-pill [104]. It should be remembered that the endothelin receptor antagonist (ERA) bosentan may reduce the efficacy of oral contraceptive agents. The Mirena coil is also effective but rarely leads to a vasovagal reaction when inserted, which may be poorly tolerated in severe PAH [104]. A combination of two methods may also be utilised. The patient who becomes pregnant should be informed of the high risk of pregnancy, and termination of pregnancy discussed. Those patients who choose to continue pregnancy should be treated with disease-targeted therapies, planned elective delivery and effective close collaboration between obstetricians and the PAH team $[105,106]$.

It is not clear if the use of hormonal therapy in postmenopausal females with PAH is advisable or not. It may be considered in cases of intolerable menopausal symptoms in conjunction with oral anticoagulation.

Travel

There are no studies using flight simulation to determine the need for supplemental $\mathrm{O}_{2}$ during prolonged flights in patients with PAH. The known physiological effects of hypoxia suggest that in-flight $\mathrm{O}_{2}$ administration should be considered for patients in WHO-FC III and IV and those with arterial blood $\mathrm{O}_{2}$ pressure consistently $<8 \mathrm{kPa}(60 \mathrm{mmHg})$. A flow rate of $2 \mathrm{~L} \cdot \mathrm{min}^{-1}$ will raise inspired $\mathrm{O}_{2}$ pressure to values seen at sea level. Similarly, such patients should avoid going to altitudes 


\section{TABLE 18 Recommendations for general measures}

\begin{tabular}{|c|c|c|}
\hline Statement & Class $^{\#}$ & Level" \\
\hline $\begin{array}{l}\text { It is recommended to avoid pregnancy in patients } \\
\text { with PAH }\end{array}$ & I & C \\
\hline $\begin{array}{l}\text { Immunisation of PAH patients against influenza } \\
\text { and pneumococcal infection is recommended }\end{array}$ & I & C \\
\hline $\begin{array}{l}\text { Physically deconditioned PAH patients should } \\
\text { be considered for supervised exercise } \\
\text { rehabilitation }\end{array}$ & Ila & B \\
\hline $\begin{array}{l}\text { Psychosocial support should be considered in } \\
\text { patients with PAH }\end{array}$ & Ila & C \\
\hline $\begin{array}{l}\text { In-flight } \mathrm{O}_{2} \text { administration should be } \\
\text { considered for patients in WHO-FC III and IV } \\
\text { and those with arterial blood } \mathrm{O}_{2} \text { pressure } \\
\text { consistently }<8 \mathrm{kPa}(60 \mathrm{mmHg})\end{array}$ & Ila & C \\
\hline $\begin{array}{l}\text { Epidural anaesthesia instead of general } \\
\text { anaesthesia should be utilised, if possible, for } \\
\text { elective surgery }\end{array}$ & Ila & C \\
\hline $\begin{array}{l}\text { Excessive physical activity that leads to } \\
\text { distressing symptoms is not recommended in } \\
\text { patients with PAH }\end{array}$ & III & C \\
\hline
\end{tabular}

PAH: pulmonary arterial hypertension; WHO-FC: World Health Organization functional class. ${ }^{\#}$ : class of recommendation; ": level of evidence.

above 1500-2000 m without supplemental $\mathrm{O}_{2}$. Patients should be advised to travel with written information about their $\mathrm{PAH}$ and be advised how to contact local PH clinics in close proximity to where they are travelling.

\section{Psychosocial support}

Many PAH patients develop anxiety and depression leading to impairment in quality of life. Timely referral to a psychiatrist or psychologist should be made when appropriate. Information on the severity of the disease is available from many nonprofessional sources, and an important role of the PAH multidisciplinary team is to support patients with accurate and up to date information. Patient support groups may also play an important role in this area, and patients should be advised to join such groups.

\section{Infection prevention}

Patients with PAH are susceptible to developing pneumonia, which is the cause of death in $7 \%$ of cases [44]. Whilst there are no controlled trials, it is recommended to vaccinate against influenza and pneumococcal pneumonia.

\section{Elective surgery}

Elective surgery is expected to have an increased risk in patients with PAH. It is not clear as to which form of anaesthesia is preferable but epidural is probably better tolerated than general anaesthesia. Patients usually maintained on oral therapy may require temporary conversion to $i . v$. or nebulised treatment until they are able both to swallow and to absorb drugs taken orally.

Recommendations for general measures are summarised in table 18
TABLE 19 Recommendations for supportive therapy

\begin{tabular}{|c|c|c|}
\hline Statement & Class $^{\#}$ & Level" \\
\hline $\begin{array}{l}\text { Diuretic treatment is indicated in PAH patients } \\
\text { with signs of RV failure and fluid retention }\end{array}$ & I & C \\
\hline $\begin{array}{l}\text { Continuous long-term } \mathrm{O}_{2} \text { therapy is indicated } \\
\text { in PAH patients when arterial blood } \mathrm{O}_{2} \text { pressure } \\
\text { is consistently }<8 \mathrm{kPa}(60 \mathrm{mmHg})^{+}\end{array}$ & । & C \\
\hline $\begin{array}{l}\text { Oral anticoagulant treatment should be } \\
\text { considered in patients with IPAH, heritable } \\
\text { PAH and PAH due to use of anorexigens }\end{array}$ & Ila & C \\
\hline $\begin{array}{l}\text { Oral anticoagulant treatment may be } \\
\text { considered in patients with APAH }\end{array}$ & $\mathrm{Ilb}$ & C \\
\hline $\begin{array}{l}\text { Digoxin may be considered in patients with } \\
\text { PAH who develop atrial tachyarrhythmias } \\
\text { to slow ventricular rate }\end{array}$ & $\mathrm{llb}$ & C \\
\hline
\end{tabular}

\subsubsection{Supportive therapy}

Oral anticoagulants

There is a high prevalence of vascular thrombotic lesions at post-mortem in patients with IPAH [107]. Abnormalities in coagulation and fibrinolytic pathways have also been reported [108-110]. This, together with the possible presence of nonspecific risk factors for venous thromboembolism, including heart failure and immobility, represents the rationale for oral anticoagulation in PAH. Evidence in favour of oral anticoagulation is confined to patients with IPAH, heritable $\mathrm{PAH}$, and PAH due to anorexigens; it is generally retrospective and based on single centre experience [65, 107]. The potential benefits of oral anticoagulation should be weighed against the risks in patients with other forms of PAH especially when there is an increased risk of bleeding such as portopulmonary hypertension with severe oesophageal varices. Further research into the role of oral anticoagulation and $\mathrm{PAH}$ is encouraged. Advice regarding the target international normalised ratio (INR) in patients with IPAH varies from 1.5-2.5 in most centres of North America to 2.0-3.0 in European centres. Generally, patients with $\mathrm{PAH}$ receiving therapy with longterm i.v. prostaglandins are anticoagulated in the absence of contraindications due in part to the additional risk of catheterassociated thrombosis.

\section{Diuretics}

Decompensated right heart failure leads to fluid retention, raised central venous pressure, hepatic congestion, ascites and peripheral oedema. Although there are no RCTs of diuretics in PAH, clinical experience shows clear symptomatic benefit in fluid-overloaded patients treated with this therapy. The choice and dose of diuretic therapy may be left to the PAH physician. The addition of aldosterone antagonists should also be considered. It is important to monitor renal function and blood biochemistry in patients to avoid hypokalaemia and the effects of decreased intravascular volume leading to pre-renal failure. 


\section{Oxygen}

Although $\mathrm{O}_{2}$ administration has been demonstrated to reduce the PVR in patients with PAH there are no randomised data to suggest that long-term $\mathrm{O}_{2}$ therapy is beneficial. Most patients with PAH except those with CHD and pulmonary-to-systemic shunts have minor degrees of arterial hypoxaemia at rest unless they have a patent foramen ovale. There are data showing that nocturnal $\mathrm{O}_{2}$ therapy does not modify the natural history of advanced Eisenmenger's syndrome [111]. Guidance may be based on evidence in patients with COPD; when arterial blood $\mathrm{O}_{2}$ pressure is consistently $<8 \mathrm{kPa}(60 \mathrm{mmHg})$ patients are advised to take $\mathrm{O}_{2}$ to achieve a arterial blood $\mathrm{O}_{2}$ pressure of $>8 \mathrm{kPa}$ for at least $15 \mathrm{~h} \cdot \mathrm{day}^{-1}$ [112]. Ambulatory $\mathrm{O}_{2}$ may be considered when there is evidence of symptomatic benefit and correctable desaturation on exercise.

\section{Digoxin}

Digoxin has been shown to improve cardiac output acutely in IPAH although its efficacy is unknown when administered chronically [113]. It may be given to slow ventricular rate in patients with PAH who develop atrial tachyarrhythmias.

Recommendations for general measures are summarised in table 19.

\subsubsection{Specific drug therapy \\ Calcium channel blockers}

Smooth muscle cell hypertrophy, hyperplasia and vasoconstriction have long been known to contribute to the pathogenesis of IPAH and this has led to the use of traditional vasodilators since the mid 1980s, principally involving the use of CCBs. It has been increasingly recognised that only a small number of patients with IPAH who demonstrate a favourable response to acute vasodilator testing at the time of RHC (see also section 7.1.11) do well with CCBs $[65,66]$.

The CCBs that have been predominantly used in reported studies are nifedipine, diltiazem and amlodipine, with particular emphasis on the first two $[65,66]$. The choice of CCB is based upon the patient's heart rate at baseline, with a relative bradycardia favouring nifedipine and amlodipine and a relative tachycardia favouring diltiazem. The daily doses of these drugs that have shown efficacy in IPAH are relatively high, 120 $240 \mathrm{mg}$ for nifedipine, $240-720 \mathrm{mg}$ for diltiazem, and up to $20 \mathrm{mg}$ for amlodipine. It is advisable to start with a low dose, e.g. $30 \mathrm{mg}$ of slow release nifedipine twice a day, $60 \mathrm{mg}$ of diltiazem three times a day (t.i.d.), or $2.5 \mathrm{mg}$ of amlodipine once a day and increase cautiously and progressively to the maximum tolerated dose. Limiting factors for dose increase are usually systemic hypotension and lower limb peripheral oedema. Patients with IPAH who meet the criteria for a positive vasodilator response and are treated with a CCB should be followed closely for both safety and efficacy with an initial reassessment after 3-4 months of therapy including RHC.

If the patient does not show an adequate response (fig. 2), defined as being in WHO-FC I or II and with a marked haemodynamic improvement, additional PAH therapy should be instituted. Patients who have not undergone a vasoreactivity study or those with a negative study should not be started on a CCB because of potential severe side-effects (e.g. hypotension, syncope and RV failure).
Vasodilator responsiveness does not appear to predict a favourable long-term response to $\mathrm{CCB}$ therapy in patients with $\mathrm{PAH}$ in the setting of CTD, and high dose CCBs are often not well tolerated in such patients [114].

\section{Prostanoids}

Prostacyclin is produced predominantly by endothelial cells and induces potent vasodilatation of all vascular beds. This compound is the most potent endogenous inhibitor of platelet aggregation and it also appears to have both cytoprotective and antiproliferative activities [115]. Dysregulation of the prostacyclin metabolic pathways has been shown in patients with PAH as assessed by reduction of prostacyclin synthase expression in the pulmonary arteries and of prostacyclin urinary metabolites [116]. The clinical use of prostacyclin in patients with PAH has been extended by the synthesis of stable analogues that possess different pharmacokinetic properties but share qualitatively similar pharmacodynamic effects.

Epoprostenol. Epoprostenol (synthetic prostacyclin) is available as a stable freeze-dried preparation that needs to be dissolved in alkaline buffer for i.v. infusion. Epoprostenol has a short half-life (3-5 $\mathrm{min})$ and is stable at room temperature for only $8 \mathrm{~h}$. This explains why it needs to be administered continuously by means of an infusion pump and a permanent tunnelled catheter. The efficacy of continuous i.v. administration of epoprostenol has been tested in three unblinded RCTs in patients with IPAH [117, 118] and in those with PAH associated with the scleroderma spectrum of diseases [119]. Epoprostenol improves symptoms, exercise capacity and haemodynamics in both clinical conditions, and is the only treatment shown to improve survival in IPAH in a randomised study [118]. Long-term persistence of efficacy has also been shown $[79,97]$ in IPAH, as well as in other APAH conditions [120-122] and in nonoperable CTEPH. [123].

Treatment with epoprostenol is initiated at a dose of 2-4 $\mathrm{ng} \cdot \mathrm{kg}^{-1} \cdot \mathrm{min}^{-1}$, with doses increasing at a rate limited by side-effects (flushing, headache, diarrhoea, leg pain). The optimal dose varies between individual patients, ranging in the majority between 20 and $40 \mathrm{ng} \cdot \mathrm{kg}^{-1} \cdot \mathrm{min}^{-1}[79,97]$.

Serious adverse events related to the delivery system include pump malfunction, local site infection, catheter obstruction and sepsis. Guidelines for the prevention of central venous catheter bloodstream infections have recently been proposed [124]. Abrupt interruption of the epoprostenol infusion should be avoided as, in some patients, this may lead to a rebound $\mathrm{PH}$ with symptomatic deterioration and even death.

Iloprost. Iloprost is a chemically stable prostacyclin analogue available for i.v., oral and aerosol administration. Inhaled therapy for $\mathrm{PAH}$ is an attractive concept that has the theoretical advantage of being selective for the pulmonary circulation. Inhaled iloprost has been evaluated in one randomised controlled trial (RCT; Aerosolized Iloprost Randomized (AIR) study) in which daily repetitive iloprost inhalations (6-9 times, 2.5-5 mg.inhalation ${ }^{-1}$, median $30 \mathrm{mg}$ daily) were compared with placebo inhalation in patients with PAH and CTEPH [125]. The study showed an increase in exercise capacity and improvement in symptoms, PVR and clinical events in enrolled patients. A second RCT (Safety and pilot efficacy Trial of inhaled iloprost in combination with 


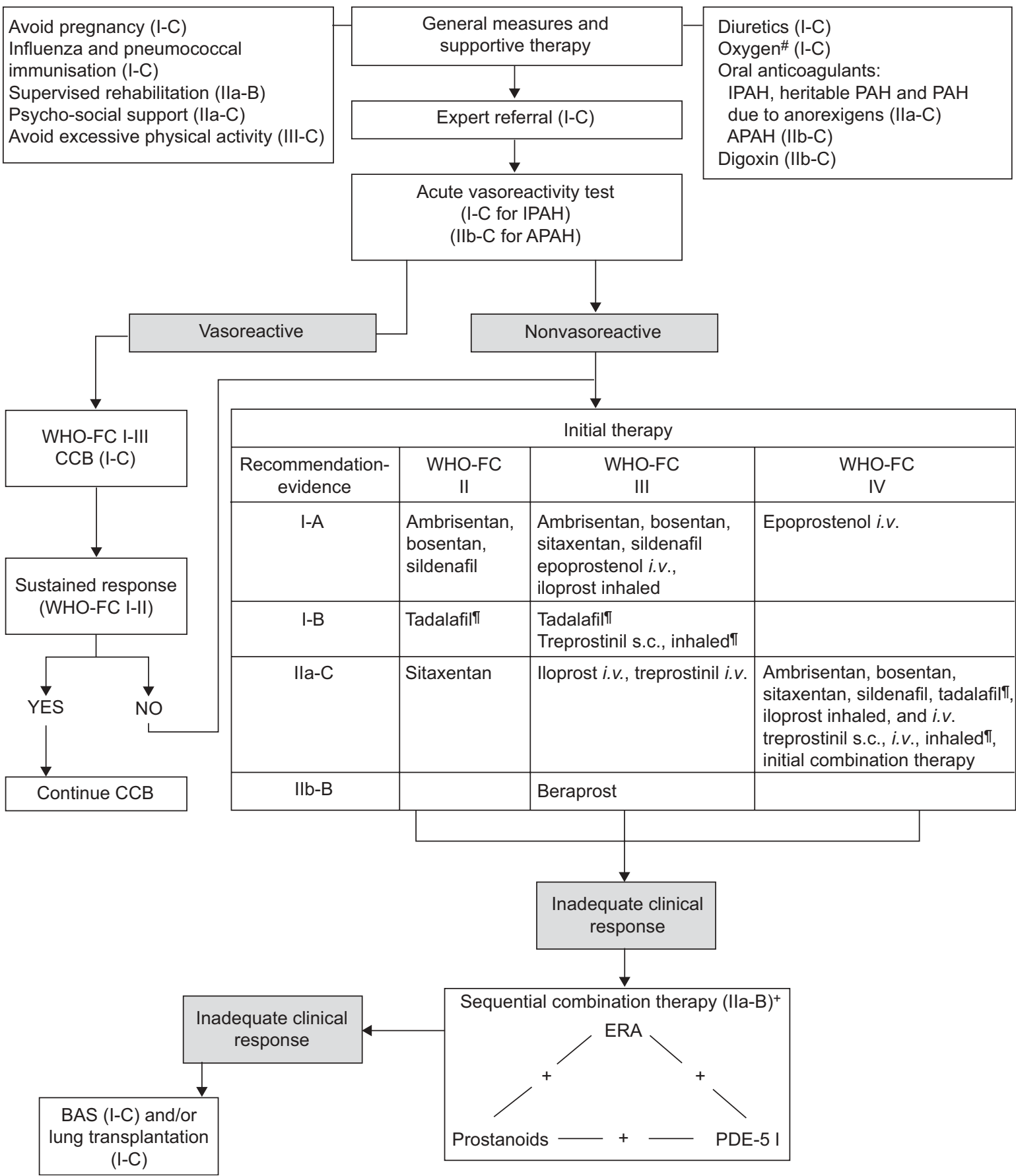

FIGURE 2. Evidence-based treatment algorithm for pulmonary arterial hypertension patients (for group 1 patients only). APAH: associated pulmonary arterial hypertension; BAS: balloon atrial septostomy; CCB: calcium channel blocker; ERA: endothelin receptor antagonist; IPAH: idiopathic pulmonary arterial hypertension; PAH: pulmonary arterial hypertension; PDE-5 I: phosphodiesterase type-5 inhibitor; s.c.: subcutaneously; WHO-FC: World Health Organization functional class. ${ }^{\#}$ : to maintain arterial blood $\mathrm{O}_{2}$ pressure $>8 \mathrm{kPa}(60 \mathrm{mmHg}) ;{ }^{\circ}$ : under regulatory review in the European Union; ${ }^{+}$: Ila-C for WHO-FC II.

bosentan for Evaluation in Pulmonary arterial hypertension (STEP)) on 60 patients already treated with bosentan has shown increase in exercise capacity $(\mathrm{p}<0.051)$ in the subjects randomised to the addition of inhaled iloprost in comparison with placebo [126]. Overall, inhaled iloprost was well tolerated, with flushing and jaw pain being the most frequent side-effects. Continuous i.v. administration of iloprost appears to be as effective as epoprostenol in a small series of patients with PAH and CTEPH [127]. The effects of oral iloprost have not been assessed in PAH.

Treprostinil. Treprostinil is a tricyclic benzidine analogue of epoprostenol, with sufficient chemical stability to be administered at ambient temperature. These characteristics allow administration of the compound by the i.v. as well as the subcutaneous (s.c.) route. The s.c. administration of treprostinil 
can be accomplished by a microinfusion pump and a small subcutaneous catheter. The effects of treprostinil in PAH were studied in the largest worldwide RCT performed in this condition, and showed improvements in exercise capacity, haemodynamics and symptoms [128]. The greatest exercise improvement was observed in patients who were more compromised at baseline and in subjects who could tolerate the upper quartile dose $\left(>13.8 \mathrm{ng} \cdot \mathrm{kg}^{-1} \cdot \mathrm{min}^{-1}\right)$. Infusion site pain was the most common adverse effect of treprostinil, leading to discontinuation of the treatment in $8 \%$ of cases on active drug and limiting dose increase in an additional proportion of patients [128]. Among the $15 \%$ of patients who continued to receive s.c. treprostinil alone, survival appears to be improved [129]. In another long-term, open-label study, a sustained improvement in exercise capacity and symptoms with s.c. treprostinil was reported in patients with IPAH or CTEPH, with a mean follow-up of 26 months [130]. Treatment with s.c. treprostinil is initiated at a dose of $1-2 \mathrm{ng} \cdot \mathrm{kg}^{-1} \cdot \mathrm{min}^{-1}$, with doses increasing at a rate limited by side-effects (local site pain, flushing, headache). The optimal dose varies between individual patients, ranging in the majority between 20 and $80 \mathrm{ng} \cdot \mathrm{kg}^{-1} \cdot \mathrm{min}^{-1}$. Treprostinil has been recently approved in the USA also for i.v. use in patients with PAH: the effects appear to be comparable with those of epoprostenol but at a dose which is between two and three times higher [131, 132]. It is, however, more convenient for the patient because the reservoir can be changed every $48 \mathrm{~h}$ as compared with $12 \mathrm{~h}$ with epoprostenol. A phase III RCT (inhaled TReprostInil sodiUM in Patients with severe Pulmonary arterial Hypertension (TRIUMPH)) of inhaled treprostinil in patients on background therapy with either the ERA bosentan or the phosphodiesterase type-5 inhibitor sildenafil was recently completed and preliminary data show improvements in exercise capacity [133]. Oral treprostinil is currently being evaluated in RCTs in PAH.

Beraprost. Beraprost is the first chemically stable and orally active prostacyclin analogue. The RCT Arterial Pulmonary Hypertension And Beraprost European Trial (ALPHABET) [134] in Europe and a second in the USA [82] with this compound have shown an improvement in exercise capacity that unfortunately persists only up to 3-6 months. There were no haemodynamic benefits. The most frequent adverse events were headache, flushing, jaw pain and diarrhoea.

\section{Endothelin receptor antagonists}

Activation of the endothelin system has been demonstrated in both plasma and lung tissue of PAH patients [135]. Although it is not clear if the increases in endothelin-1 plasma levels are a cause or a consequence of $\mathrm{PH}$ [136], these data support a prominent role for the endothelin system in the pathogenesis of PAH [137]. Endothelin-1 exerts vasoconstrictor and mitogenic effects by binding to two distinct receptor isoforms in the pulmonary vascular smooth muscle cells, endothelin-A and endothelin-B receptors. Endothelin-B receptors are also present in endothelial cells, and their activation leads to release of vasodilators and antiproliferative substances such as $\mathrm{NO}$ and prostacyclin that may counterbalance the deleterious effects of endothelin-1. Despite potential differences in receptor isoform activity, the efficacy in PAH of the dual endothelin-A and endothelin-B receptor antagonist drugs and of the selective ERA compounds appears to be comparable.
Bosentan. Bosentan is an oral active dual endothelin- $\mathrm{A}$ and endothelin-B receptor antagonist and the first molecule of its class that was synthesised. Bosentan has been evaluated in $\mathrm{PAH}$ (idiopathic, associated with CTD and Eisenmenger's syndrome) in five RCTs (Pilot, Bosentan Randomised trial of Endothelin Antagonist THErapy (BREATHE)-1, BREATHE-2, BREATHE-5, and Endothelin Antagonist tRial in mildLY symptomatic pulmonary arterial hypertension patients (EARLY)) that have shown improvement in exercise capacity, functional class, haemodynamics, echocardiographic and Doppler variables, and time to clinical worsening [138-142]. Two RCTs have enrolled exclusively patients with WHO-FC II [141] or patients with Eisenmenger's syndrome [142]. This has resulted in regulatory authority approval for the use of bosentan in the treatment of PAH patients in WHO-FC II and also in patients with $\mathrm{PAH}$ associated with congenital systemic-to-pulmonary shunts and Eisenmenger's syndrome. Bosentan treatment is started at the dose of $62.5 \mathrm{mg}$ twice daily and uptitrated to $125 \mathrm{mg}$ twice daily after 4 weeks. In paediatric patients doses are reduced according to the body weight. Long-term observational studies have demonstrated the durability of the effect of bosentan in adult IPAH patients over time [98]. Increases in hepatic aminotransferases occurred in $\sim 10 \%$ of the subjects but were found to be dose dependent and reversible after dose reduction or discontinuation. For these reasons, liver function test should be performed monthly in patients receiving bosentan. Reductions on haemoglobin levels and impaired spermatogenesis have also been observed.

Sitaxentan. Sitaxentan, a selective orally active endothelin-A receptor antagonist, has been assessed in two RCTs (Sitaxsentan To Relieve ImpaireD Exercise (STRIDE) 1 and 2) on patients with WHO-FC II and III PAH $[83,143]$. Aetiology included IPAH and PAH associated with CTDs or CHD. The studies demonstrated improvements in exercise capacity and haemodynamics. A 1-yr, open-label observational study has demonstrated the durability of the effects of sitaxentan over time [144]. The incidence of abnormal liver function tests was $3-5 \%$ for the approved dose of $100 \mathrm{mg}$ once daily. Monthly checking of liver function tests is required. Sitaxentan interacts with warfarin, and co-administration requires dose reductions of warfarin to avoid increases of INR (table 20).

Ambrisentan. Ambrisentan is a nonsulfonamide, propanoic acid-class, ERA that is selective for the endothelin-A receptor. Ambrisentan has been evaluated in a pilot study [145] and in two large RCTs (Ambrisentan in pulmonary arterial hypertension, Randomized, double- blind, placebo-controlled, multicentre, Efficacy Study (ARIES) 1 and 2), which have demonstrated efficacy on symptoms, exercise capacity, haemodynamics, and time to clinical worsening of patients with IPAH and PAH associated with CTD and HIV infection. The open-label continuation study has demonstrated the durability of the effects of ambrisentan for at least $1 \mathrm{yr}$ [146]. Ambrisentan has been approved for the treatment of WHOFC II and III patients. The current approved dose is $5 \mathrm{mg}$ once daily which can be increased to $10 \mathrm{mg}$ once daily when the drug is tolerated at the initial dose.

The incidence of abnormal liver function tests ranges from 0.8 to $3 \%$. In a small group of patients in which treatment with either bosentan or sitaxentan was discontinued due to liver 
TABLE 20 Potentially significant drug interactions with pulmonary arterial hypertension (PAH)-targeted therapies

\begin{tabular}{|c|c|c|c|}
\hline Ambrisentan & & Ketoconazole & ketoconazole and cyclosporine \\
\hline \multirow[t]{7}{*}{ Bosentan } & CYP3A4 inducer & Sildenafil & $\begin{array}{l}\text { Sildenafil levels fall } 50 \% \text {; bosentan levels increase } 50 \% \text {. May not } \\
\text { require dose adjustments of either drug. }\end{array}$ \\
\hline & CYP3A4 substrate & Erythromycin & $\begin{array}{l}\text { Bosentan levels increase. May not require dose adjustment of } \\
\text { bosentan during a short course. }\end{array}$ \\
\hline & CYP3A4 substrate & Ketoconazole & Bosentan levels increase two-fold. \\
\hline & $\begin{array}{l}\text { CYP3A4 substrate }+ \text { bile } \\
\text { salt pump inhibitor }\end{array}$ & Glibenclamide & $\begin{array}{l}\text { Increase incidence of elevated aminotransferases. Potential decrease } \\
\text { of hypoglycaemic effect of glibenclamide. Combination indicated. }\end{array}$ \\
\hline & CYP2C9 inducer & $\begin{array}{l}\text { HMG CoA reductase } \\
\text { inhibitors }\end{array}$ & $\begin{array}{l}\text { Simvastatin levels reduce } 50 \% \text {; similar effects likely with atorvastatin. } \\
\text { Cholesterol level should be monitored. }\end{array}$ \\
\hline & CYP2C9 inducer & Warfarin & $\begin{array}{l}\text { Increases warfarin metabolism, may need to adjust warfarin dose. } \\
\text { Intensified monitoring of warfarin recommended following initiation } \\
\text { but dose adjustment usually necessary. }\end{array}$ \\
\hline & $\begin{array}{l}\text { CYP2C9 and CYP3A4 } \\
\text { inducers }\end{array}$ & Hormonal contraceptives & Hormone levels decrease. Contraception unreliable. \\
\hline \multirow[t]{2}{*}{ Sitaxentan } & CYP2C9 inhibitor & Warfarin & $\begin{array}{l}\text { Inhibits warfarin metabolism, warfarin dose needs } \\
\text { to be reduced by } 80 \% \text { when initiating sitaxentan } \\
\text { and INR monitoring intensified. }\end{array}$ \\
\hline & $\begin{array}{l}\text { ? inhibition of OATP } \\
\text { transporter }\end{array}$ & Cyclosporine & Increases sitaxen levels; combination contraindicated. \\
\hline \multirow{6}{*}{ Sildenafil } & CYP3A4 inducer & Phenytoin & Sildenafil level may fall. \\
\hline & CYP3A4 substrate & Erythromycin & Sildenafil levels increase may not require dose adjustment for a short course. \\
\hline & CYP3A4 substrate & Ketoconazole & Sildenafil levels increase. May not require dose adjustment. \\
\hline & CYP3A4 substrate & Cimetidine & Sildenafil levels increase. May not require dose adjustment. \\
\hline & cGMP & Nitrates & Profound systemic hypotension, combination contraindicated. \\
\hline & & Nicorandil & \\
\hline \multirow[t]{3}{*}{ Tadalafil } & CYP3A4 substrate & Bosentan & $\begin{array}{l}\text { Tadafil plasma levels decrease by } 42 \% \text {, no significant changes in bosentan levels. } \\
\qquad \text { May not require dose adjustment. }\end{array}$ \\
\hline & cGMP & Nitrates & Profound systemic hypotension, combination contraindicated. \\
\hline & & Nicorandil & \\
\hline
\end{tabular}

HMG CoA: 3-hydroxy-3-methylglutary coenzyme A; OATP: organic anion transporter proteins; cGMP: cyclic guanosine monophosphate. The table is adapted from National Pulmonary Hypertension Centres of the UK and Ireland, "Consensus Statement on the Management of Pulmonary Hypertension in Clinical Practice in the UK and Ireland" [180], wih permmission from the publisher.

function test abnormalities, ambrisentan at a dose of $5 \mathrm{mg}$ was well tolerated [147]. Nevertheless, patients treated with ambrisentan require monthly liver function test assessment. An increased incidence of peripheral oedema has been reported with ambrisentan use.
Phosphodiesterase type-5 inhibitors

Inhibition of the cGMP-degrading enzyme phosphodiesterase type-5 results in vasodilatation through the NO/cGMP pathway at sites expressing this enzyme. Since the pulmonary vasculature contains substantial amounts of phosphodiesterase 
type-5 the potential clinical benefit of phosphodiesterase type-5 inhibitors has been investigated in PAH. In addition, phosphodiesterase type-5 inhibitors exert antiproliferative effects [148, 149]. All three phosphodiesterase type-5 inhibitors approved for the treatment of erectile dysfunction, sildenafil, tadalafil and vardenafil, cause significant pulmonary vasodilation, with maximum effects observed after 60, 75-90 and 40-45 min, respectively [150].

Sildenafil. Sildenafil is an orally active, potent and selective inhibitor of phosphodiesterase type-5. A number of uncontrolled studies have reported favourable effects of sildenafil in IPAH, PAH associated with CTD, CHD and CTEPH [151-153]. An RCT (Sildenafil Use in Pulmonary artERial hypertension (SUPER)-1) on 278 PAH patients treated with sildenafil 20, 40, or $80 \mathrm{mg}$ t.i.d. has confirmed favourable results on exercise capacity, symptoms and haemodynamics [154]. A post hoc analysis of $84 \mathrm{PAH}$ associated with CTD patients receiving sildenafil in the SUPER-1 trial revealed improved exercise capacity, haemodynamic parameters and functional class at 12 weeks when compared with placebo [155]. The approved dose is $20 \mathrm{mg}$ t.i.d., but the durability of effect up to a year has been demonstrated only with the dose of $80 \mathrm{mg}$ t.i.d. In clinical practice, up-titration beyond $20 \mathrm{mg}$ t.i.d. (mainly $40-80 \mathrm{mg}$ t.i.d.) is needed quite frequently. The Pulmonary Arterial hypertension Combination study of Epoprostenol and Sildenafil (PACES) trial addressing the effects of adding sildenafil to epoprostenol is discussed in the "Combination therapy" section [156]. Most side-effects of sildenafil were mild to moderate and mainly related to vasodilation (headache, flushing, epistaxis).

Tadalafil. Tadalafil is a once-daily dispensed, selective phosphodiesterase type-5 inhibitor, currently approved for the treatment of erectile dysfunction. An RCT (Pulmonary arterial Hypertension and ReSponse to Tadalafil (PHIRST)) on 406 PAH patients ( $~ 50 \%$ on background bosentan therapy) treated with tadalafil 5, 10, 20 or $40 \mathrm{mg}$ once daily has shown favourable results on exercise capacity, symptoms, haemodynamics and time to clinical worsening at the largest dose [157]. The durability of the effect has also been shown. The side-effect profile was similar to that of sildenafil.

\section{Experimental compounds and alternative medical strategies}

Despite the progress on the treatment of PAH, the functional limitation and the survival of these patients remain unsatisfactory. For these reasons, additional therapeutic strategies targeted to diverse pathobiological changes are being explored in order to improve symptoms and prognosis further. Phase II and III studies are currently being performed with the following compounds: NO-independent stimulators and activators of cGMP, inhaled vasoactive intestinal peptide, nonprostanoid prostacyclin receptor agonists, tissular dual ERA, tyrosine kinase inhibitors (platelet-derived growth factor inhibitors) and serotonin antagonists.

The following additional compounds are in an earlier stage of development: rho-kinase inhibitors, vascular endothelial growth factor receptor inhibitors, angiopoietin-1 inhibitors and elastase inhibitors.

Gene therapy strategies have been tested in animal models. Stem cell therapy has proven to be effective in the monocrotalin rat model and is currently being tested in proof-of-concept and dose-finding studies in PAH patients.

\section{Combination therapy}

The term combination therapy describes the simultaneous use of more than one PAH-specific class of drugs, e.g. ERAs, phosphodiesterase type- 5 inhibitors, prostanoids and novel substances. Combination therapy has become the standard of care in many $\mathrm{PAH}$ centres, although long-term safety and efficacy have not yet been amply explored. Numerous case series have suggested that various drug combinations appear to be safe and effective [140,158-161]. In one series, a step-wise use of combination therapy according to predefined treatment goals was associated with an improved outcome compared with a historical control group [162].

Results of a few RCTs evaluating combination therapy for $\mathrm{PAH}$ have been published. The relatively small BREATHE-2 study [140] showed a trend to a better haemodynamic effect of the initial combination epoprostenol-bosentan as compared to epoprostenol alone. The STEP-1 study [163] addressed the safety and efficacy of 12 weeks therapy with inhaled iloprost in addition to bosentan and found a marginal increase in the post-inhalation $6 \mathrm{~min}$ walk distance by $+26 \mathrm{~m}(\mathrm{p}=0.051)$. When measured at pre-inhalation, the placebo-corrected improvement in 6 min walk distance was $+19 \mathrm{~m}(\mathrm{p}=0.14)$. There was no improvement in pre-inhalation haemodynamics in the iloprost group after 12 weeks of treatment, but time to clinical worsening was significantly prolonged in the iloprost group ( 0 events versus 5 events in the placebo group; $\mathrm{p}=0.02$ ). In contrast, another RCT, COMbination therapy of Bosentan and aerosolised Iloprost in idiopathic pulmonary arterial hypertension (COMBI), which also studied the effects of inhaled iloprost added to bosentan, was stopped prematurely after a planned futility analysis did not show an effect on $6 \mathrm{~min}$ walking distance or time to clinical worsening [164].

Two other RCTs on combination therapy have been concluded: TRIUMPH [133] and PACES [156]. TRIUMPH studied the effects of inhaled treprostinil in patients already treated with bosentan or sildenafil. The primary end-point, change in 6-MWT at peak exposure, improved by $20 \mathrm{~m}$ compared with placebo $(\mathrm{p}<0.0006)$. At trough exposure, i.e. after $>4$ h postinhalation, the difference was $14 \mathrm{~m}$ in favour of the treprostinil group $(\mathrm{p}<0.01)$. There were no significant differences in Borg dyspnoea index, functional class and time to clinical worsening.

The PACES trial addressed the effects of adding sildenafil to epoprostenol in $267 \mathrm{PAH}$ patients. The most pertinent findings of this study were significant improvements after 12 weeks in 6-MWT and time to clinical worsening. Of note, seven deaths occurred in this trial, all in the placebo group.

Additional data from RCTs are available for the combination of ERAs and phosphodiesterase type- 5 inhibitors. In the subgroup of patients enrolled in the EARLY study [141] (bosentan in WHO-FC II PAH patients) who were already on treatment with sildenafil, the haemodynamic effect of the addition of bosentan was comparable with that achieved in patients without background sildenafil treatment. A pharmacokinetic interaction has been described between bosentan and sildenafil, which act as inducers or inhibitors of cytochrome P450 CYP3A4, respectively. The co-administration of both substances results in a 
decline of sildenafil plasma levels and in an increase in bosentan plasma levels [165]. So far there is no indication that these interactions are associated with reduced safety [166], but the issue of whether the clinical efficacy of sildenafil is significantly reduced is still under debate. No pharmacokinetic interactions have been reported between sildenafil and the two other available ERAs, sitaxentan and ambrisentan.

In the PHIRST study [157, 167], the combination of tadalafil and bosentan resulted in an improvement of exercise capacity of borderline statistical significance (subgroup analysis). For these two compounds a pharmacokinetic interaction has also been shown (table 20).

There are many open questions regarding combination therapy, including the choice of combination agents, the optimal timing [initial combination (in naive patients) or sequential combination (according to the response to the first drug)], when to switch and when to combine. When combination therapy is considered, patients should be treated within clinical trials or registries whenever possible. Combination therapy of established PAH drugs is recommended for patients not responding adequately to monotherapy, but combination therapy should be instituted by expert centres only. Whether the response to monotherapy is sufficient or not can only be decided on an individual basis. This is judged in an individual patient who, despite monotherapy and optimised background treatment, has an inadequate clinical response (figure 2 and table 22).

The safety and efficacy of tyrosine kinase inhibitors in PAH must be further evaluated and, at present, the use of these drugs should be restricted to RCTs.

\section{Drug interactions}

Significant drug interactions involving the disease-specific therapies for PAH are shown in table 20. This table highlights known important interactions but does not include theoretical untested interactions, which may still be clinically important.

Bosentan is an inducer of cytochrome $\mathrm{P} 450$ isoenzymes CYP3A4 and CYP2C9. Plasma concentrations of drugs metabolised by these iso-enzymes will be reduced when coadministered with bosentan. Bosentan is also metabolised by these enzymes so that their inhibition may increase the plasma concentration of bosentan. In addition to interactions shown in table 20, a combination of a potent CYP3A4 inhibitor (ketoconazole or ritonavir) and/or a CYP2C9 inhibitor (e.g. amiodarone of fluconazole) with bosentan may cause a potentially contraindicated significant increase in plasma bosentan levels and it is contraindicated. Interactions may theoretically occur with itraconazole, tacrolimus, sirolimus, carbamazepine, phenytoin, phenobarbitone, dapsone and St John's Wort.

Sitaxentan is an inhibitor of cytochrome P450 isoenzyme CYP2C9 and a weak inhibitor of CYP3A4/5, CYP2C19 and CYP2C8. It is metabolised by CYP2C9 and CYP3A $4 / 5$. Sitaxentan may also be a substrate for organic anion transporter proteins, and plasma sitaxentan levels may be elevated by drugs that interact with organic anion transporter proteins such as cyclosporine, some statins and drugs for tuberculosis. When administered with oral contraceptive agents, sitaxentan increases oestrogen exposure, which may result in a theoretically greater risk of thromboembolism.
Sildenafil is metabolised by cytochrome P450 isoenzymes CYP3A4 (major route) and CYP2C9 (minor route). There is an increase in sildenafil bioavailability and reduced clearance with CYP3A4 substrates, and CYP3A4 substrates plus betaadrenoceptor blockers. CYP3A4 inducers such as carbamazepine, phenytoin, phenobarbital, rifampicin and St John's Wort may significantly lower sildenafil levels. Sildenafil levels are modestly increased by fresh grapefruit juice, a weak inhibitor of CYP3A4.

Finally, care is needed when PAH-specific medications are coadministered with antihypertensive drugs such as $\beta$-adrenoceptor blockers, angiotensin-converting enzyme inhibitors, etc., to avoid excessive systemic hypotension.

\subsubsection{Treatment of arrhythmias}

Arrhythmias are an increasing clinical problem in $\mathrm{PAH}$ patients. In contrast to patients with left heart disease, malignant ventricular arrhythmias such as ventricular tachycardia, ventricular flutter and ventricular fibrillation are rare in PAH patients. In a series of 132 witnessed cardiac arrests in patients with $\mathrm{PAH}$, ventricular fibrillation was observed in only $8 \%$ of the cases [168]. Another series of 231 patients with PAH or CTEPH followed over a 6-yr period did not report any case of malignant ventricular arrhythmia [46]. In that series, supraventricular tachyarrhythmias occurred with an annual incidence of $2.8 \%$. Atrial flutter and atrial fibrillation were equally common and both arrhythmias invariably led to clinical deterioration with signs of right heart failure. Treatment of atrial flutter proved to be more successful than treatment of atrial fibrillation. Restoration of a stable sinus rhythm was associated with a favourable long-term survival while persistent atrial fibrillation was associated with a 2-yr mortality of $>80 \%$ [46]. Although prospective and controlled data are lacking, these findings suggest that maintenance of a stable sinus rhythm should be considered an important treatment goal in patients with $\mathrm{PAH}$. In order to achieve a stable sinus rhythm, prophylaxis with antiarrhythmic drugs without negative inotropic effects such as amiodarone (see interactions in table 20) should also be considered even if specific data regarding its efficacy are lacking.

\subsubsection{Balloon atrial septostomy}

Patients with Eisenmenger's syndrome and patients with IPAH with a patent foramen ovale have a survival advantage over those without a patent foramen ovale [169], supporting the concept of atrial septostomy as a treatment for IPAH. The creation of an inter-atrial right-to-left shunt can decompress the right heart chambers, and increase LV preload and $\mathrm{CO}$ $[170,171]$. In addition, this improves systemic $\mathrm{O}_{2}$ transport despite arterial $\mathrm{O}_{2}$ desaturation [170] and decreases sympathetic hyperactivity. The recommended technique is graded balloon dilation atrial septostomy, which produces equivalent improvements in haemodynamics and symptoms but reduced risk compared with the original blade technique. Other techniques are considered to be experimental [172].

A careful pre-procedure risk assessment ensures reduced mortality. Balloon atrial septostomy (BAS) should be avoided in end-stage patients presenting with a baseline mean RAP of $>20 \mathrm{mmHg}$ and $\mathrm{O}_{2}$ saturation at rest of $<80 \%$ on room air. Patients should be on optimal medical therapy, which may 
include pre-conditioning with i.v. inotropic drugs, prior to considering BAS. Evidence suggests a benefit in patients who are in WHO-FC IV with right heart failure refractory to medical therapy or with severe syncopal symptoms [170, 171]. It may also be considered in patients awaiting transplantation or when medical therapy is not available. Severe IPAH has been the main indication for BAS in adults, although other indications include $\mathrm{PAH}$ associated with surgically corrected CHD, CTD, distal CTEPH, PVOD and pulmonary capillary haemangiomatosis.

Evidence shows improvements in $\mathrm{CI}$, decreases in right atrial pressure with improvement in 6-MWT [170, 171].

The impact of BAS on long-term survival has not been established in RCTs [170, 171]. BAS should be regarded as a palliative or bridging procedure to be performed only by centres with experience in the method [42].

\subsubsection{Transplantation}

The advent of disease-specific therapy for severe PAH has reduced patient referral for lung transplant programmes [42]. The long-term outcomes of medically treated patients remain uncertain and transplantation should remain an important option for those who fail on such therapy. Studies indicate that up to $25 \%$ of patients with IPAH may fail to improve on diseasespecific therapy and the prognosis of patients who remain in WHO-FC III or IV is poor $[79,97]$. International guidelines to aid referral and listing have been published by the International Society for Heart and Lung Transplantation [173].

The prognosis of PAH varies according to the aetiology, and PAH associated with CTD has a worse prognosis than IPAH even when treated with prostanoids, while patients with PAH associated with CHD have a better survival. The worst prognosis is seen in patients with PVOD and pulmonary capillary haemangiomatosis because of the lack of effective medical treatments, and those patients should be listed for transplantation at diagnosis.

In any case, patients with features identifying a worse prognosis profile (table 15) despite maximal medical therapy should be referred for transplant listing.

Both heart-lung and double-lung transplantation have been performed for $\mathrm{PAH}$, although the threshold of unrecoverable RV systolic dysfunction and/or LV diastolic dysfunction is unknown. As a consequence, each centre has developed its own strategy for the choice of the type of transplantation in the individual patient. However, due to the shortage of donor organs, most patients are considered for double-lung transplantation. While RV afterload is immediately reduced after double-lung transplantation, RV systolic and LV diastolic functions do not improve immediately and haemodynamic instability is a common problem in the early post-operative period. Both single and bilateral procedures have been performed, apparently with similar survival. However, any complication occurring in the allograft following single lung transplantation is associated with severe hypoxaemia. Currently the vast majority of patients worldwide receive bilateral lungs, as evidenced by the International Society for Heart and Lung Transplantation Registry figures [174].
Although patients with Eisenmenger's syndrome due to simple shunts have been treated by isolated lung transplantation and repair of the cardiac defect [174], patients with ventricular septal defects may have a better outcome with heart-lung transplantation [175].

The overall 5-yr survival following transplantation for $\mathrm{PAH}$ is $45-50 \%$, with evidence of continued good quality of life [174].

\subsubsection{Treatment algorithm}

- A treatment algorithm for PAH patients [176] is shown in figure 2. The grades of recommendation and levels of evidence for the PAH treatments [177] are shown also in table 21. The definition of clinical response to treatments is reported in table 22. Country-specific regulatory approval and labelling for PAH medical treatments are shown in table 23. Potential drug interactions are shown in table 20.

- Drug classes are listed in alphabetical order (ERAs, phosphodiesterase type-5 inhibitors, prostanoids) and single compounds are listed in alphabetical order within each class in figure 2 and tables 21 and 23.

- The treatment algorithm does not apply to patients in other clinical groups, and in particular not to patients with $\mathrm{PH}$ associated with group 2-left heart disease or with group $3-$ lung diseases. In addition, the different treatments have been evaluated by RCTs mainly in IPAH, heritable PAH, $\mathrm{PAH}$ due to anorexigen drugs, and in $\mathrm{PAH}$ associated with CTD or with CHD (surgically corrected or not). The grades of recommendation and levels of evidence for the other $\mathrm{PAH}$ subgroups are lower (see the section on specific $\mathrm{PAH}$ subsets).

- The suggested initial approach after the diagnosis of PAH, is the adoption of the general measures, the initiation of the supportive therapy and referral to an expert centre.

- Acute vasoreactivity testing should be performed in all patients with group 1-PAH, although patients with IPAH, heritable $\mathrm{PAH}$ and $\mathrm{PAH}$ associated with anorexigen use are the most likely to exhibit an acute positive response and to benefit from high-dose CCB therapy. Vasoreactive patients, as defined above, should be treated with optimally tolerated doses of CCBs (see section 7.3.3); adequate response should be confirmed after 3-4 months of treatment.

- Nonresponders to acute vasoreactivity testing who are in WHO-FC II should be treated with an ERA or a phosphodiesterase type-5 inhibitor.

- Nonresponders to acute vasoreactivity testing, or responders who remain in (or progress to) WHO-FC III should be considered candidates for treatment with either an ERA or a phosphodiesterase type- 5 inhibitor, or a prostanoid.

- As head-to-head comparisons among different compounds are not available, no evidence-based first-line treatment can be proposed. In this case the choice of the drug is dependent on a variety of factors including the approval status, the route of administration, the side-effect profile, patients' preferences and physicians' experience. Some experts still use first-line i.v. epoprostenol in WHO-FC III patients because of its survival benefits.

- Continuous i.v. epoprostenol is recommended as first-line therapy for WHO-FC IV PAH patients because of the 
TABLE 21 Recommendations for efficacy of specific drug therapy, balloon atrial septostomy and lung transplantation for pulmonary arterial hypertension (group 1) according to World Health Organization functional class (WHO-FC)

Measure/treatment
Classes of recommendation-level of evidence

\begin{tabular}{|c|c|c|c|c|}
\hline & & \\
\hline & & WHO-FC II & WHO-FC III & WHO-FC IV \\
\hline Calcium channel blockers & & $\mathrm{I}-\mathrm{C}^{\#}$ & $1-C^{\#}$ & - \\
\hline \multirow{2}{*}{ Endothelin receptor antagonists } & Bosentan & $\mathrm{I}-\mathrm{A}$ & I-A & Ila-C \\
\hline & Sitaxentan & $\| \mathrm{a}-\mathrm{C}$ & I-A & $\| \mathrm{a}-\mathrm{C}$ \\
\hline Phosphodiesterase type-5 inhibitors & Sildenafil & I-A & $1-A$ & Ila-C \\
\hline \multirow{5}{*}{ Prostanoids } & Epoprostenol (intravenous) & - & I-A & I-A \\
\hline & lloprost (inhaled) & - & I-A & Ila-C \\
\hline & Iloprost (intravenous) & - & Ila-C & $\| \mathrm{la}-\mathrm{C}$ \\
\hline & Treprostinil (subcutaneous) & - & I-B & Ila-C \\
\hline & Treprostinil (intravenous) & - & $\| \mathrm{la}-\mathrm{C}$ & Ila-C \\
\hline Lung transplantation & & - & $\mathrm{I}-\mathrm{C}$ & $\mathrm{I}-\mathrm{C}$ \\
\hline
\end{tabular}

\#: only in responders to acute vasoreactivity tests, I for idiopathic pulmonary arterial hypertension (PAH), heritable PAH and PAH due to anorexigens; Ila for APAH conditions; $\bullet$ : under regulatory review in the European Union.

survival benefit in this subset. S.c. and i.v. treprostinil have been also approved for the treatment of WHO-FC IV patients in the USA. Although no RCTs have been performed with the i.v. delivery of iloprost, this prostacyclin analogue has been approved in New Zealand.

- Although ambrisentan, bosentan and sildenafil are approved in WHO-FC IV patients in the USA, only a small number of these patients were included in the RCTs of these agents. Accordingly, most experts consider these treatments as a second line in severely ill patients.

- In WHO-FC IV patients, initial combination therapy should also be considered.

- In the case of inadequate clinical response (table 22, fig. 2), sequential combination therapy should be considered. Combination therapy can include either an ERA plus a

\section{TABLE 22 Definition of inadequate response to pulmonary arterial hypertension (PAH) treatments (see also section 7.2 .5 and 7.2.6)}

\section{Inadequate clinical response for patients who were} initially in WHO-FC II or III:

(1) Resulting clinical status defined as stable and not satisfactory

(2) Resulting clinical status defined as unstable and deteriorating

Inadequate clinical response for patients who were initially in WHO-FC IV:

(1) No rapid improvement to WHO-FC III or better

(2) Resulting clinical status defined as stable and not satisfactory

WHO-FC: World Health Organization functional class. phosphodiesterase type- 5 inhibitor, or a prostanoid plus an ERA, or a prostanoid plus a phosphodiesterase type- 5 inhibitor. Appropriate protocols for timing and dosing to limit possible side-effects of the combination have still to be defined. In expert centres also triple combination therapy is considered.

- BAS and/or lung transplantation are indicated for PAH with inadequate clinical response (table 22) despite optimal medical therapy or where medical treatments are unavailable. These procedures should be performed only in experienced centres.

\subsubsection{End of life care and ethical issues}

The clinical course of $\mathrm{PH}$ is one of progressive deterioration interspersed with episodes of acute decompensation. It is difficult to predict when patients will die because death may come either suddenly or slowly because of progressive heart failure. It has been shown that physicians caring for patients tend to be overoptimistic in their prognostication and frequently misunderstand their patients' wishes.

Open and sensitive communication with patients allows advanced planning and discussion about their fears, concerns and wishes, which is essential to good care. Opportunities to discuss prognosis should be created at the time of initial diagnosis. Recognition that cardiopulmonary resuscitation in severe $\mathrm{PH}$ has poor outcomes may enable a "do not resuscitate" order. This may increase the chance of patients being in their preferred place of care at the end of life.

Patients approaching the end of life require frequent assessment of their full needs by a multidisciplinary team. Attention 


\begin{tabular}{|c|c|c|c|}
\hline \multirow{3}{*}{$\begin{array}{l}\text { TABLE } 23 \\
\text { Treatment }\end{array}$} & \multicolumn{3}{|c|}{$\begin{array}{l}\text { Country-specific regulatory approval and } \\
\text { labelling for pulmonary arterial hypertension } \\
\text { (PAH)-specific drug therapy }\end{array}$} \\
\hline & Country & Labelling & \\
\hline & & Aetiology & WHO-FC \\
\hline $\begin{array}{l}\text { Calcium channel } \\
\text { blockers }\end{array}$ & - & - & - \\
\hline \multirow[t]{2}{*}{ Ambrisentan } & USA, Canada & PAH & $\| I I I I-I V$ \\
\hline & European Union & PAH & $\|-1\|$ \\
\hline \multirow[t]{2}{*}{ Bosentan ${ }^{\#}$} & European Union & $\mathrm{PAH}$ & $\|-1\|$ \\
\hline & USA, Canada & $\mathrm{PAH}$ & $\| I I I I-I V$ \\
\hline Sitaxentan & European Union & $\mathrm{PAH}$ & III \\
\hline \multirow[t]{2}{*}{ Sildenafil } & USA, Canada & $\mathrm{PAH}$ & $\|-I I I-I V$ \\
\hline & European Union & PAH & $\|-1\|$ \\
\hline Tadalafil" & USA & PAH & |I-III-IV \\
\hline Beraprost & Japan, Korea & $\mathrm{PAH}$ & $\|-I I I-I V$ \\
\hline \multirow{2}{*}{$\begin{array}{l}\text { Epoprostenol } \\
\text { (intravenous) }\end{array}$} & Europe $^{+}$ & PAH & III-IV \\
\hline & USA, Canada & $\begin{array}{l}\text { IPAH and } \\
\text { PAH-CTD }\end{array}$ & III-IV \\
\hline \multirow{2}{*}{$\begin{array}{l}\text { lloprost } \\
\quad \text { (inhaled) }\end{array}$} & European Union & IPAH & III \\
\hline & USA & $\mathrm{PAH}$ & III-IV \\
\hline $\begin{array}{l}\text { lloprost } \\
\quad \text { (intravenous) }\end{array}$ & New Zealand & $\begin{array}{c}\text { IPAH, PAH-CTD } \\
\text { and CTEPH }\end{array}$ & III-IV \\
\hline \multirow{3}{*}{$\begin{array}{l}\text { Treprostinil } \\
\text { (subcutaneous) }\end{array}$} & USA & $\mathrm{PAH}$ & $\|-I I I-I V$ \\
\hline & Canada & $\mathrm{PAH}$ & III-IV \\
\hline & $\begin{array}{l}\text { European } \\
\text { Union }^{5}\end{array}$ & IPAH & III \\
\hline \multirow{2}{*}{$\begin{array}{l}\text { Treprostinil } \\
\text { (intravenous) }\end{array}$} & USA $A^{f}$ & PAH & II-III-IV \\
\hline & Canada & PAH & III-IV \\
\hline $\begin{array}{l}\text { Treprostinil } \\
\text { (inhaled) }\end{array}$ & USA & PAH & III \\
\hline
\end{tabular}

WHO-FC: World Health Organization functional class; IPAH: idiopathic PAH; CTD: connective tissue disease; CTEPH: chronic thromboembolic pulmonary hypertension. ${ }^{\#}$ : specifically approved also for PAH associated with congenital systemic-to-pulmonary shunts and Eisenmenger's physiology; ": under regulatory review in the European Union; ${ }^{+}$: epoprostenol in Europe has not been registered through the centralised procedure of the European Medicines Agency (EMEA) but it is approved in different European countries on a national basis; ${ }^{\text {s: }}$ treprostinil in Europe has not been registered through the centralised procedure of the EMEA but it is approved in France and in other countries through the mutual recognition process on a national basis; ${ }^{f}$ : in the case of intolerance of the subcutaneous form

should be given to controlling the distressing symptoms and prescribing appropriate drugs while withdrawing unnecessary medication. Well-informed psychological, social and spiritual support is also vital. Specialist palliative care should be consulted about patients whose needs are beyond the expertise of the PH team.

\subsection{Specific pulmonary arterial hypertension subsets}

Some conditions included in the group 1-PAH, although presenting similarities with IPAH, bear sufficient differences to require specific comments. These conditions comprise paediatric PAH and APAH forms (table 4) such as CHD, CTD, portal hypertension and HIV infection. Recognition of these differences is critical because they may influence not only the diagnostic approach but also the global management of $\mathrm{PAH}$.

\subsubsection{Paediatric pulmonary arterial hypertension}

Paediatric $\mathrm{PH}$ is similar to adult disease even if the lungs are still developing in a growing child. The worse prognosis in children with a median survival estimated at 10 months compared with 2.8 yrs in the adult [8] has not been confirmed. The exact incidence and prevalence of $\mathrm{PH}$ in children is not known. All forms of $\mathrm{PH}$ included in the clinical classification (table 4) have been described in children, but the majority of patients present with $\mathrm{PH}$ associated with CHD or idiopathic/ heritable forms. In contrast, the prevalence of $\mathrm{PH}$ associated with CTD, portal hypertension, HIV infection and drugs and toxins is lower. Patients with chronic lung disease of prematurity are a growing population. Persistent $\mathrm{PH}$ of the neonate is also classified under PAH. Its natural history, treatment and outcome are sufficiently different to justify its exclusion from this discussion [178].

No clear differences have been identified among the mechanisms involved in the development of $\mathrm{PAH}$ in children and adults.

\section{Diagnosis}

Based on old studies it was thought that $40 \%$ of children with IPAH were vasoreactive, but it seems that new figures are closer to those of the adult patient population, with a range of $10-15 \%$ of acute responders or even less $[179,180]$.

Children often present sicker than adults. Dyspnoea, fatigue and failure to thrive are common symptoms. Syncope is more frequent in the child, but overt RV failure is a late event and the child may die suddenly before the appearance of RV failure. A similar diagnostic work-up to that in the adult is suggested. Even if some associations are rare they should be excluded before a definite diagnosis. A thorough family and personal history with pregnancy, delivery and postnatal details is essential. 6-MWT and cardiopulmonary exercise testing can be performed but require expertise and should be adapted to age. Diagnosis requires RHC and vasoreactivity testing which are perfomed as in adults. In children these procedures may require general anaesthesia, which increases the risks.

\section{Therapy}

The response to therapy is difficult to predict, with some patients having a dramatic response and some requiring rapid escalation of therapy. The therapeutic algorithm used for children is similar to the one used in adults even if specific RCTs are lacking. Several expert centres have suggested specific, but indeed very similar, treatment algorithms [179]. Only a few studies have been performed to confirm the exact dose of new therapies to be applied in children.

Therapy should include close follow-up. Rapid treatment of any upper or lower airway infection is essential because of the danger of a rapid deterioration. The use of anticoagulation is controversial as no studies are available in children. The riskbenefit profile is a problem in small children. The use of aspirin instead of coumadin is also controversial. The consensus is to anticoagulate patients with overt right heart failure. 
CCBs are used in responders, but close follow-up is mandatory as patients may fail long-term therapy.

Data are available with bosentan, the pharmakokinetics of which have been assessed in one study [181]. Several uncontrolled studies in children have shown positive results similar to adults, with survival rates of $80-90 \%$ at $1 \mathrm{yr}$ [182]. A new paediatric formulation has been recently approved by the European Medicines Agency. Data about selective endothelin-A receptor antagonists are not available so far.

Sildenafil has shown some efficacy [183], and an RCT is underway to define dose and efficacy.

Indications for epoprostenol are similar to those in adults. The usual starting dose is $2 \mathrm{ng} \cdot \mathrm{kg}^{-1} \cdot \mathrm{min}^{-1}$ with a rapid increase. Optimal doses vary considerably between patients and thus individual titration is required [184, 185]. Administration of i.v. iloprost and trepostinil has been reported as in adults. Oral beraprost is only used in some countries, but lack of proof of efficacy is a problem. S.c. trepostinil may be an option, but local pain is a serious problem in children. Inhaled iloprost is also difficult, but a recent report has shown some efficacy [186].

An increasing number of paediatric patients are on combination therapy even though evidence is still lacking [187]. Atrial septostomy as well as a Pott's shunt [188] are possible in children, with good results. As in adults, cure of PAH is only obtained with lung transplantation, but lack of suitable donors is a major problem.

Recommendations for paediatric $\mathrm{PAH}$ are summarised in table 24

\subsubsection{Pulmonary arterial hypertension associated with congenital cardiac shunts}

$\mathrm{PAH}$ associated with CHD is included in group 1 of the $\mathrm{PH}$ clinical classification (table 4). A specific clinical classification (table 6) and an anatomical-pathophysiological classification (table 7) are useful to better define each individual patient with PAH associated with CHD $[1,16]$.

Epidemiological data remain scarce as no studies were designed to assess the prevalence of PAH in adult CHD, although 5-10\% was suggested in a recent study [189]. The persistent exposure of the pulmonary vasculature to increased blood flow due to systemic-to-pulmonary shunts as well as increased pressure may result in a typical pulmonary obstructive arteriopathy (identical to other PAH forms) that leads to the increase of PVR.

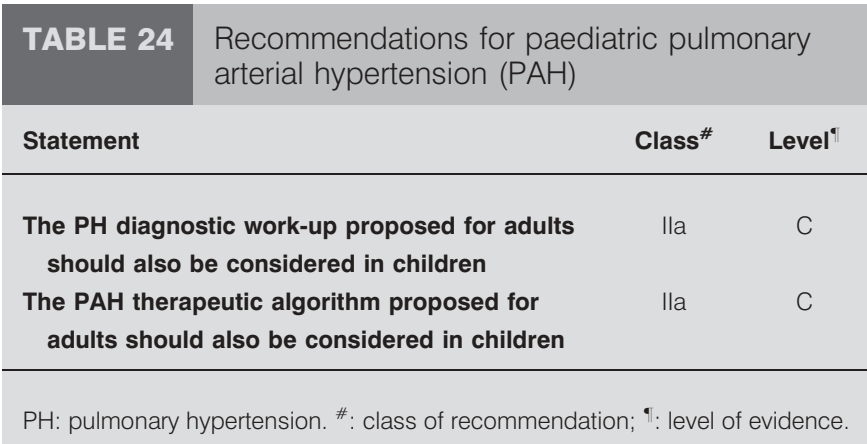

If PVR approaches or exceeds systemic vascular resistance, the shunt is reversed (Eisenmenger's syndrome) [190].

\section{Diagnosis}

The signs and symptoms of Eisenmenger's syndrome result from $\mathrm{PH}$, low arterial $\mathrm{O}_{2}$ saturation and secondary erythrocytosis. They include dyspnoea, fatigue and syncope. In patients with PAH associated with CHD without reversal of the shunt, the degree of cyanosis and erythrocytosis may be mild to moderate. Eisenmenger's syndrome patients also suffer from haemoptysis, cerebrovascular accidents, brain abscesses, coagulation abnormalities and sudden death. Subjects with Eisenmenger's syndrome have reduced life expectancy, although many survive into their third or fourth decade, with some even surviving into their seventh decade [191]. In patients listed for lung or heart-lung transplantation when no medical treatment was available, Eisenmenger's syndrome had better survival compared with IPAH, with a 3-yr survival rate of $77 \%$ compared with $35 \%$ for untreated IPAH [192]. Of all patients with $\mathrm{CHD}$, those with Eisenmenger's syndrome are the most severely compromised in terms of exercise intolerance [193].

Improved survival may result possibly from preservation of RV function as the RV does not undergo remodelling at birth and remains hypertrophied [194]. The RV is also relieved by the right-to-left shunt, sustaining systemic $\mathrm{CO}$, at the expense of hypoxaemia and cyanosis.

Patients with CHD (in particular those without shunts) may also develop PH due to left heart disease (group 2, table 4) or to concomitant lung diseases (group 3, table 4). In these cases a comprehensive diagnostic work-up, as reported in section 7.1.12, is recommended.

Therapy

The treatment strategy for patients with PAH associated with CHD and in particular for subjects with Eisenmenger's syndrome is mainly based on the clinical experience of experts rather than formally evidence based [190]. A specific treatment algorithm similar to that in figure 2 has been recently proposed [16].

Eisenmenger's syndrome patients should be managed in specialised centres. Patient education, behavioural modifications and awareness of potential medical risk factors are important aspects of management.

Patients with Eisenmenger's syndrome may present with clinical deterioration in different circumstances, including noncardiac surgery with general anaesthesia, dehydration, lung infections and high altitude. It is recommended to avoid strenuous exercise but mild activities seem to be beneficial. Pregnancy is associated with high risk to both mother and fetus. Pregnancy should be discouraged, and contraception is indicated.

Long-term home $\mathrm{O}_{2}$ therapy may improve symptoms, but has not been shown to modify survival, at least when given only at night [111]. The use of supplemental $\mathrm{O}_{2}$ therapy is recommended in cases in which it produces a consistent increase in arterial oxygen saturation and reduces symptoms.

The use of oral anticoagulant treatment in Eisenmenger's syndrome is controversial: a high incidence of PA thrombosis and stroke is reported but there is also an increased risk of 
haemorrhage and haemoptysis [195]. No data exist on this issue and definite recommendations cannot therefore be made. Oral anticoagulant treatment may be considered in patients with PA thrombosis, signs of heart failure and absent or only mild haemoptysis [195].

Secondary erythrocytosis is beneficial for adequate $\mathrm{O}_{2}$ transport and delivery, and routine phlebotomy should be avoided. If symptoms of hyperviscosity are present, phlebotomy with isovolumic replacement should be performed, usually when the haematocrit is $>65 \%$. Iron deficiency should be corrected. No clear data support the use of CCBs in patients with Eisenmenger's syndrome, and the empirical use of CCBs is dangerous and should be avoided.

One RCT is available with specific drug therapy: bosentan has been shown to improve 6-MWT and decrease PVR after 16 weeks of treatment in WHO-FC III patients [142]. The longterm follow-up (40 weeks) showed sustained improvement [196]. Bosentan is currently approved in Europe for WHO-FC III Eisenmenger's syndrome patients. No studies are available with the use of other ERAs in this setting.

Anecdotal experiences with the phosphodiesterase type-5 inhibitors sildenafil [197] and tadalafil [198] show favourable functional and haemodynamic results in patients with $\mathrm{PAH}$ associated with CHD and Eisenmenger's syndrome.

The use of i.v. epoprostenol has been reported in Eisenmenger's syndrome patients, with favourable effects on haemodynamics and exercise capacity, although central lines expose the patients to the risk of paradoxical embolism and sepsis [120]. No data are available with the use of other prostanoids.

There are no published data on combination therapy, but the rationale is the same as in IPAH. Since the introduction of targeted therapies in Eisenmenger's syndrome, there is growing interest in pre-Eisenmenger's syndrome patients considered inoperable on the basis of haemodynamic changes (PVR too high) in order to remodel the pulmonary vascular bed and perform interventional or surgical correction. No recommendation can be given in this setting as only anecdotal cases have been reported.

Heart-lung or lung transplantation with heart surgery is an option in special cases not responsive to medical treatment, but is limited by organ availability. Short- and long-term survival rates following heart-lung transplantation are similar to other forms of PAH. The prolonged estimated survival of patients with Eisenmenger's syndrome makes the decision if and when patients should be listed difficult [16].

Recommendations for pulmonary arterial hypertension associated with congenital cardiac shunts are summarised in table 25 .

\subsubsection{Pulmonary arterial hypertension associated with connective tissue disease}

PAH is a well-known complication of CTDs such as systemic sclerosis,114 systemic lupus erythematosus, mixed CTD and, to a lesser extent, rheumatoid arthritis, dermatomyositis and Sjögren's syndrome. PAH associated with CTD is the second most prevalent type of PAH after IPAH in registries [3, 4].

\begin{tabular}{|c|c|c|c|}
\hline TABLE 25 & \multicolumn{3}{|c|}{$\begin{array}{l}\text { Recommendations for pulmonary arterial } \\
\text { hypertension (PAH) associated with congenital } \\
\text { cardiac shunts }\end{array}$} \\
\hline Statement & & Class $^{\#}$ & Level" \\
\hline \multicolumn{2}{|c|}{$\begin{array}{l}\text { The ERA bosentan is indicated in WHO-FC } \\
\text { III patients with Eisenmenger's syndrome }\end{array}$} & I & B \\
\hline \multicolumn{2}{|c|}{$\begin{array}{l}\text { Other ERAs, phosphodiesterase type- } 5 \\
\text { inhibitors, and prostanoids should be } \\
\text { considered in patients with Eisenmenger's } \\
\text { syndrome }\end{array}$} & Ila & C \\
\hline \multicolumn{2}{|c|}{$\begin{array}{l}\text { In the absence of significant haemoptysis, } \\
\text { oral anticoagulant treatment should be } \\
\text { considered in patients with PA thrombosis } \\
\text { or signs of heart failure }\end{array}$} & lla & C \\
\hline \multicolumn{2}{|c|}{$\begin{array}{l}\text { The use of supplemental } \mathrm{O}_{2} \text { therapy should } \\
\text { be considered in cases in which it produces a } \\
\text { consistent increase in arterial oxygen } \\
\text { saturation and reduces symptoms }\end{array}$} & Ila & C \\
\hline \multicolumn{2}{|c|}{$\begin{array}{l}\text { If symptoms of hyperviscosity are present, } \\
\text { phlebotomy with isovolumic replacement } \\
\text { should be considered usually when the } \\
\text { haematocrit is }>65 \%\end{array}$} & lla & C \\
\hline \multicolumn{2}{|c|}{$\begin{array}{l}\text { Combination therapy may be considered in } \\
\text { patients with Eisenmenger's syndrome }\end{array}$} & $\mathrm{llb}$ & C \\
\hline \multicolumn{2}{|c|}{$\begin{array}{l}\text { The use of CCBs is not recommended in } \\
\text { patients with Eisenmenger's syndrome }\end{array}$} & III & C \\
\hline
\end{tabular}

Systemic sclerosis, particularly in its limited variant (CREST syndrome), represents the main CTD associated with PAH. The prevalence of haemodynamically proven $\mathrm{PAH}$ in large cohorts of patients with systemic sclerosis is between 7 and $12 \%[2,114]$. In these patients, $\mathrm{PAH}$ may occur in association with interstitial fibrosis or as a result of an isolated pulmonary arteriopathy. In addition, pulmonary venous hypertension from left heart disease may be present. It is imperative to determine which mechanism is operative since this dictates treatment.

Histopathological changes in PAH associated with CTD are generally indistinguishable from those of classical IPAH, although there is more frequent involvement of the pulmonary veins [199]. The pathophysiological mechanisms leading to $\mathrm{PAH}$ in patients with CTD remain unknown. The presence of antinuclear antibody, rheumatoid factor, immunoglobulin $G$ and complement fraction deposits in the pulmonary vessels wall suggest a role for an immunological mechanism.

\section{Diagnosis}

Compared with IPAH, patients with CTD and PAH are mainly females (female/male ratio 4:1), are older (mean age at diagnosis, 66 yrs), may present concomitant disorders (pulmonary fibrosis, left heart disease) and have shorter survival [114]. The unadjusted risk of death for systemic sclerosis-associated PAH compared with IPAH is 2.9 [200] and the predictors of outcome are the same 
as for IPAH (RAP, PAP and CI). Symptoms and clinical presentation are very similar to those of IPAH and occasional patients thought to have IPAH can be identified as having an associated CTD by immunological screening tests. High-resolution CT is helpful for evaluating the presence of associated interstitial lung disease. An isolated reduction of diffusion capacity of carbon monoxide is a frequent abnormality in systemic sclerosis associated with PAH.

Echocardiographic screening for the detection of $\mathrm{PH}$ has been recommended annually in asymptomatic patients with the scleroderma spectrum of diseases but only in the presence of symptoms in other CTDs. The cost-effectiveness of this strategy has not been clarified as compared with symptom-based screening (see also section 7.1.5). As in other forms of PAH, RHC is recommended in all cases of suspected PAH associated with CTD to confirm the diagnosis, determine severity and rule out left-sided heart disease. RHC is mandatory if targeted treatments are considered. The proportion of responders in the acute vasodilator test is lower than in IPAH [66].

\section{Therapy}

Treatment of patients with PAH associated with CTD appears more complex than that of patients with IPAH. Immunosuppressive therapy combining glucocorticosteroids and cyclophosphamide may result in clinical improvement in patients with $\mathrm{PAH}$ associated with systemic lupus erythematosus or mixed CTD [201].

Long-term favourable response to $\mathrm{CCB}$ treatment in vasoreactive patients is seen less often than in IPAH. The risk-tobenefit ratio of oral anticoagulation is not well understood.

Treatment of patients with CTD and PAH should follow the same treatment algorithm as in IPAH (fig. 2). This recommendation is based on the fact that patients with CTD have been included in most of the major RCTs for regulatory approval of PAH therapy, including those with combination therapy.

Subgroup analyses of patients with scleroderma enrolled in the RCTs performed with bosentan [139], sitaxentan [202], sildenafil [155] and s.c. treprostinil [203] have shown favourable effects. In some of these trials the magnitude of the response in the PAH subgroup associated with CTD was lower than in IPAH.

Continuous i.v. epoprostenol therapy has been shown to improve exercise capacity, symptoms and haemodynamics in a 3-month RCT of patients with the scleroderma spectrum of the diseases [119]. Retrospective analysis shows, however, that the effect of i.v. epoprostenol on survival of IPAH patients seems to be better than that of scleroderma patients. The presence of a CTD is not a contraindication for lung transplantation per se if medical treatments fail.

Recommendations for PAH associated with CTD are summarised in table 26.

\subsubsection{Pulmonary arterial hypertension associated with portal hypertension}

PAH is a well-recognised complication of chronic liver diseases [204, 205]. Portal hypertension rather than the hepatic disorder itself seems to be the main determining risk factor for developing PAH [204].

TABLE $26 \begin{aligned} & \text { Recommendations for pulmonary arterial } \\ & \text { hypertension (PAH) associated with connective } \\ & \text { tissue disease (CTD) }\end{aligned}$
$\begin{aligned} & \text { Statement } \\ & \text { Class }{ }^{\#}\end{aligned}$
In patients with PAH associated with CTD
the same treatment algorithm as in patients
with IPAH is recommended
Echocardiographic screening for the
detection of PH is recommended in
symptomatic patients with scleroderma
spectrum of diseases
Echocardiographic screening for the
detection of PH is recommended in
symptomatic patients with all other CTDs
RHC is indicated in all cases of suspected
PAH associated with CTD, in particular if
specific drug therapy is considered
Oral anticoagulation should be considered
on an individual basis
Echocardiographic screening for the
detection of PH may be considered in
asymptomatic patients with the scleroderma
spectrum of disease

IPAH: idiopathic $\mathrm{PAH}$; $\mathrm{PH}$ : pulmonary hypertension; $\mathrm{RHC}$ : right heart catheterisation. ${ }^{*}$ : class of recommendation; ": level of evidence.

The condition is not uncommon since PAH associated with portal hypertension (also named as portopulmonary hypertension) represents $\sim 10 \%$ of the PAH population [3]. It is believed that $1-2 \%$ of patients with liver disease and portal hypertension develop PAH, but the prevalence of $\mathrm{PAH}$ may reach $5 \%$ among patients with advanced liver disease evaluated for liver transplantation [206]. The pathogenesis is unclear and may be related to toxic substances derived from the gastrointestinal tract, which are not eliminated by the liver due to portosystemic shunts, thus causing damage to the lung endothelium. Another possibility is that the high $\mathrm{CO}$ state is inducing PAH.

\section{Diagnosis}

The clinical picture of patients with portopulmonary hypertension may be indistinguishable from that of those with IPAH or may include a combination of symptoms and signs of the underlying liver disease [204].

Echocardiographic screening for the detection of $\mathrm{PH}$ in patients with liver diseases is appropriate in symptomatic patients and/or in candidates for liver transplantation. An RHC should be performed in all cases with increased systolic PAP in order to clarify the underlying haemodynamic changes and define prognostic and therapeutic implications. Patients with portopulmonary hypertension have a significantly higher $\mathrm{CO}$ and significantly lower systemic vascular resistance and PVR, compared with patients with IPAH. In a retrospective study [204], patients with portopulmonary hypertension had a better rate of survival than patients with IPAH, although this is debated. 


\section{Therapy}

Portopulmonary hypertension is part of the PAH spectrum of disease and in general these patients should be treated similarly to those with other forms of $\mathrm{PAH}$, while taking into consideration the presence of liver disease and its consequences for their management. The treatment algorithm (fig. 2) can also be applied in this setting with adaptations.

Anticoagulant therapy should be avoided in patients at increased risk of bleeding. $\beta$-adrenoceptor blockers, often used in patients with portal hypertension to reduce the risk of variceal bleeding, worsen haemodynamics and exercise capacity in portopulmonary PAH patients [207].

Patients with portopulmonary hypertension have been excluded from almost all RCTs in PAH. Case series suggest that epoprostenol, bosentan and sildenafil may exert beneficial haemodynamic and clinical effects in selected patients [208210]. In a retrospective study treatment with bosentan appeared to be better than inhaled iloprost [211]. Careful monitoring should be performed if ERA treatment is initiated because of the hepatotoxicity of these compounds.

PAH can substantially increase the risk associated with liver transplantation and usually $\mathrm{PAH}$ is a contraindication if $\bar{P}_{\mathrm{pa}}$ is $>35 \mathrm{mmHg}$ and/or PVR is $\geqslant 250$ dynes.s.cm ${ }^{-5}[206,212]$. It has been suggested that PAH-specific drug therapy should be used to improve haemodynamics prior to liver transplantation, but the effects on the outcome of liver transplantation have not been evaluated sufficiently.

Selected patients with end-stage liver disease and severe $\mathrm{PH}$ may be considered for combined liver-lung or liver-heartlung transplantation. The largest series of combined liver-lung transplantation so far has reported a $3-y r$ survival of $62 \%$. This treatment option is offered by only a few centres worldwide [213].

Recommendations for pulmonary arterial hypertension associated with portal hypertension are summarised in table 27.

\subsubsection{Pulmonary arterial hypertension associated with HIV infection}

The use of highly active antiretroviral therapy and aggressive management of opportunistic infections has contributed to increased life expectancy in HIV-infected patients. Consequently, the spectrum of complications has shifted towards other long-term conditions, including cardiovascular diseases such as dilated cardiomyopathy, pericardial disorders, noninfectious thrombotic endocarditis, accelerated atherosclerosis and $\mathrm{PAH}$. The initial prevalence of $\mathrm{PAH}$ was found to be $0.1-0.5 \%$ with an estimated incidence of $0.1 \%$ per year [214]. It was suggested that the use of highly active antiretroviral therapy could decrease the rate of PAH associated with HIV infection, but a population study recently conducted in France contradicts this hypothesis because the calculated minimal prevalence of HIV-related PAH was $0.46 \%$, very similar to before the highly active antiretroviral therapy era [49].

The pathogenesis of HIV-related PAH remains unclear. The absence of viral particles in the complex plexiform lesions found from these patients suggests that an indirect action of viral infection on inflammation and growth factors may act as a trigger on a predisposed patient [49].

\begin{tabular}{|c|c|c|c|}
\hline TABLE 27 & \multicolumn{3}{|c|}{$\begin{array}{l}\text { Recommendations for pulmonary arterial } \\
\text { hypertension }(\mathrm{PAH}) \text { associated with portal } \\
\text { hypertension }\end{array}$} \\
\hline Statement & & Class ${ }^{\#}$ & Level $^{\circ}$ \\
\hline \multicolumn{2}{|c|}{$\begin{array}{l}\text { Echocardiographic screening for the detection } \\
\text { of } \mathrm{PH} \text { is recommended in symptomatic patients } \\
\text { with liver diseases and/or in candidates } \\
\text { for liver transplantation }\end{array}$} & I & B \\
\hline \multicolumn{2}{|c|}{$\begin{array}{l}\text { In patients with PAH associated with portal } \\
\text { hypertension the same treatment algorithm as } \\
\text { in patients with IPAH should be considered, } \\
\text { taking into consideration comorbidities }\end{array}$} & Ila & C \\
\hline \multicolumn{2}{|c|}{$\begin{array}{l}\text { Anticoagulation is not recommended in } \\
\text { patients with increased risk of bleeding }\end{array}$} & III & C \\
\hline \multicolumn{2}{|c|}{$\begin{array}{l}\text { Significant } \mathrm{PAH} \text { is a contraindication to liver } \\
\text { transplantation if } \bar{P} \text { pa is } \geqslant 35 \mathrm{mmHg} \text { and/or } \\
\mathrm{PVR} \text { is } \geqslant 250 \text { dynes } \cdot \mathrm{s}^{-1} \cdot \mathrm{cm}^{-5}\end{array}$} & III & C \\
\hline \multicolumn{4}{|c|}{$\begin{array}{l}\text { PH: pulmonary hypertension; IPAH: idiopathic PAH; } \bar{P} \text { pa: mean pulmonary } \\
\text { arterial pressure; PVR: pulmonary vascular resistance. }{ }^{\#} \text { : class of recommendation; } \\
\text { : level of evidence. }\end{array}$} \\
\hline
\end{tabular}

\section{Diagnosis}

HIV-related PAH shares a similar clinical presentation with IPAH. At the time of diagnosis, $71-81 \%$ of patients are in an advanced WHO-FC $[49,122]$. Patients may present with other risk factors for $\mathrm{PAH}$ such as liver disease (chronic hepatitis B or C), exposure to drugs and toxins, or pulmonary embolism due to i.v. drug abuse. Patients with HIV-related PAH are more likely to be male and i.v. drug abusers [49]. More than $80 \%$ are well controlled on highly active antiretroviral therapy, and CD4 count does not appear to be a risk factor for PAH [49, 122].

Asymptomatic HIV-infected patients should not be screened for PAH. Echocardiography must be performed in patients with unexplained dyspnoea to detect HIV-related cardiovascular complications such as myocarditis, cardiomyopathy, or PAH. An RHC confirmation is mandatory to establish the diagnosis of HIV-related PAH and the absence of left heart disease.

$\mathrm{PAH}$ is an independent risk factor for death in HIV-infected patients, with a 3 -yr survival rate as low as $21 \%$ in the most advanced cases (WHO-FC III/IV), compared with $84 \%$ in mildly symptomatic patients [122]. In a single-centre study, a better outcome was associated with CD4 count .212 cells $\cdot \mathrm{mL}^{-1}$, highly active antiretroviral therapy and epoprostenol therapy [122].

\section{Therapy}

Treatment of HIV-related PAH is less well established in comparison with other forms of PAH. Only three RCTs, one with the orally active prostanoid beraprost [134] and two with the selective endothelin receptors antagonist ambrisentan [146], allowed inclusion of patients with HIV-related PAH who represented, $5 \%$ of the total population.

Anticoagulation is not routinely recommended because of an increased risk of bleeding, anticipated compliance issues and drug interactions. Patients with HIV-related PAH appear to be 
nonresponders to vasoreactivity tests [66] and thus should not receive $\mathrm{CCBs}$.

Several uncontrolled studies suggest that i.v. epoprostenol [122], s.c. treprostinil [215] and inhaled iloprost [216] may improve exercise tolerance, haemodynamics and symptoms in HIV-related PAH.

Two open-label studies reported the effects of bosentan in patients with HIV-related PAH [217, 218], showing an improvement in all efficacy measures, including 6-MWT, WHO-FC, Doppler-derived haemodynamic variables and invasive haemodynamics. Hepatic tolerability was similar to previously reported observations in other forms of PAH. The interpretation of these studies is limited by the small sample size and the open-label nature.

In the case of use of sildenafil, the dose should be adjusted if ritonavir and saquinovir are co-administered due to drugdrug interactions (table 20).

HIV infection is generally considered an exclusion criterion for lung transplantation even if in some centres a specific programme has been implemented.

Recommendations for pulmonary arterial hypertension associated with HIV infection are summarised in table 28.

\section{PULMONARY VENO-OCCLUSIVE DISEASE AND PULMONARY CAPILLARY HAEMANGIOMATOSIS (GROUP 1')}

Both PVOD and pulmonary capillary haemangiomatosis are uncommon conditions, but are increasingly recognised as causes of PAH [219]. They have been classified in a specific subgroup of the clinical classification (table 4, group $1^{\prime}$ ) for the pathological, clinical and therapeutic differences with the other forms of PAH included in group 1. Fewer than 200 cases of PVOD and pulmonary capillary haemangiomatosis have been reported in the literature. PVOD and pulmonary capillary haemangiomatosis are similar in some respects particularly in relation to the changes in the pulmonary parenchyma which have been described above [20]. Familial occurrence of PVOD has been reported, and a bone morphogenetic protein receptor-2 mutation has been found in a patient with this disease [220]. These findings suggest that PAH and PVOD may represent different phenotypic manifestations of a spectrum of a single disease. In contrast to IPAH, there is a male predominance in PVOD [221] and the prognosis appears to be worse.

\subsection{Pulmonary veno-occlusive disease}

\subsubsection{Diagnosis}

The diagnosis of PVOD can be established with a high probability by the combination of clinical suspicion, physical examination, bronchoscopy and radiological findings [221]. This noninvasive approach may avoid lung biopsy (the gold standard to confirm a diagnosis of PVOD) in most of the cases. Most patients complain of dyspnoea on exertion and fatigue, a clinical presentation that is indistinguishable from IPAH. Physical examination may reveal digital clubbing and bi-basal crackles on lung auscultation, these being unusual in other forms of PAH. Case series suggest that patients with PVOD are more severely hypoxaemic and have a much lower diffusion

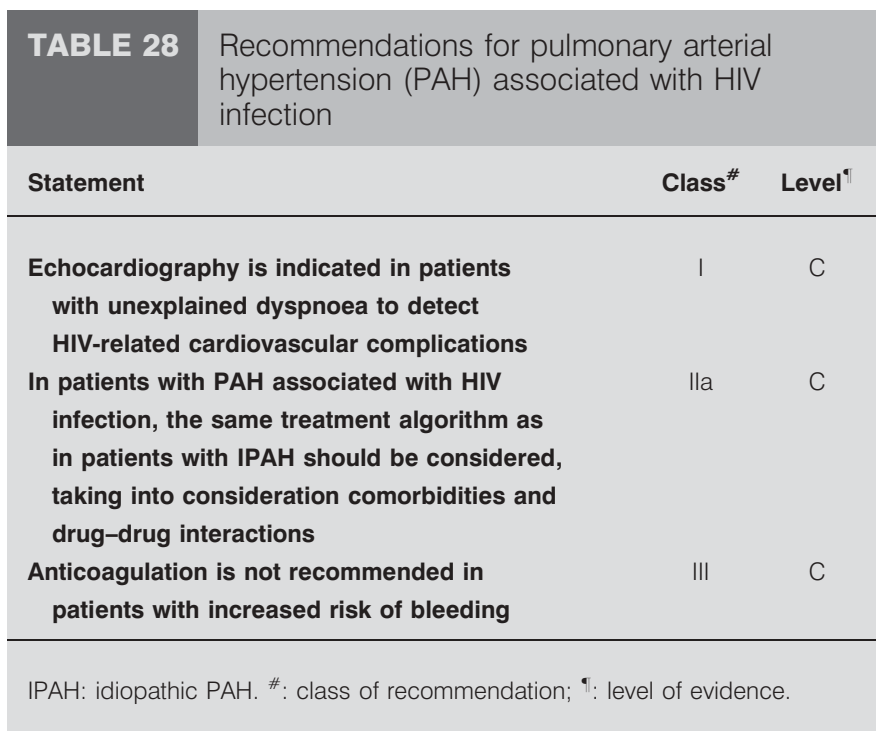

capacity of carbon monoxide than in other forms of PAH [54, 221, 222]. This can be explained by the presence of chronic interstitial pulmonary oedema typical of PVOD and/or a low $\mathrm{CO}$ state and/or the presence of a patent foramen ovale.

Chest radiograph may reveal Kerley B lines and peripheral interstitial infiltrate in addition to other typical signs of $\mathrm{PH}$.

High-resolution CT scanning is the investigation of choice. Typical findings suggestive of PVOD are the presence of subpleural thickened septal lines, centrilobular ground-glass opacities (contrasting with a panlobular distribution found in IPAH) and mediastinal lymphadenopathy [54]. The association of these three findings was found to be $100 \%$ specific for PVOD in cases of PAH, with a $66 \%$ sensitivity [54]. In addition, their presence appears to correlate closely with the risk of pulmonary oedema with epoprostenol therapy [223, 224].

Because PVOD may be associated with occult alveolar haemorrhage, bronchoscopy with bronchoalveolar lavage may be a useful tool in the diagnostic strategy. In a retrospective study, the results of bronchoalveolar lavage performed in 19 patients with suspicion of IPAH were analysed [222]. Compared with IPAH, the eight cases of PVOD presented with a significantly elevated cell count, a higher percentage of haemosiderin-laden macrophages and a markedly elevated Golde score. The percentage of macrophages, lymphocytes and neutrophils was similar.

Haemodynamic presentation of PVOD is similar to IPAH. Importantly, $P$ pcw is almost invariably normal because the pathological changes occur in small venulae and do not affect the larger pulmonary veins. Vasoreactivity testing may be complicated by acute pulmonary oedema.

\subsubsection{Therapy}

There is no established medical therapy for PVOD. Most importantly, vasodilators and especially prostanoids must be used with great caution because of the high risk of pulmonary oedema [223, 224]. However, there are reports of sustained clinical improvement in individual patients treated with these medications. There are no data regarding the use of newer 
medical therapies such as ERAs or phosphodiesterase type-5 inhibitors in the treatment of PVOD and pulmonary capillary haemangiomatosis. Therefore, therapy for PVOD should be undertaken only at centres with extensive experience in the management of $\mathrm{PH}$, and patients should be fully informed about the risks. Atrial septostomy may be considered but is usually limited by hypoxaemia. The only curative therapy for PVOD and pulmonary capillary haemangiomatosis is lung transplantation, and similarly to IPAH there are no reports of recurrence of disease following transplantation. Patients with PVOD should be referred to a transplant centre for evaluation as soon as the diagnosis is established.

Recommendations for PVOD are summarised in table 29.

\subsection{Pulmonary capillary haemangiomatosis}

This very rare condition may be difficult to differentiate from PVOD, and the diagnostic and therapeutic aspects are very similar. Often, only pathological examination is able to distinguish the two conditions [20].

\section{PULMONARY HYPERTENSION DUE TO LEFT HEART DISEASE (GROUP 2)}

Most of the advances in the treatment of $\mathrm{PH}$ have been made in $\mathrm{PAH}$. At the same time, virtually no progress has been made for the much more common forms of $\mathrm{PH}$ as encountered in patients with left heart diseases, lung diseases, or CTEPH. Despite the lack of data, drugs with proven efficacy in $\mathrm{PAH}$ are increasingly being used for other forms of PH. This may be clinically justified in some carefully selected patients but may turn out to be useless or even harmful in many others. This development is of concern, and the use of PAH drugs for other forms of $\mathrm{PH}$ outside expert centres is discouraged.

The pathology, pathophysiology and epidemiology of PH due to left heart disease have been discussed previously.

$\mathrm{PH}$ carries a poor prognosis for patients with chronic heart failure [225]. In one study the mortality rate after 28 months of follow-up was $57 \%$ in patients with moderate $\mathrm{PH}$ compared with $17 \%$ in patients without $\mathrm{PH}$. In addition, patients who have a PVR exceeding 6-8 Wood units (480-640 dynes.s.cm ${ }^{-5}$ ) have an increased risk of post-operative RV failure following heart transplantation.

\begin{tabular}{|c|c|c|c|}
\hline TABLE 29 & \multicolumn{3}{|c|}{$\begin{array}{l}\text { Recommendations for pulmonary } \\
\text { veno-occlusive disease }\end{array}$} \\
\hline Statement & & Class $^{\#}$ & Level" \\
\hline \multicolumn{2}{|c|}{$\begin{array}{l}\text { Referral of patients with PVOD to a } \\
\text { transplant centre for evaluation is indicated } \\
\text { as soon as the diagnosis is established }\end{array}$} & । & C \\
\hline \multicolumn{2}{|c|}{$\begin{array}{l}\text { Patients with PVOD should be managed only } \\
\text { in centres with extensive experience in PAH } \\
\text { due to the risk of lung oedema after the } \\
\text { initiation of PAH-specific drug therapy }\end{array}$} & Ila & C \\
\hline
\end{tabular}

\subsection{Diagnosis}

The diagnostic approach to $\mathrm{PH}$ due to left heart disease is similar to that for PAH, Doppler echocardiography being the best tool for screening purposes. LV diastolic dysfunction should be suspected in the presence of a dilated left atrium, atrial fibrillation, characteristic changes in mitral flow profile, pulmonary venous flow profile and mitral annulus tissue Doppler signals and LV hypertrophy $[64,226]$. Data on tissue Doppler assessment show that the ratio $E / E^{\prime}$ of early mitral valve flow velocity $(E)$ divided by the early diastolic $\left(E^{\prime}\right)$ lengthening velocities correlates closely with LV filling pressures: when the ratio $E / E^{\prime}$ exceeds $15, \mathrm{LV}$ filling pressures are elevated and when the ratio is lower than $8, \mathrm{LV}$ filling pressures are low; if $15>E / E^{\prime}>8$, additional noninvasive investigations are required [64]. Characteristic clinical and echocardiographic features of $\mathrm{PH}$ associated with LV diastolic dysfunction are listed in table 30 [227].

Although increased left-sided filling pressures can be estimated by Doppler echocardiography [64, 228] invasive measurements of $P$ pcw or LV end-diastolic pressure may be necessary to confirm the diagnosis of $\mathrm{PH}$ due to left heart disease (see also section 7.1.11) [64]. P pcw and LV end-diastolic pressure can be 'pseudo-normal', especially when patients have been treated with diuretics. In this setting, exercise haemodynamics volume challenge has been proposed to identify LV dysfunction, but these diagnostic tools require further standardisation. An elevated transpulmonary gradient $\left(\bar{P}_{\text {pa }}-\bar{P}_{\mathrm{pcw}}\right)>12 \mathrm{mmHg}$ is suggestive of intrinsic changes in the pulmonary circulation over-riding the passive increase in $P$ pcw.

TABLE 30 Factors favouring diagnosis of left ventricular diastolic dysfunction in the presence of pulmonary hypertension as assessed by Doppler echocardiography

Clinical features
Age $>65$ yrs
Elevated systolic blood pressure
Elevated pulse pressure
Obesity, metabolic syndrome
Hypertension
Coronary artery disease
Diabetes mellitus
Atrial fibrillation
Echocardiography
Left atrial enlargement
Concentric remodelling of the LV (relative wall thickness $>0.45$ )
LV hypertrophy
Presence of echocardiographic indicators of elevated LV
filling pressure [64, 226]
Interim evaluation (after echocardiography)
Symptomatic response to diuretics
Exaggerated increase in systolic blood pressure with exercise
Re-evaluation of chest radiograph consistent with heart failure [226]

LV: left ventricle. Modified from HOEPER et al.[227], with permission from the publisher. 
In some patients, it may be difficult to distinguish PAH from $\mathrm{PH}$ associated with LV dysfunction especially in patients with borderline values of $P_{\mathrm{pcw}}(15-18 \mathrm{mmHg})$.

The usefulness of BNP plasma levels for the diagnosis of left heart disease in the presence of $\mathrm{PH}$ is not well established because BNP elevations can be observed in both pathophysiological conditions. The value of performing a haemodynamic evaluation with exercise or fluid challenge is also not well established.

The role, significance and setting of pharmacological testing remain unclear in $\mathrm{PH}$ due to left heart disease, although it is recommended in heart transplant candidates to identify patients at higher risk of acute post-operative RV failure [229]. In heart transplant candidates, a persistent increase in PVR $>2.5$ Wood units and/or TPG $>15 \mathrm{mmHg}$ are associated with up to a threefold increase in risk of RV failure and early post-transplant mortality [230]. When the PVR can be lowered pharmacologically (e.g. with i.v. nitroprusside) this risk may be reduced [231]. The absence of consensus on a standardised protocol leads to the use of various agents for testing the responsiveness of the pulmonary circulation, including inotropic agents, vasodilators, prostanoids, NO and phosphodiesterase type- 5 inhibitors. Acute post-operative RV failure may also be observed in patients with normal baseline pulmonary haemodynamics, suggesting that other mechanisms may be involved.

\subsection{Therapy}

Currently, there is no specific therapy for $\mathrm{PH}$ due to left heart disease. A number of drugs (including diuretics, nitrates, hydralazine, ACE inhibitors, (3-adrenoceptor blockers, nesiritide and inotropic agents) or interventions (LV assist device implantation, valvular surgery, resynchronisation therapy and heart transplantation) may lower PAP more or less rapidly through a drop in left-sided filling pressures [12]. Therefore, management of $\mathrm{PH}$ due to left heart disease should be aimed at the optimal treatment of the underlying disease. No heart failure drugs are contraindicated because of $\mathrm{PH}$ [226]. Few studies have examined the role of drugs currently recommended in PAH. RCTs evaluating the effects of chronic use of epoprostenol [232] and bosentan [233, 234] in advanced heart failure have been terminated early due to an increased rate of events in the investigational drug-treated group compared with conventional therapy. A small sized study recently suggested that sildenafil may improve exercise capacity and quality of life in patients with $\mathrm{PH}$ due to left heart disease [235]. The history of medical therapy for heart failure is full of examples where drugs had positive effects on surrogate endpoints but eventually turned out to be detrimental, such as the phosphodiesterase type- 3 inhibitors. Thus, the use of PAHspecific drugs is not recommended until robust data from long-term studies are available, in particular in 'out of proportion' $\mathrm{PH}$ associated with left heart disease (table 3). A sustained reduction of $\mathrm{PH}$ is expected in weeks to months in most patients successfully operated for mitral valve disease even if $\mathrm{PH}$ represents a risk factor for surgery [33, 236].

Recommendations for $\mathrm{PH}$ due to left heart disease are summarised in table 31 .

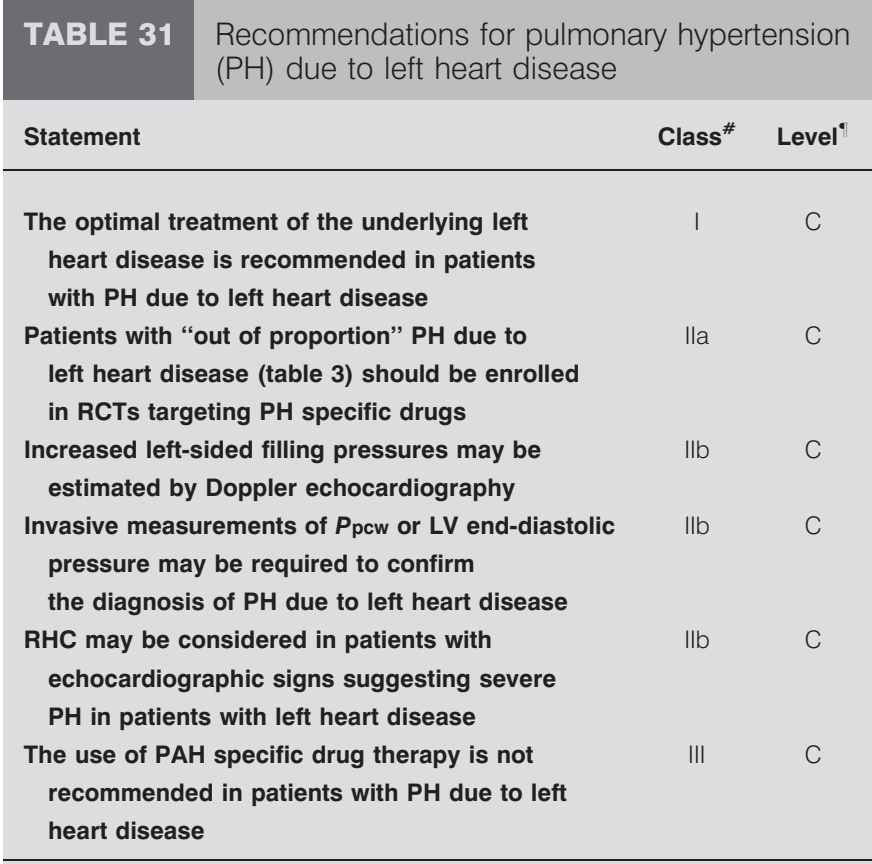

RCT: randomised controlled trial; Ppcw: pulmonary capillary wedge pressure LV: left ventricular; RHC: right heart catheterisation; PAH: pulmonary arterial hypertension. " : class of recommendation; ": level of evidence.

\section{PULMONARY HYPERTENSION DUE TO LUNG DISEASES AND/OR HYPOXIA (GROUP 3)}

The pathology, pathophysiology and epidemiology of these conditions have been discussed previously. In COPD, the presence of $\mathrm{PH}$ is associated with shorter survival [237] and frequent episodes of exacerbation [238]. PH is a poor prognostic factor in interstitial lung diseases and PAP is the most important predictor of mortality [37].

\subsection{Diagnosis}

Clinical symptoms and physical signs of $\mathrm{PH}$ may be difficult to identify in patients with respiratory disorders. In addition, in COPD, peripheral oedema may not be a sign of RV failure, because it may result from the effects of hypoxaemia and hypercapnia on the renin-angiotensin-aldosterone system. Furthermore, concomitant left heart disease, which is commonly associated with chronic respiratory diseases, may also contribute to raise PAP.

As in other forms of $\mathrm{PH}$, echocardiography is the best screening tool for the assessment of PH. Nevertheless, its diagnostic value in advanced respiratory diseases is lower than in PAH. Reliable assessment of systolic PAP is only feasible in a limited number of cases; estimation of systolic PAP may be inaccurate. The specificity of systolic PAP in detecting $\mathrm{PH}$ is low, although the negative predictive value is acceptable [239, 240]. Indications for echocardiography for the screening of $\mathrm{PH}$ in COPD and interstitial lung diseases include: 1) exclusion of significant $\mathrm{PH} ; 2$ ) evaluation of concomitant left heart disease; and 3) selection of patients for RHC.

A definite diagnosis of $\mathrm{PH}$ relies on measurements obtained at RHC. The indication for RHC in advanced lung disease are: 
1) proper diagnosis of $\mathrm{PH}$ in candidates for surgical treatments (transplantation, lung volume reduction); 2) suspected "out of proportion" PH potentially amenable to be enrolled in an RCT with specific PAH drug therapy; 3) frequent episodes of RV failure; and 4) inconclusive echocardiographic study in cases with a high level of suspicion.

\subsection{Therapy}

Currently there is no specific therapy for $\mathrm{PH}$ associated with COPD or interstitial lung diseases. Long-term $\mathrm{O}_{2}$ administration has been shown partially to reduce the progression of $\mathrm{PH}$ in COPD. Nevertheless, with this treatment PAP rarely returns to normal values and the structural abnormalities of pulmonary vessels remain unaltered [112]. In interstitial lung diseases, the role of long-term $\mathrm{O}_{2}$ therapy in $\mathrm{PH}$ progression is less clear. Treatment with conventional vasodilators is not recommended because they may impair gas exchange due to the inhibition of hypoxic pulmonary vasoconstriction [241, 242] and their lack of efficacy after long-term use [243, 244]. Published experience with specific PAH drug therapy is scarce and consists of the assessment of acute effects [245, 246] and uncontrolled studies in small series [247-251].

The treatment of choice for patients with COPD or interstitial lung diseases and associated $\mathrm{PH}$ who are hypoxaemic is longterm $\mathrm{O}_{2}$ therapy. Patients with "out of proportion" $\mathrm{PH}$ due to lung diseases (characterised by dyspnoea insufficiently explained by lung mechanical disturbances and $\bar{P}_{\text {pa }} \geqslant 40$ $45 \mathrm{mmHg}$ at rest) should be referred to expert centres and enrolled in clinical trials targeting PAH-specific drug therapy. The use of targeted PAH therapy in patients with COPD or interstitial lung diseases and $\bar{P}_{\text {pa }}<40 \mathrm{mmHg}$ is currently discouraged because there are no systematic data regarding its safety or efficacy.

Recommendations for $\mathrm{PH}$ due to lung diseases are summarised in table 32.

\section{CHRONIC THROMBOEMBOLIC PULMONARY HYPERTENSION (GROUP 4)}

The pathology, pathophysiology and epidemiology of this condition have been discussed above. CTEPH is one of the most prevalent forms of $\mathrm{PH}$. Nevertheless, it is almost impossible to determine the overall prevalence of CTEPH since not all of these patients have a history of acute pulmonary embolism. While acute pulmonary embolism may be clinically silent [252], there is accumulating evidence that CTEPH may also develop in the absence of previous pulmonary embolism [40]. In these cases, the disease is probably initiated by thrombotic or inflammatory lesions in the pulmonary vasculature. Once vessel obliteration is sufficient to cause increases in the PAP, a process of pulmonary vascular remodelling is started which self-perpetuates the progression of $\mathrm{PH}$, even in the absence of further thromboembolic events [253]. Certain conditions are associated with an increased risk of $\mathrm{CTEPH}$, including previous splenectomy, the presence of a ventriculo-atrial shunt for the treatment of hydrocephalus, myeloproliferative disorders and chronic inflammatory bowel diseases. The mechanisms linking these conditions to CTEPH have not been fully explored, but chronic inflammation or chronic bloodstream infection may play a critical role [254].

TABLE $32 \quad \begin{aligned} & \text { Recommendations for pulmonary hypertension } \\ & (\mathrm{PH}) \text { due to lung diseases }\end{aligned}$
Statement
Echocardiography is recommended as a
screening tool for the assessment of PH due to
lung diseases
RHC is recommended for a definite diagnosis
of PH due to lung diseases
The optimal treatment of the underlying lung
disease including long-term $\mathrm{O}_{2}$ therapy in
patients with chronic hypoxaemia is recommended
in patients with PH due to lung diseases
Patients with "out of proportion" PH due to
lung diseases should be enrolled in RCTs
targeting PAH-specific drugs
The use of PAH-specific drug therapy is not
recommended in patients with $\mathrm{PH}$ due to lung
diseases
RHC: right heart catheterisation; RCT: randomised controlled trial; PAH:
pulmonary arterial hypertension. \#: class of recommendation; : level of
evidence.

\subsection{Diagnosis}

Any patient with unexplained $\mathrm{PH}$ should be evaluated for the presence of CTEPH. Suspicion should be high when the patient presents with a history of previous venous thromboembolism. Survivors of acute pulmonary embolism should be followed after the acute episode to detect signs or symptoms of CTEPH. Patients with acute pulmonary embolism showing signs of $\mathrm{PH}$ or RV dysfunction at any time during their hospital stay should receive a follow-up echocardiography after discharge (usually after 3-6 months) to determine whether or not $\mathrm{PH}$ has resolved.

In patients with unexplained $\mathrm{PH}$, a ventilation/perfusion lung scan is recommended to exclude CTEPH. A normal ventilation/perfusion scan rules out CTEPH. Multirow CT angiography is indicated when the ventilation/perfusion lung scan is indeterminate or reveals perfusions defects. Even in the era of modern multi-row CT scanners, there is not yet enough evidence to suggest that a normal CT angiography excludes the presence of operable CTEPH. Once ventilation/perfusion scanning and/or CT angiogram show signs compatible with $\mathrm{CTEPH}$, the patient should be referred to a centre with expertise in the medical and surgical management of these patients. To determine the appropriate therapeutic strategy, invasive tools including RHC and traditional pulmonary angiography are usually required. Coronary angiography is indicated in candidates for PEA and risk factors for coronary artery disease. In order to minimise risks and repeated procedures these investigations should be performed at the expert centre rather than at the referring hospitals [63]. The final diagnosis of CTEPH is based on the presence of precapillary $\mathrm{PH}\left(\bar{P}_{\mathrm{pa}}>25 \mathrm{mmHg}, \quad P\right.$ pcw $<15 \mathrm{mmHg}$, PVR $>2$ Wood units) in patients with multiple chronic/organised occlusive thrombi/emboli in the elastic pulmonary arteries (main, lobar, segmental, subsegmental). 


\subsection{Therapy}

Patients with CTEPH should receive life-long anticoagulation, usually with vitamin $\mathrm{K}$ antagonists adjusted to a target INR between 2.0 and 3.0.

The decision on how to treat patients with CTEPH should be made at an experienced centre based upon interdisciplinary discussion among internists, radiologists and expert surgeons. PEA is the treatment of choice for patients with CTEPH as it is a potentially curative option. As a rule, a patient should not be considered inoperable as long as the case has not been reviewed by an experienced surgeon. Detailed pre-operative patient evaluation and selection, surgical technique and experience and meticulous post-operative management are essential prerequisites for success after this intervention [55]. The selection of patients for surgery depends on the extent and location of the organised thrombi in relation to the degree of $\mathrm{PH}$ and taking into consideration age and comorbidities. Proximal organised thrombi represent the ideal indication, while more distal obstructions may prevent a successful procedure. After an effective intervention, a dramatic drop of PVR can be expected with a near normalisation of pulmonary haemodynamics. A centre can be considered to have sufficient expertise in this field if it performs at least 20 PEA operations per year with a mortality rate $<10 \%$.

Specific PAH drug therapy may play a role in selected CTEPH patients, mainly for three different scenarios: 1) if patients are not considered candidates for surgery; 2) if pre-operative treatment is deemed appropriate to improve haemodynamics; and 3) if patients present with symptomatic residual/recurrent $\mathrm{PH}$ after pulmonary endarterectomy surgery. Several uncontrolled clinical studies suggest that prostanoids, ERAs and phosphodiesterase type- 5 inhibitors may exert haemodynamic and clinical benefits in patients with CTEPH, regardless of whether these patients were considered operable or inoperable [255-260]. The only randomised, placebo-controlled clinical trial that has so far addressed the safety and efficacy of medical treatment was the Bosentan Effects in iNopErable Forms of chronic Thromboembolic pulmonary hypertension (BENEFIT) study, which investigated the effects of bosentan in patients with inoperable CTEPH for a 16-week period [261]. This study revealed a significant drop in PVR in the bosentan group but no change in 6-MWT, functional class, or time to clinical worsening.

Given these limited data, further studies are necessary to obtain reliable long-term data on the effects of medical therapies in patients with CTEPH, and these patients should be treated within clinical trials whenever possible. For the present time, no medical therapy has been approved in Europe or the USA for CTEPH. Bilateral lung transplantation is an option for advanced cases that are not suited for PEA.

Recommendations for $\mathrm{PH}$ due to CTEPH are summarised in table 33.

\section{DEFINITION OF A PULMONARY ARTERIAL HYPERTENSION REFERRAL CENTRE}

The purpose of a referral centre is to undertake assessment and investigation of all causes of $\mathrm{PH}$, routinely manage appropriate patients with PAH-specific drug therapy, work with other

\begin{tabular}{|c|c|c|c|}
\hline TABLE 33 & $\begin{array}{l}\text { Recommendations for chronic th } \\
\text { pulmonary hypertension (CTEP }\end{array}$ & t) & mbolic \\
\hline \multicolumn{2}{|l|}{ Statement } & Class $^{\#}$ & Level" \\
\hline \multicolumn{2}{|c|}{$\begin{array}{l}\text { The diagnosis of CTEPH is based on the presence } \\
\text { of pre-capillary } \mathrm{PH}\left(\bar{P}_{\mathrm{pa}} \geqslant 25 \mathrm{mmHg}, P \mathrm{pcw}\right. \\
\leqslant 15 \mathrm{mmHg}, \mathrm{PVR}>2 \text { Wood units) in patients with } \\
\text { multiple chronic/organised occlusive thrombi/emboli } \\
\text { in the elastic pulmonary arteries (main, } \\
\text { lobar, segmental, subsegmental) }\end{array}$} & । & C \\
\hline \multicolumn{2}{|c|}{$\begin{array}{l}\text { In patients with CTEPH lifelong anticoagulation } \\
\text { is indicated }\end{array}$} & । & $\mathrm{C}$ \\
\hline \multicolumn{2}{|c|}{$\begin{array}{l}\text { Surgical pulmonary endarterectomy is the } \\
\text { recommended treatment for patients with CTEPH }\end{array}$} & । & C \\
\hline \multicolumn{2}{|c|}{$\begin{array}{l}\text { Once perfusion scanning and/or CT angiography } \\
\text { show signs compatible with CTEPH, the } \\
\text { patient should be referred to a centre } \\
\text { with expertise in surgical pulmonary } \\
\text { endarterectomy }\end{array}$} & lia & C \\
\hline \multicolumn{2}{|c|}{$\begin{array}{l}\text { The selection of patients for surgery should } \\
\text { be based on the extent and location of the } \\
\text { organised thrombi, on the degree of } \mathrm{PH}, \\
\text { and on the presence of comorbidities }\end{array}$} & lia & C \\
\hline \multicolumn{2}{|c|}{$\begin{array}{l}\text { PAH-specific drug therapy may be indicated } \\
\text { in selected CTEPH patients such as patients } \\
\text { not candidates for surgery or patients with } \\
\text { residual PH after pulmonary endarterectomy }\end{array}$} & lib & C \\
\hline
\end{tabular}

PH: pulmonary hypertension; $\bar{P}$ pa: mean pulmonary arterial pressure; $P$ pcw: pulmonary capillary wedge pressure; PVR: pulmonary vascular resistance; $C T$ : computed tomography; PAH: pulmonary arterial hypertension. *: class of recommendation; ": level of evidence.

healthcare providers to obtain best outcomes for patients, and undertake audit, research and education. Since, in general, centres with a high volume of patients tend to obtain best outcomes, referral centres will need to have sufficient patients on chronic therapy and new referrals to warrant this status. A referral centre should follow at least 50 patients with PAH or CTEPH and should receive at least two new referrals per month with documented PAH or CTEPH. These figures can be adapted according to specific country characteristics (population distribution, geographical constraints, etc.).

Facilities and skills in a referral centre [180]:

1. Referral centres will provide care by a multiprofessional team, which should as a minimum comprise:

- Two consultant physicians (normally from either or both of cardiology and respiratory medicine) with a special interest in $\mathrm{PH}$

- Clinical nurse specialist

- Radiologist with expertise in PH imaging

- Cardiologist with expertise in echocardiography

- Access to psychological and social work support

- Appropriate on-call cover and expertise. 


\begin{tabular}{|c|c|c|c|}
\hline TABLE 34 & $\begin{array}{l}\text { Recommendations for a pulmor } \\
\text { hypertension referral centre }\end{array}$ & & \\
\hline \multicolumn{2}{|l|}{ Statement } & Class $^{\#}$ & Level" \\
\hline \multicolumn{2}{|c|}{$\begin{array}{l}\text { Referral centres are required to provide care } \\
\text { by a multiprofessional team (cardiology and } \\
\text { respiratory medicine physicians, clinical nurse } \\
\text { specialist, radiologists, psychological and } \\
\text { social work support, appropriate on-call expertise) }\end{array}$} & 1 & C \\
\hline \multicolumn{2}{|c|}{$\begin{array}{l}\text { Referral centres are required to have direct } \\
\text { links and quick referral patterns to other } \\
\text { services (such as CTD service, family planning } \\
\text { service, PEA service, lung transplantation } \\
\text { service, adult congenital heart disease service) }\end{array}$} & 1 & C \\
\hline \multicolumn{2}{|c|}{$\begin{array}{l}\text { A referral centre should follow at least } 50 \\
\text { patients with PAH or CTEPH and should } \\
\text { receive at least two new referrals per month } \\
\text { with documented PAH or CTEPH }\end{array}$} & Ila & C \\
\hline \multicolumn{2}{|c|}{$\begin{array}{l}\text { Referral centres should perform at least } 20 \\
\text { vasoreactivity tests in PAH patients per year }\end{array}$} & Ila & C \\
\hline \multicolumn{2}{|c|}{$\begin{array}{l}\text { Referral centres should participate in } \\
\text { collaborative clinical research in PAH, which } \\
\text { includes phase II and phase III clinical trials }\end{array}$} & Ila & C \\
\hline
\end{tabular}

2. Referral centres will have the following facilities:

- A ward where staff have special expertise in $\mathrm{PH}$

- An intensive therapy unit with relevant expertise

- A specialist outpatient service

- Emergency care

- Diagnostic investigations including echocardiography, CT scanning, nuclear scanning, magnetic resonance imaging, ultrasound, exercise testing, lung function testing and catheterisation laboratory (with expertise in performing vasoreactivity test)

- Access to the full range of specific PAH drug therapy in their country.

3. There will be established links (e.g. referral criteria, patient pathway and clinical management protocols) to other services, which may not necessarily be on the same site:

- Genetics service (for research purposes)

- CTD service

- Family planning service

- PEA service

- Lung transplantation services

- Adult congenital heart disease service.

4. Referral centres are required to undertake a programme of clinical audit of outcomes, which will include survival analysis.
5. Referral centres will participate in collaborative clinical research in PAH, which includes phase II and phase III clinical trials.

6. Referral centres will provide regular education about all clinical aspects of $\mathrm{PH}$ to appropriate healthcare professionals.

7. Referral centres will have a link to their national and/or European pulmonary hypertension patients association.

Recommendations for a $\mathrm{PH}$ referral centre are summarised in table 34 .

\section{STATEMENT OF INTEREST}

Statements of interest for N. Galiè, M.M. Hoeper, M. Humbert, A. Torbicki, J-L. Vachiery, J.A. Barbera, M. Beghetti, P. Corris, S. Gaine, J.S. Gibbs, M.A. Gomez-Sanchez, C. Opitz, A. Peacock, L. Rubin and G. Simonneau can be found at www.erj.ersjournals.com/misc/ statements.dtl

\section{ACKNOWLEDGEMENTS}

Affiliations of the authors/Task Force members. N. Galiè, Institute of Cardiology, Bologna University Hospital Bologna, Italy. M.M. Hoeper, Dept of Pulmonary Medicine, Hannover Medical School, Hanover, Germany. M. Humbert, Service de Pneumologie et Réanimation Respiratoire, Hôpital Antoine Béclère, Clamart, France. A. Torbicki, Dept of Chest Medicine, Institute of Lung Diseases and Tuberculosis, Warsaw, Poland. J-L. Vachiery, Departemente de Cardiologie, Hôpital Erasme, Université Libre de Bruxelles, Brussels, Belgium. J.A. Barbera, Servei de Pneumologia, Hospital Clinic i Provincial de Barcelona, Barcelona, Spain. M. Beghetti, Unite de Cardiopediatrie, Hopital des Enfants, Geneva, Switzerland. P. Corris, Institute of Cellular Medicine, Newcastle University, Newcastle-upon-Tyne, UK. S. Gaine, Pulmonary Hypertension Unit, Mater Misericordiae University Hospital, Dublin, Ireland. J.S. Gibbs, Dept of Cardiology, Hammersmith Hospital, London, UK. M.A. Gomez-Sanchez, Dept of Microbiology, Hospital Doce de Octubre, Madrid, Spain. G. Jondeau, Service de Cardiologie, Hôpital Bichat, Paris, France. W. Klepetko, Division of Cardiothoracic Surgery, Medical University of Vienna, Vienna, Austria. C. Opitz, Dept of Internal Medicine/Cardiology, DRK Kliniken Berlin Köpenick, Berlin, Germany. A. Peacock, Scottish Pulmonary Vascular Unit, Western Infirmary, Glasgow, UK. L. Rubin, La Jolla, CA, USA. M. Zellweger, Cardiology Dept, University Hospital, Basel, Switzerland. G. Simonneau, Dept of Pneumology and ICU, Hopital Antoine Beclere, Clamart, France.

Members of the ESC Committee for Practice Guidelines (CPG). A Vahanian (Chairperson), Service de Cardiologie, Hopital Bichat, Paris, France. A. Auricchio, Dept of Cardiology, Fondazione Cardiocentre Ticino, Lugano, Ticino, Switzerland. J. Bax, Dept of Cardiology, Leiden University Medical Center, Leiden, The Netherlands. C. Ceconi, U.O. Cardiologia, Arcispedale S. Anna, Ferrara, Italy. V. Dean, ESC Practice Guidelines Dept, Les Templiers, Sophia Antipolis, France. G. Filippatos, Dept of Cardiology, HF Unit CCU, Attikon University Hospital, Athens, Greece. C. Funck-Brentano, Service de Pharmacologie, Hopital SaintAntoine, Paris, France. R. Hobbs, Primary Care and General Practice, University of Birmingham, Birmingham, UK. P. Kearney, Cork University Hospital, Wilton, Cork, Ireland. T. McDonagh, Royal Brompton Hospital, London, UK. K.H. McGregor, ESC Scientific Division Director, Les Templiers, Sophia Antipolis, France. B.A. Popescu, Cardiologist, Bucharest, Romania. Z. Reiner, University Hospital Center Zagreb, Zagreb, Croatia. U. Sechtem, Robert-Bosch Krankenhaus, Stuttgart, Germany. P.A. Sirnes, Cardiology Practice, Ostlandske Hjertsenter, Moss, Les Templiers, Sophia Anitpolis, Norway. M. Tendera, 3rd Division of Cardiology, Medical University of Silesia, Katowice, Poland. P. Vardas, Dept of Cardiology, Heraklion University Hospital, Stavrakia, Heraklion, Greece. P. Widimsky, Cardiocenter, 3rd Faculty of Medicine, Charles University, Prague, Czech Republic. 
Document reviewers. U. Sechtem, CPG Review Coordinator, Germany. N. Al Attar, Service de Chirurgie Cardiaque, Hôpital Bichat, Paris, France. F. Andreotti, Dept of Cardiovascular Medicine, Gemelli University Hospital, Rome, Italy. M. Aschermann, 2nd Dept of Internal Medicine, UFN, Prague, Czech Republic. R. Asteggiano, Torrino, Italy. R. Benza, Pittsburgh, PA, USA. R. Berger, University Medical Center Groningen, Groningen, the Netherlands. D. Bonnet, Cardiopédiatrie MC3 Hôpital Necker Enfants Malade, Paris, France. M. Delcroix, Dept of Pneumology, University Hospital Leuven, Leuven, Belgium. L. Howard, Dept of Cardiac Sciences, Hammersmith Hospital, London, UK. A.N. Kitsiou, Athens, Greece. I. Lang, Medical University of Vienna, Vienna, Austria. A. Maggioni, ANMCO Research Center, Florence, Italy. J.E. Nielsen-Kudsk, Aarhus University Hospital, Dept of Cardiology, Aarhus, Denmark. M. Park, University of Maryland School of Medicine, Baltimore, MD, USA. P. Perrone-Filardi, Federico II University of Naples, Naples, Italy. S. Price, Royal Brompton Hospital, London, UK. M.T. Subirana Domenech, Barcelona, Spain. A. Vonk-Noordegraaf, Dept of Pulmonary Medicine, Amsterdam, the Netherlands. J.L. Zamorano, Hospital Clinico San Carlos, Cardiologia, Madrid, Spain.

\section{REFERENCES}

1 Simonneau G, Robbins I, Beghetti M, et al. Updated clinical classification of pulmonary hypertension. J Am Coll Cardiol 2009; 54: Suppl. 1, S43-S54.

2 Hachulla E, Gressin V, Guillevin L, et al. Early detection of pulmonary arterial hypertension in systemic sclerosis: a French nationwide prospective multicenter study. Arthritis Rheum 2005; 52: $3792-3800$.

3 Humbert M, Sitbon O, Chaouat A, et al. Pulmonary arterial hypertension in France: results from a national registry. Am J Respir Crit Care Med 2006; 173: 1023-1030.

4 Peacock AJ, Murphy NF, McMurray JJV, et al. An epidemiological study of pulmonary arterial hypertension. Eur Respir J 2007; 30: 104-109.

5 Duffels MGJ, Engelfriet PM, Berger RMF, et al. Pulmonary arterial hypertension in congenital heart disease: an epidemiologic perspective from a Dutch registry. Int J Cardiol 2007; 120: 198-204.

6 Condliffe R, Kiely DG, Gibbs JS, et al. Improved outcomes in medically and surgically treated chronic thromboembolic pulmonary hypertension patients. Am J Respir Crit Care Med 2008; 177: $1122-1127$.

7 Hatano S, Strasser T. World Health Organization 1975. Primary pulmonary hypertension. Geneva: WHO; 1975.

8 D'Alonzo GE, Barst RJ, Ayres SM, et al. Survival in patients with primary pulmonary hypertension. Results from a national prospective registry. Ann Intern Med 1991; 115: 343-349.

9 Kovacs G, Berghold A, Scheidl S, et al. Pulmonary arterial pressure during rest and exercise in healthy subjects: a systematic review. Eur Respir J 2009; 34: 888-894.

10 Badesch BD, Champion HC, Gomez-Sanchez MA, et al. Diagnosis and assessment of pulmonary arterial hypertension. J Am Coll Cardiol 2009; 54: Suppl. 1, S55-S56.

11 Naeije R, Melot C, Niset G, et al. Mechanisms of improved arterial oxygenation after peripheral chemoreceptor stimulation during hypoxic exercise. J Appl Physiol 1993; 74: 1666-1671.

12 Oudiz RJ. Pulmonary hypertension associated with left-sided heart disease. Clin Chest Med 2007; 28: 233-241.

13 Simonneau G, Galie' N, Rubin LJ, et al. Clinical classification of pulmonary hypertension. J Am Coll Cardiol 2004; 43: S5-S12.

14 Machado RD, Aldred MA, James V, et al. Mutations of the TGFbeta type II receptor BMPR2 in pulmonary arterial hypertension. Hum Mutat 2006; 27: 121-132.
15 Machado R, Eickelberg O, Elliott CG, et al. Genetics and genomics of pulmonary arterial hypertension. J Am Coll Cardiol 2009; 54: Suppl. 1, S32-S42.

16 Galie' N, Manes A, Palazzini M, et al. Management of pulmonary arterial hypertension associated with congenital systemic-topulmonary shunts and Eisenmenger's syndrome. Drugs 2008; 68: 1049-1066.

17 Lapa MS, Ferreira EV, Jardim C, et al. [Clinical characteristics of pulmonary hypertension patients in two reference centers in the city of Sao Paulo]. Rev Assoc Med Bras 2006; 52: 139-143.

18 Gladwin MT, Sachdev V, Jison ML, et al. Pulmonary hypertension as a risk factor for death in patients with sickle cell disease. N Engl J Med 2004; 350: 886-895.

19 Reiter CD, Wang X, Tanus-Santos JE, et al. Cell-free hemoglobin limits nitric oxide bioavailability in sickle-cell disease. Nat Med 2002; 8: 1383-1389.

20 Pietra GG, Capron F, Stewart S, et al. Pathologic assessment of vasculopathies in pulmonary hypertension. J Am Coll Cardiol 2004; 43: S25-S32.

21 Tuder RM, Abman SH, Braun T, et al. Pulmonary circulation: development and pathology. J Am Coll Cardiol 2009; 54: Suppl. 1, S3-S9.

22 Fedullo PF, Auger WR, Kerr KM, et al. Chronic thromboembolic pulmonary hypertension. N Engl J Med 2001; 345: 1465-1472.

23 Galie N, Kim NHS. Pulmonary microvascular disease in chronic thromboembolic pulmonary hypertension. Proc Am Thorac Soc 2006; 3: 571-576.

24 Humbert M, Morrell NW, Archer SL, et al. Cellular and molecular patho-biology of pulmonary arterial hypertension. J Am Coll Cardiol 2004; 43: S13-S24.

25 Hassoun PM, Mouthon L, Barbera JA, et al. Inflammation, growth factors, and pulmonary vascular remodeling. J Am Coll Cardiol 2009; 54: Suppl. 1, S10-S19.

26 Morrell N, Adnot S, Archer S, et al. Cellular and molecular basis of pulmonary arterial hypertension. J Am Coll Cardiol 2009; 54: Suppl. 1, S20-S31.

27 Delgado JF, Conde E, Sanchez V, et al. Pulmonary vascular remodeling in pulmonary hypertension due to chronic heart failure. Eur J Heart Fail 2005; 7: 1011-1016.

28 Lang IM. Chronic thromboembolic pulmonary hypertension-not so rare after all. N Engl J Med 2004; 350: 2236-2238.

29 Gabbay E, Yeow W, Playford D. Pulmonary arterial hypertension $(\mathrm{PAH})$ is an uncommon cause of pulmonary hypertension $(\mathrm{PH})$ in an unselected population: the Armadale echocardiography study. Am J Resp Crit Care Med 2007; 175: A713.

30 Sztrymf B, Coulet F, Girerd B, et al. Clinical outcomes of pulmonary arterial hypertension in carriers of BMPR2 mutation. Am J Respir Crit Care Med 2008; 177: 1377-1383.

31 Trembath RC, Thomson JR, Machado RD, et al. Clinical and molecular genetic features of pulmonary hypertension in patients with hereditary hemorrhagic telangiectasia. $N$ Engl J Med 2001; 345: 325-334.

32 Ghio S, Gavazzi A, Campana C, et al. Independent and additive prognostic value of right ventricular systolic function and pulmonary artery pressure in patients with chronic heart failure. J Am Coll Cardiol 2001; 37: 183-188.

33 Vahanian A, Baumgartner H, Bax J, et al. Guidelines on the management of valvular heart disease: The Task Force on the Management of Valvular Heart Disease of the European Society of Cardiology. Eur Heart J 2007; 28: 230-268.

34 Eddahibi S, Chaouat A, Morrell N, et al. Polymorphism of the serotonin transporter gene and pulmonary hypertension in chronic obstructive pulmonary disease. Circulation 2003; 108: 1839-1844.

35 Thabut G, Dauriat G, Stern JB, et al. Pulmonary hemodynamics in advanced COPD candidates for lung volume reduction surgery or lung transplantation. Chest 2005; 127: 1531-1536. 
36 Chaouat A, Bugnet AS, Kadaoui N, et al. Severe pulmonary hypertension and chronic obstructive pulmonary disease. Am J Respir Crit Care Med 2005; 172: 189-194.

37 Lettieri CJ, Nathan SD, Barnett SD, et al. Prevalence and outcomes of pulmonary arterial hypertension in advanced idiopathic pulmonary fibrosis. Chest 2006; 129: 746-752.

38 Cottin V, Nunes H, Brillet PY, et al. Combined pulmonary fibrosis and emphysema: a distinct underrecognised entity. Eur Respir J 2005; 26: 586-593.

39 Pengo V, Lensing $\mathrm{AW}$, Prins $\mathrm{MH}$, et al. Incidence of chronic thromboembolic pulmonary hypertension after pulmonary embolism. N Engl J Med 2004; 350: 2257-2264.

40 Hoeper MM, Mayer E, Simonneau G, et al. Chronic thromboembolic pulmonary hypertension. Circulation 2006; 113: 2011-2020.

41 Bristow MR, Minobe W, Rasmussen R, et al. Beta-adrenergic neuroeffector abnormalities in the failing human heart are produced by local rather than systemic mechanisms. J Clin Invest 1992; 89: 803-815.

42 Keogh A, Benza RL, Corris $\mathrm{P}$, et al. Interventional and surgical modalities of treatment in pulmonary arterial hypertension. J Am Coll Cardiol 2009; 54: S67-S77.

43 Abraham WT, Raynolds MV, Gottschall B, et al. Importance of angiotensin-converting enzyme in pulmonary hypertension. Cardiology 1995; 10: Suppl. 1, 9-15.

44 Rich S, Dantzker DR, Ayres SM, et al. Primary pulmonary hypertension. A national prospective study. Ann Intern Med 1987; 107: 216-223.

45 Gaine SP, Rubin LJ. Primary pulmonary hypertension. Lancet 1998; 352: 719-725.

46 Tongers J, Schwerdtfeger B, Klein G, et al. Incidence and clinical relevance of supraventricular tachyarrhythmias in pulmonary hypertension. Am Heart J 2007; 153: 127-132.

47 Fisher MR, Forfia PR, Chamera E, et al. Accuracy of Doppler echocardiography in the hemodynamic assessment of pulmonary hypertension. Am J Resp Crit Care Med 2009; 179: 615-621.

48 McQuillan BM, Picard MH, Leavitt M, et al. Clinical correlates and reference intervals for pulmonary artery systolic pressure among echocardiographically normal subjects. Circulation 2001; 104: 2797-2802.

49 Sitbon O, Lascoux-Combe C, Delfraissy JF, et al. Prevalence of HIV-related pulmonary arterial hypertension in the current antiretroviral therapy era. Am J Respir Crit Care Med 2008; 177: 108-113.

50 Mukerjee D, St George D, Knight C, et al. Echocardiography and pulmonary function as screening tests for pulmonary arterial hypertension in systemic sclerosis. Rheumatology 2004; 43: 461-466.

51 Launay D, Mouthon L, Hachulla E, et al. Prevalence and characteristics of moderate to severe pulmonary hypertension in systemic sclerosis with and without interstitial lung disease. J Rheumatol 2007; 34: 1005-1011.

52 Grunig E, Weissmann S, Ehlken N, et al. Stress Doppler echocardio-graphy in relatives of patients with idiopathic and familial pulmonary arterial hypertension: results of a multicenter European analysis of pulmonary artery pressure response to exercise and hypoxia. Circulation 2009; 119: 1747-1757.

53 Tunariu N, Gibbs SJR, Win Z, et al. Ventilation-perfusion scintigraphy is more sensitive than multidetector CTPA in detecting chronic thromboembolic pulmonary disease as a treatable cause of pulmonary hypertension. J Nucl Med 2007; 48: 680-684.

54 Resten A, Maitre S, Humbert M, et al. Pulmonary hypertension: $\mathrm{CT}$ of the chest in pulmonary venoocclusive disease. Am J Roentgenol 2004; 183: 65-70.

55 Dartevelle P, Fadel E, Mussot S, et al. Chronic thromboembolic pulmonary hypertension. Eur Respir J 2004; 23: 637-648.
56 Reichelt A, Hoeper MM, Galanski M, et al. Chronic thromboembolic pulmonary hypertension: evaluation with 64-detector row CT versus digital substraction angio-graphy. Eur J Radiol 2009; 71: 49-54.

57 Marcus JT, Gan CT, Zwanenburg JJ, et al. Interventricular mechanical asynchrony in pulmonary arterial hypertension: left-to-right delay in peak shortening is related to right ventricular overload and left ventricular underfilling. J Am Coll Cardiol 2008; 51: 750-757.

58 Torbicki A Cardiac magnetic resonance in pulmonary arterial hypertension, a step in the right direction. Eur Heart J 2007; 28: 1187-1189.

59 Rich S, Kieras K, Groves B, et al. Antinuclear antibodies in primary pulmonary hypertension. J Am Coll Cardiol 1986; 8: 1307-1311.

60 Chu JW, Kao PN, Faul JL, et al. High prevalence of autoimmune thyroid disease in pulmonary arterial hypertension. Chest 2002; 122: $1668-1673$.

61 Albrecht T, Blomley MJ, Cosgrove DO, et al. Non-invasive diagnosis of hepatic cirrhosis by transit-time analysis of an ultrasound contrast agent. Lancet 1999; 353: 1579-1583.

62 Naeije R. Hepatopulmonary syndrome and portopulmonary hypertension. Swiss Med Wkly 2003; 133: 163-169.

63 Hoeper MM, Lee SH, Voswinckel R, et al. Complications of right heart catheterization procedures in patients with pulmonary hypertension in experienced centers. J Am Coll Cardiol 2006; 48: 2546-2552.

64 Paulus WJ, Tschope C, Sanderson JE, et al. How to diagnose diastolic heart failure: a consensus statement on the diagnosis of heart failure with normal left ventricular ejection fraction by the Heart Failure and Echocardiography Associations of the European Society of Cardiology. Eur Heart J 2007; 28: 2539-2550.

65 Rich S, Kaufmann E, Levy PS. The effect of high doses of calcium-channel blockers on survival in primary pulmonary hypertension. N Engl J Med 1992; 327: 76-81.

66 Sitbon O, Humbert M, Jais X, et al. Long-term response to calcium channel blockers in idiopathic pulmonary arterial hypertension. Circulation 2005; 111: 3105-3111.

67 Galie N, Ussia G, Passarelli P, et al. Role of pharmacologic tests in the treatment of primary pulmonary hypertension. Am J Cardiol 1995; 75: 55A-62A.

68 McLaughlin VV, Genthner DE, Panella MM, et al. Reduction in pulmonary vascular resistance with long-term epoprostenol (prostacyclin) therapy in primary pulmonary hypertension. N Engl J Med 1998; 338: 273-277.

69 McLaughlin VV, Presberg KW, Doyle RL, et al. Prognosis of pulmonary arterial hypertension ACCP evidence-based clinical practice guidelines. Chest 2004; 126: 78S-92S.

70 Eysmann SB, Palevsky HI, Reichek N, et al. Two-dimensional and Doppler-echocardiographic and cardiac catheterization correlates of survival in primary pulmonary hypertension. Circulation 1989; 80: 353-360.

71 Raymond RJ, Hinderliter AL, Willis PW, et al. Echocardiographic predictors of adverse outcomes in primary pulmonary hypertension. J Am Coll Cardiol 2002; 39: 1214-1219.

72 Tei C, Dujardin KS, Hodge DO, et al. Doppler echocardiographic index for assessment of global right ventricular function. $J \mathrm{Am}$ Soc Echocardiogr 1996; 9: 838-847.

73 Yeo TC, Dujardin KS, Tei C, et al. Value of a Doppler-derived index combining systolic and diastolic time intervals in predicting outcome in primary pulmonary hypertension. Am J Cardiol 1998; 81: 1157-1161.

74 Forfia PR, Fisher MR, Mathai SC, et al. Tricuspid annular displacement predicts survival in pulmonary hypertension. Am J Respir Crit Care Med 2006; 174: 1034-1041.

75 Wensel R, Opitz CF, Anker SD, et al. Assessment of survival in patients with primary pulmonary hypertension: importance 
of cardiopulmonary exercise testing. Circulation 2002; 106: 319-324.

76 Barst RJ, McGoon M, Torbicki A, et al. Diagnosis and differential assessment of pulmonary arterial hypertension. J Am Coll Cardiol 2004; 43: S40-S47.

77 ATS Committee on Proficiency Standards for Clinical Pulmonary Function LaboratoriesATS statement: guidelines for the sixminute walk test. Am J Respir Crit Care Med 2002; 166: 111-117.

78 Miyamoto S, Nagaya N, Satoh T, et al. Clinical correlates and prognostic significance of six-minute walk test in patients with primary pulmonary hypertension. Comparison with cardiopulmonary exercise testing. Am J Respir Crit Care Med 2000; 161 487-492.

79 Sitbon $\mathrm{O}$, Humbert $\mathrm{M}$, Nunes $\mathrm{H}$, et al. Long-term intravenous epoprostenol infusion in primary pulmonary hypertension: prognostic factors and survival. J Am Coll Cardiol 2002; 40: 780-788.

80 Paciocco G, Martinez F, Bossone E, et al. Oxygen desaturation on the six-minute walk test and mortality in untreated primary pulmonary hypertension. Eur Respir J 2001; 17: 647-652.

81 Oudiz RJ, Barst RJ, Hansen JE, et al. Cardiopulmonary exercise testing and six-minute walk correlations in pulmonary arterial hypertension. Am J Cardiol 2006; 97: 123-126.

82 Barst RJ, McGoon M, Mc Laughlin VV, et al. Beraprost therapy for pulmonary arterial hypertension. J Am Coll Cardiol 2003; 41: 2125.

83 Barst RJ, Langleben D, Frost A, et al. Sitaxsentan therapy for pulmonary arterial hypertension. Am J Respir Crit Care Med 2004; 169: 441-447.

84 Ross RM. ATS/ACCP statement on cardiopulmonary exercise testing. Am J Respir Crit Care Med 2003; 167: 1451.

85 Palange $\mathrm{P}$, Ward SA, Carlsen $\mathrm{KH}$, et al. Recommendations on the use of exercise testing in clinical practice. Eur Respir J 2007; 29 : 185-209.

86 Voelkel MA, Wynne KM, Badesch DB, et al. Hyperuricemia in severe pulmonary hypertension. Chest 2000; 117: 19-24.

87 Nagaya N, Nishikimi T, Uematsu M, et al. Plasma brain natriuretic peptide as a prognostic indicator in patients with primary pulmonary hypertension. Circulation 2000; 102: 865-870.

88 Williams MH, Handler CE, Akram R, et al. Role of N-terminal brain natriuretic peptide (N-TproBNP) in scleroderma-associated pulmonary arterial hypertension. Eur Heart J 2006; 27: 1485-1494.

89 Fijalkowska A, Kurzyna M, Torbicki A, et al. Serum N-terminal brain natriuretic peptide as a prognostic parameter in patients with pulmonary hypertension. Chest 2006; 129: 1313-1321.

90 Andreassen AK, Wergeland R, Simonsen $\mathrm{S}$, et al. N-terminal pro-B-type natriuretic peptide as an indicator of disease severity in a heterogeneous group of patients with chronic precapillary pulmonary hypertension. Am J Cardiol 2006; 98: 525-529.

91 Torbicki A, Kurzyna M, Kuca P, et al. Detectable serum cardiac troponin $\mathrm{T}$ as a marker of poor prognosis among patients with chronic precapillary pulmonary hypertension. Circulation 2003, 108: 844-848.

92 Lankeit M, Dellas C, Panzenbock A, et al. Heart-type fatty acidbinding protein for risk assessment of chronic thromboembolic pulmonary hypertension. Eur Respir J 2008; 31: 1024-1029.

93 Nickel N, Kempf T, Tapken H, et al. Growth differentiation factor-15 in idiopathic pulmonary arterial hypertension. Am J Respir Crit Care Med 2008; 178: 534-541.

94 McLaughlin VV, McGoon MD. Pulmonary arterial hypertension. Circulation 2006; 114: 1417-1431.

95 Sitbon O, McLaughlin VV, Badesch DB, et al. Survival in patients with class III idiopathic pulmonary arterial hypertension treated with first line oral bosentan compared with an historical cohort of patients started on intravenous epoprostenol. Thorax 2005; 60: $1025-1030$.
96 Sun XG, Hansen JE, Oudiz R, et al. Exercise pathophysiology in patients with primary pulmonary hypertension. Circulation 2001; 104: 429-435.

97 McLaughlin VV, Shillington A, Rich S. Survival in primary pulmonary hypertension: the impact of epoprostenol therapy. Circulation 2002; 106: 1477-1482.

98 McLaughlin VV, Sitbon O, Badesch DB, et al. Survival with firstline bosentan in patients with primary pulmonary hypertension. Eur Respir J 2005; 25: 244-249.

99 Galie N, Manes A, Negro L, et al. A meta-analysis of randomized controlled trials in pulmonary arterial hypertension. Eur Heart J 2009; 30: 394-403.

100 Loewe B, Graefe K, Ufer C, et al. Anxiety and depression in patients with pulmonary hypertension. Psycosom Med 2004; 66: 831-836

101 Mereles D, Ehlken N, Kreuscher S, et al. Exercise and respiratory training improve exercise capacity and quality of life in patients with severe chronic pulmonary hypertension. Circulation 2006; 114: 1482-1489.

102 The Task Force on the Management of Cardiovascular Diseases During Pregnancy of the European Society of CardiologyExpert consensus document on management of cardiovascular diseases during pregnancy. Eur Heart J 2003; 24: 761-781.

103 Bedard E, Dimopoulos K, Gatzoulis MA. Has there been any progress made on pregnancy outcomes among women with pulmonary arterial hypertension? Eur Heart J 2009; 30: 256-265.

104 Thorne S, Nelson-Piercy C, MacGregor A, et al. Pregnancy and contraception in heart disease and pulmonary arterial hypertension. J Fam Plann Reprod Health Care 2006; 32: 75-81.

105 Bendayan D, Hod M, Oron G, et al. Pregnancy outcome in patients with pulmonary arterial hypertension receiving prostacyclin therapy. Obstet Gynecol 2005; 106: 1206-1210.

106 Bonnin M, Mercier FJ, Sitbon O, et al. Severe pulmonary hypertension during pregnancy: mode of delivery and anesthetic management of 15 consecutive cases. Anestesiology 2005; 102: 1133-1137.

107 Fuster V, Steele PM, Edwards WD, et al. Primary pulmonary hypertension: natural history and the importance of thrombosis Circulation 1984; 70: 580-587.

108 Herve P, Humbert M, Sitbon O, et al. Pathobiology of pulmonary hypertension: the role of platelets and thrombosis. Clin Chest Med 2001; 22: 451-458.

109 Hoeper MM, Sosada M, Fabel H. Plasma coagulation profiles in patients with severe primary pulmonary hypertension. Eur Respir J 1998; 12: 1446-1449.

110 Huber K, Beckmann R, Frank H, et al. Fibrinogen, t-PA, and PAI-1 plasma levels in patients with pulmonary hypertension. Am J Respir Crit Care Med 1994; 150: 929-933.

111 Sandoval J, Aguirre JS, Pulido T, et al. Nocturnal oxygen therapy in patients with the Eisenmenger syndrome. Am J Respir Crit Care Med 2001; 164: 1682-1687.

112 Weitzenblum E, Sautegeau A, Ehrhart M, et al. Long-term oxygen therapy can reverse the progression of pulmonary hypertension in patients with chronic obstructive pulmonary disease. Am Rev Respir Dis 1985; 131: 493-498.

113 Rich S, Seidlitz M, Dodin E, et al. The short-term effects of digoxin in patients with right ventricular dysfunction from pulmonary hypertension. Chest 1998; 114: 787-792.

114 Mukerjee D, St George D, Coleiro B, et al. Prevalence and outcome in systemic sclerosis associated pulmonary arterial hypertension: application of a registry approach. Ann Rheum Dis 2003; 62: 1088-1093.

115 Jones DA, Benjamin CW, Linseman DA. Activation of thromboxane and prostacyclin receptors elicits opposing effects on vascular smooth muscle cell growth and mitogen-activated protein kinase signaling cascades. Mol Pharmacol 1995; 48: 890-896. 
116 Galie N, Manes A, Branzi A. Prostanoids for pulmonary arterial hypertension. Am J Respir Med 2003; 2: 123-137.

117 Rubin LJ, Mendoza J, Hood M, et al. Treatment of primary pulmonary hypertension with continuous intravenous prostacyclin (epoprostenol). Results of a randomized trial. Ann Intern Med 1990; 112: 485-491.

118 Barst RJ, Rubin LJ, Long WA, et al. A comparison of continuous intravenous epoprostenol (prostacyclin) with conventional therapy for primary pulmonary hypertension. The Primary Pulmonary Hypertension Study Group. N Engl J Med 1996; 334: 296-302.

119 Badesch DB, Tapson VF, McGoon MD, et al. Continuous intravenous epoprostenol for pulmonary hypertension due to the scleroderma spectrum of disease. A randomized, controlled trial. Ann Intern Med 2000; 132: 425-434.

120 Rosenzweig EB, Kerstein D, Barst RJ. Long-term prostacyclin for pulmonary hypertension with associated congenital heart defects. Circulation 1999; 99: 1858-1865.

121 Krowka MJ, Frantz RP, McGoon MD, et al. Improvement in pulmonary hemodynamics during intravenous epoprostenol (prostacyclin): a study of 15 patients with moderate to severe portopulmonary hypertension. Hepatology 1999; 30: 641-648.

122 Nunes $H$, Humbert M, Sitbon O, et al. Prognostic factors for survival in human immunodeficiency virus-associated pulmonary arterial hypertension. Am J Respir Crit Care Med 2003; 167: 1433-1439.

123 Cabrol S, Souza R, Jais X, et al. Intravenous epoprostenol in inoperable chronic thromboembolic pulmonary hypertension. J Heart Lung Transplant 2007; 26: 357-362.

124 Doran AK, Ivy DD, Barst RJ, et al. Guidelines for the prevention of central venous catheter-related blood stream infections with prostanoid therapy for pulmonary arterial hypertension. Int $J$ Clin Pract Suppl. 2008; 160: 5-9.

125 Olschewski H, Simonneau G, Galie N, et al. Inhaled iloprost in severe pulmonary hypertension. N Engl J Med 2002; 347: 322-329.

126 McLaughlin VV, Oudiz RJ, Frost A, et al. Randomized study of adding inhaled iloprost to existing bosen-tan in pulmonary arterial hypertension. Am J Respir Crit Care Med 2006; 174: 12571263.

127 Higenbottam T, Butt AY, McMahon A, et al. Long-term intravenous prostaglandin (epoprostenol or iloprost) for treatment of severe pulmonary hypertension. Heart 1998; 80: 151-155.

128 Simonneau G, Barst RJ, Galie N, et al. Continuous subcutaneous infusion of treprostinil, a prostacyclin analogue, in patients with pulmonary arterial hypertension. A double-blind, randomized, placebo-controlled trial. Am J Respir Crit Care Med 2002; 165: 800-804.

129 Barst RJ, Galie N, Naeije R, et al. Long-term outcome in pulmonary arterial hypertension patients treated with subcutaneous treprostinil. Eur Respir J 2006; 28: 1195-1203.

130 Lang I, Gomez-Sanchez M, Kneussl M, et al. Efficacy of long-term subcutaneous treprostinil sodium therapy in pulmonary hypertension. Chest 2006; 129: 1636-1643.

131 Tapson VF, Gomberg-Maitland M, McLaughlin VV, et al. Safety and efficacy of IV treprostinil for pulmonary arterial hypertension: a prospective, multicenter, open-label, 12-week trial. Chest 2006; 129: 683-688.

132 Sitbon O, Manes A, Jais X, et al. Rapid switch from intravenous epoprostenol to intravenous treprostinil in patients with pulmonary arterial hypertension. J Cardiovasc Pharmacol 2007; 49: $1-5$.

133 McLaughlin V, Rubin L, Benza RL, et al. TRIUMPH I: efficacy and safety of inhaled treprostinil sodium in patients with pulmonary arterial hypertension. Am J Respir Crit Care Med 2009; 177: A965.

134 Galie N, Humbert M, Vachiery JL, et al. Effects of beraprost sodium, an oral prostacyclin analogue, in patients with pulmonary arterial hypertension: a randomised, double-blind placebo-controlled trial. J Am Coll Cardiol 2002; 39: 1496-1502.

135 Giaid A, Yanagisawa M, Langleben D, et al. Expression of endothelin-1 in the lungs of patients with pulmonary hypertension. N Engl J Med 1993; 328: 1732-1739.

136 Stewart DJ, Levy RD, Cernacek $\mathrm{P}$, et al. Increased plasma endothelin-1 in pulmonary hypertension: marker or mediator of disease? Ann Intern Med 1991; 114: 464-469.

137 Galie N, Manes A, Branzi A. The endothelin system in pulmonary arterial hypertension. Cardiovasc Res 2004; 61: 227-237.

138 Channick RN, Simonneau G, Sitbon O, et al. Effects of the dual endothelin-receptor antagonist bosentan in patients with pulmonary hypertension: a randomised placebo-controlled study. Lancet 2001; 358: 1119-1123.

139 Rubin LJ, Badesch DB, Barst RJ, et al. Bosentan therapy for pulmonary arterial hypertension. $N$ Engl J Med 2002; 346: 896-903.

140 Humbert M, Barst RJ, Robbins IM, et al. Combination of bosentan with epoprostenol in pulmonary arterial hypertension: BREATHE-2. Eur Respir J 2004; 24: 353-359.

141 Galie' N, Rubin LJ, Hoeper M, et al. Treatment of patients with mildly symptomatic pulmonary arterial hypertension with bosentan (EARLY study): a double-blind, randomised controlled trial. Lancet 2008; 371: 2093-2100.

142 Galie N, Beghetti M, Gatzoulis MA, et al. Bosentan therapy in patients with Eisenmenger syndrome: a multicenter, doubleblind, randomized, placebo-controlled study. Circulation 2006; 114: 48-54.

143 Barst RJ, Langleben D, Badesch D, et al. Treatment of pulmonary arterial hypertension with the selective endothelin-A receptor antagonist sitaxsentan. J Am Coll Cardiol 2006; 47: 2049-2056.

144 Benza RL, Barst RJ, Galie N, et al. Sitaxsentan for the treatment of pulmonary arterial hypertension: a one year, prospective, open label, observation of outcome and survival. Chest 2008; 134: 775-782.

145 Galie N, Badesch BD, Oudiz R, et al. Ambrisentan therapy for pulmonary arterial hypertension. J Am Coll Cardiol 2005; 46: 529-535.

146 Galie N, Olschewski H, Oudiz RJ, et al. Ambrisentan for the treatment of pulmonary arterial hypertension. Results of the ambrisentan in pulmonary arterial hypertension, randomized, double-blind, placebo-controlled, multicenter, efficacy (ARIES) study 1 and 2. Circulation 2008; 117: 3010-3019.

147 McGoon M, Frost A, Oudiz R, et al. Ambrisentan therapy in patients with pulmonary arterial hypertension who discontinued bosentan or sitaxsentan due to liver function test abnormalities. Chest 2009; 135: 122-129.

148 Wharton J, Strange JW, Moller GMO, et al. Antiproliferative effects of phosphodiesterase type 5 inhibition in human pulmonary artery cells. Am J Respir Crit Care Med 2005; 172: 105-113.

149 Tantini B, Manes A, Fiumana E, et al. Antiproliferative effect of sildenafil on human pulmonary artery smooth muscle cells. Basic Res Cardiol 2005; 100: 131-138.

150 Ghofrani HA, Voswinckel R, Reichenberger F, et al. Differences in hemodynamic and oxygenation responses to three different phosphodiesterase- 5 inhibitors in patients with pulmonary arterial hypertension: a randomized prospective study. J Am Coll Cardiol 2004; 44: 1488-1496.

151 Bhatia S, Frantz RP, Severson CJ, et al. Immediate and long-term hemodynamic and clinical effects of sildenafil in patients with pulmonary arterial hypertension receiving vasodilator therapy. Mayo Clin Proc 2003; 78: 1207-1213.

152 Michelakis ED, Tymchak W, Noga M, et al. Long-term treatment with oral sildenafil is safe and improves functional capacity and 
hemodynamics in patients with pulmonary arterial hypertension. Circulation 2003; 108: 2066-2069.

153 Ghofrani HA, Schermuly RT, Rose F, et al. Sildenafil for longterm treatment of nonoperable chronic thromboembolic pulmonary hypertension. Am J Respir Crit Care Med 2003; 167: 11391141.

154 Galie N, Ghofrani HA, Torbicki A, et al. Sildenafil citrate therapy for pulmonary arterial hypertension. New Engl J Med 2005; 353: 2148-2157.

155 Badesch DB, Hill NS, Burgess G, et al. Sildenafil for pulmonary arterial hypertension associated with connective tissue disease. J Rheumatol 2007; 34: 2417-2422.

156 Simonneau G, Rubin L, Galie N, et al. Addition of sildenafil to long-term intravenous epoprostenol therapy in patients with pulmonary arterial hypertension. Ann Intern Med 2008; 149: 521-530.

157 Galiè N, Brundage B, Ghofrani A, et al. Tadalafil therapy for pulmonary arterial hypertension. Circulation 2009; 119: 28942903.

158 Ghofrani HA, Rose F, Schermuly RT, et al. Oral sildenafil as longterm adjunct therapy to inhaled iloprost in severe pulmonary arterial hypertension. J Am Coll Cardiol 2003; 42: 158-164.

159 Hoeper MM, Faulenbach C, Golpon H, et al. Combination therapy with bosentan and sildenafil in idiopathic pulmonary arterial hypertension. Eur Respir J 2004; 24: 1007-1010.

160 Hoeper M, Taha N, Bekjarova A, et al. Bosentan treatment in patients with primary pulmonary hypertension receiving nonparenteral prostanoids. Eur Respir J 2003; 22: 330-334.

161 Mathai SC, Girgis RE, Fisher MR, et al. Addition of sildenafil to bosentan monotherapy in pulmonary arterial hypertension. Eur Respir J 2007; 29: 469-475.

162 Hoeper MM, Markevych I, Spiekerkoetter E, et al. Goal-oriented treatment and combination therapy for pulmonary arterial hypertension. Eur Respir J 2005; 26: 858-863.

163 McLaughlin VV, Oudiz RJ, Frost A, et al. Randomized study of adding inhaled iloprost to existing bosentan in pulmonary arterial hypertension. Am J Respir Crit Care Med 2006; 174: 12571263.

164 Hoeper M, Leuchte H, Halank M, et al. Combining inhaled iloprost with bosentan in patients with idiopathic pulmonary arterial hypertension. Eur Respir J 2006; 4: 691-694.

165 Paul GA, Gibbs JS, Boobis AR, et al. Bosentan decreases the plasma concentration of sildenafil when coprescribed in pulmonary hypertension. Br J Clin Pharmacol 2005; 60: 107-112.

166 Humbert M, Segal ES, Kiely DG, et al. Results of European postmarketing surveillance of bosentan in pulmonary hypertension. Eur Respir J 2007; 30: 338-344.

167 Wrishko RE, Dingemanse J, Yu A, et al. Pharmacokinetic interaction between tadalafil and bosentan in healthy male subjects. J Clin Pharmacol 2008; 48: 610-618.

168 Hoeper MM, Galie N, Murali S, et al. Outcome after cardiopulmonary resuscitation in patients with pulmonary arterial hypertension. Am J Respir Crit Care Med 2002; 165: 341-344.

169 Rozkovec A, Montanes P, Oakley CM. Factors that influence the outcome of primary pulmonary hypertension. Br Heart J 1986; 55 $449-458$.

170 Sandoval J, Gaspar J, Pulido T, et al. Graded balloon dilation atrial septostomy in severe primary pulmonary hypertension. A therapeutic alternative for patients nonresponsive to vasodilator treatment. J Am Coll Cardiol 1998; 32: 297-304.

171 Kurzyna M, Dabrowski M, Bielecki D, et al. Atrial septostomy in treatment of end-stage right heart failure in patients with pulmonary hypertension. Chest 2007; 131: 977-983.

172 Althoff TF, Knebel F, Panda A, et al. Long-term follow-up of a fenestrated Amplatzer atrial septal occluder in pulmonary arterial hypertension. Chest 2008; 133: 283-285.
173 Orens JB, Estenne M, Arcasoy S, et al. International guidelines for the selection of lung transplant candidates: 2006 update-a consensus report from the Pulmonary Scientific Council of the International Society for Heart and Lung Transplantation. J Heart Lung Transplant 2006; 25: 745-755.

174 Trulock EP, Edwards LB, Taylor DO, et al. Registry of the International Society for Heart and Lung Transplantation: twenty third official adult lung and heart lung transplantation report-2006. J Heart Lung Transplant 2006; 25: 880-892.

175 Waddell TK, Bennett L, Kennedy R, et al. Heart-lung or lung transplantation for Eisenmenger syndrome. J Heart Lung Transplant 2002; 21: 731-737.

176 Barst RJ, Gibbs JS, Ghofrani HA, et al. Updated evidence-based treatment algorithm in pulmonary arterial hypertension. $J$ Am Coll Cardiol 2009; 54: S78-S84.

177 Committee for Practice Guidelines (CPG) of the European Society of Cardiology. Recommendations for Task Force Creation and Report Production. A document for Task Force members and expert panels responsible for the creation and production of Guidelines and Expert Consensus Documents Committee for Practice Guidelines (CPG) of the European Society of Cardiology. European Society of Cardiology Website. www.escardio.org/ guidelines-surveys/esc-guidelines/about/Pages/rules-writing. aspx

178 Konduri GG. New approaches for persistent pulmonary hypertension of newborn. Clin Perinatol 2004; 31: 591-611.

179 Rosenzweig EB, Widlitz A, Barst R. Pulmonary arterial hypertension in children. Pediatr Pulmon 2004; 38: 2-22.

180 National Pulmonary Hypertension Centres of the UK and Ireland, Consensus statement on the management of pulmonary hypertension in clinical practice in the UK and Ireland. Heart 2008; 94: i1-i41.

181 Barst R, Ivy D, Widlitz AC, et al. Pharmacokinetics, safety, and efficacy of bosentan in pediatric patients with pulmonary arterial hypertension. Clin Pharmacol Ther 2003; 73: 372-382.

182 Rosenzweig EB, Ivy DD, Widlitz A, et al. Effects of long-term bosentan in children with pulmonary arterial hypertension. J Am Coll Cardiol 2005; 46: 697-704.

183 Humpl T, Reyes JT, Holtby $\mathrm{H}$, et al. Beneficial effect of oral sildenafil therapy on childhood pulmonary arterial hypertension: twelve-month clinical trial of a single-drug, open-label, pilot study. Circulation 2005; 111: 3274-3280.

184 Barst RJ, Maislin G, Fishman AP. Vasodilator therapy for primary pulmonary hypertension in children. Circulation 1999; 99: 1197-1208.

185 Lammers AE, Hislop AA, Flynn Y, et al. Epoprostenol treatment in children with severe pulmonary hypertension. Heart 2007; 93: 739-743.

186 Ivy DD, Doran AK, Smith KJ, et al. Short- and long-term effects of inhaled iloprost therapy in children with pulmonary arterial hypertension. J Am Coll Cardiol 2008; 51: 161-169.

187 Micheletti A, Hislop AA, Lammers A, et al. Role of atrial septostomy in the treatment of children with pulmonary arterial hypertension. Heart 2006; 92: 969-972.

188 Blanc J, Vouhe P, Bonnet D. Potts shunt in patients with pulmonary hypertension. N Engl J Med 2004; 350: 623.

189 Engelfriet PM, Duffels MGJ, Moller T, et al. Pulmonary arterial hypertension in adults born with a heart septal defect: the Euro Heart Survey on adult congenital heart disease. Heart 2007; 93: 682-687.

190 Beghetti M, Galiè N. Eisenmenger syndrome: a clinical perspective in a new therapeutic era of pulmonary arterial hypertension. J Am Coll Cardiol 2009; 53: 733-740.

191 Daliento L, Somerville J, Presbitero P, et al. Eisenmenger syndrome. Factors relating to deterioration and death. Eur Heart J 1998; 19: 1845-1855. 
192 Hopkins WE, Ochoa LL, Richardson GW, et al. Comparison of the hemodynamics and survival of adults with severe primary pulmonary hypertension or Eisenmenger syndrome. J Heart Lung Transplant 1996; 15: 100-105.

193 Diller GP, Gatzoulis MA. Pulmonary vascular disease in adults with congenital heart disease. Circulation 2007; 115: 1039-1050.

194 Hopkins WE. The remarkable right ventricle of patients with Eisenmenger syndrome. Coron Artery Dis 2005; 16: 19-25.

195 Broberg CS, Ujita M, Prasad S, et al. Pulmonary arterial thrombosis in Eisenmenger syndrome is associated with biventricular dysfunction and decreased pulmonary flow velocity. J Am Coll Cardiol 2007; 50: 634-642.

196 Gatzoulis MA, Beghetti M, Galie N, et al. Longer-term bosentan therapy improves functional capacity in Eisenmenger syndrome: results of the BREATHE-5 open-label extension study. Int $J$ Cardiol 2007; 127: 27-32.

197 Palazzini M, Manes A, Romanazzi S, et al. Effects of sildenafil treatment in patients with pulmonary hypertension associated with congenital cardiac shunts. Eur Heart J 2007; 28: 308.

198 Mukhopadhyay S, Sharma M, Ramakrishnan S, et al. Phosphodiesterase-5 inhibitor in Eisenmenger syndrome: a preliminary observational study. Circulation 2006; 114: 1807-1810.

199 Dorfmuller P, Humbert M, Perros F, et al. Fibrous remodeling of the pulmonary venous system in pulmonary arterial hypertension associated with connective tissue diseases. Hum Pathol 2007; 38: 893-902.

200 Kawut SM, Taichman DB, Archer-Chicko CL, et al. Hemodynamics and survival in patients with pulmonary arterial hypertension related to systemic sclerosis. Chest 2003; 123: 344-350.

201 Jais X, Launay D, Yaici A, et al. Immunosuppressive therapy in lupus- and mixed connective tissue disease-associated pulmonary arterial hypertension: a retrospective analysis of twentythree cases. Arthritis Rheum 2008; 58: 521-531.

202 Girgis RE, Frost AE, Hill NS, et al. Selective endothelinA receptor antagonism with sitaxsentan for pulmonary arterial hypertension associated with connective tissue disease. Ann Rheum Dis 2007; 66: 1467-1472.

203 Oudiz RJ, Schilz RJ, Barst RJ, et al. Treprostinil, a prostacyclin analogue, in pulmonary arterial hypertension associated with connective tissue disease. Chest 2004; 126: 420-427.

204 Herve $\mathrm{P}$, Lebrec D, Brenot F, et al. Pulmonary vascular disorders in portal hypertension. Eur Respir J 1998; 11: 1153-1166.

205 Hoeper MM, Krowka MJ, Strassburg CP. Portopulmonary hypertension and hepatopulmonary syndrome. Lancet 2004; 363: 1461-1468.

206 Krowka MJ, Swanson KL, Frantz RP, et al. Portopulmonary hypertension: results from a 10-year screening algorithm. Hepatology 2006; 44: 1502-1510.

207 Provencher S, Herve P, Jais X, et al. Deleterious effects of betablockers on exercise capacity and hemodynamics in patients with portopulmonary hypertension. Gastroenterology 2006; 130: $120-126$.

208 Hoeper MM, Halank M, Marx C, et al. Bosentan therapy for portopulmonary hypertension. Eur Respir J 2005; 25: 502-508.

209 Reichenberger F, Voswinckel R, Steveling E, et al. Sildenafil treatment for portopulmonary hypertension. Eur Respir J 2006; 28: 563-567.

210 Kuo PC, Johnson LB, Plotkin JS, et al. Continuous intravenous infusion of epoprostenol for the treatment of portopulmonary hypertension. Transplantation 1997; 63: 604-606.

211 Hoeper MM, Seyfarth HJ, Hoeffken G, et al. Experience with inhaled iloprost and bosentan in portopulmonary hypertension. Eur Respir J 2007; 30: 1096-1102.

212 Krowka MJ, Plevak DJ, Findlay JY, et al. Pulmonary hemodynamics and perioperative cardiopulmonary-related mortality in patients with porto-pulmonary hypertension undergoing liver transplantation. Liver Transpl 2000; 6: 443-450.

213 Grannas G, Neipp M, Hoeper MM, et al. Indications for and outcomes after combined lung and liver transplantation: a singlecenter experience on 13 consecutive cases. Transplantation 2008; 85: 524-531.

214 Opravil M, Peche're M, Speich R, et al. HIV-associated primary pulmonary hypertension. A case control study. Swiss HIV Cohort Study. Am J Respir Crit Care Med 1997; 155: 990-995.

215 Cea-Calvo L, Escribano Subias P, Tello de Menesses R, et al. Treatment of HIV-associated pulmonary hypertension with treprostinil. Rev Esp Cardiol 2003; 56: 421-425.

216 Ghofrani HA, Friese G, Discher T, et al. Inhaled iloprost is a potent acute pulmonary vasodilator in HIV-related severe pulmonary hypertension. Eur Respir J 2004; 23: 321-326.

217 Sitbon O, Gressin V, Speich R, et al. Bosentan for the treatment of human immunodeficiency virus-associated pulmonary arterial hypertension. Am J Respir Crit Care Med 2004; 170: 1212-1217.

218 Barbaro G, Lucchini A, Pellicelli AM, et al. Highly active antiretroviral therapy compared with HAART and bosentan in combination in patients with HIV-associated pulmonary hypertension. Heart 2006; 92: 1164-1166.

219 Holcomb BW Jr, Loyd JE, Ely EW, et al. Pulmonary venoocclusive disease: a case series and new observations. Chest 2000; 118: 1671-1679.

220 Runo JR, Vnencak-Jones CL, Prince M, et al. Pulmonary venoocclusive disease caused by an inherited mutation in bone morphogenetic protein receptor II. Am J Respir Crit Care Med 2003; 167: 889-894.

221 Mandel J, Mark EJ, Hales CA. Pulmonary veno-occlusive disease. Am J Respir Crit Care Med 2000; 162: 1964-1973.

222 Rabiller A, Jais X, Hamid A, et al. Occult alveolar haemorrhage in pulmonary veno-occlusive disease. Eur Respir J 2006; 27: 108-113.

223 Montani D, Price LC, Dorfmuller P, et al. Pulmonary venoocclusive disease. Eur Respir J 2009; 33: 189-200.

224 Humbert M, Maître S, Capron F, et al. Pulmonary edema complicating continuous intravenous prostacyclin in pulmonary capillary hemangiomatosis. Am J Respir Crit Care Med 1998; 157: 1681-1685.

225 Grigioni F, Potena L, Galie N, et al. Prognostic implications of serial assessments of pulmonary hypertension in severe chronic heart failure. J Heart Lung Transplant 2006; 25: 1241-1246.

226 Task Force for Diagnosis and Treatment of Acute and Chronic Heart Failure 2008 of European Society of Cardiology, Dickstein $\mathrm{K}$, Cohen-Solal A, et al. ESC Guidelines for the diagnosis and treatment of acute and chronic heart failure 2008: The Task Force for the Diagnosis and Treatment of Acute and Chronic Heart Failure 2008 of the European Society of Cardiology. Developed in collaboration with the Heart Failure Association of the ESC (HFA) and endorsed by the European Society of Intensive Care Medicine (ESICM). Eur Heart J 2008; 29: 2388-2442.

227 Hoeper M, Barbera JA, Channick R, et al. Diagnosis, assessment, and treatment of non-PAH pulmonary hypertension. J Am Coll Cardiol 2009; 54: Suppl. 1, S85-S96.

228 Aurigemma GP, Gaasch WH. Clinical practice. Diastolic heart failure. N Engl J Med 2004; 351: 1097-1105.

229 Costanzo MR, Augustine S, Bourge R, et al. Selection and treatment of candidates for heart transplantation. A statement for health professionals from the Committee on Heart Failure and Cardiac Transplantation of the Council on Clinical Cardiology, American Heart Association. Circulation 1995; 92: 3593-3612.

230 Chang PP, Longenecker JC, Wang NY, et al. Mild vs. severe pulmonary hypertension before heart transplantation: different effects on posttransplantation pulmonary hypertension and mortality. J Heart Lung Transplant 2005; 24: 998-1007. 
231 Costard-Jackle A, Fowler MB. Influence of preoperative pulmonary artery pressure on mortality after heart transplantation: testing of potential reversibility of pulmonary hypertension with nitroprusside is useful in defining a high risk group. J Am Coll Cardiol 1992; 19: 48-54.

232 Califf RM, Adams KF, McKenna WJ, et al. A randomized controlled trial of epoprostenol therapy for severe congestive heart failure: The Flolan International Randomized Survival Trial (FIRST). Am Heart J 1997; 134: 44-54.

233 Packer M, McMurray J, Massie BM, et al. Clinical effects of endothelin receptor antagonism with bosentan in patients with severe chronic heart failure: results of a pilot study. I Card Fail 2005; 11: 12-20.

234 Kalra PR, Moon JC, Coats AJ. Do results of the ENABLE (Endothelin Antagonist Bosentan for Lowering Cardiac Events in Heart Failure) study spell the end for non-selective endothelin antagonism in heart failure? Int J Cardiol 2002; 85: 195-197.

235 Lewis GD, Shah R, Shahzad K, et al. Sildenafil improves exercise capacity and quality of life in patients with systolic heart failure and secondary pulmonary hypertension. Circulation 2007; 116: $1555-1562$.

236 Roques F, Nashef SA, Michel P, et al. Risk factors and outcome in European cardiac surgery: analysis of the EuroSCORE multinational database of 19030 patients. Eur J Cardiothorac Surg 1999; 15: 816-822.

237 Oswald-Mammosser M, Weitzenblum E, Quoix E, et al. Prognostic factors in COPD patients receiving long-term oxygen therapy. Importance of pulmonary artery pressure. Chest 1995; 107: 1193-1198.

238 Kessler R, Faller M, Fourgaut G, et al. Predictive factors of hospitalization for acute exacerbation in a series of 64 patients with chronic obstructive pulmonary disease. Am J Respir Crit Care Med 1999; 159: 158-164.

239 Arcasoy SM, Christie JD, Ferrari VA, et al. Echocardiographic assessment of pulmonary hypertension in patients with advance lung disease. Am J Respir Crit Care Med 2003; 167: 735-740.

240 Fisher MR, Criner GJ, Fishman AP, et al. Estimating pulmonary artery pressures by echocardiography in patients with emphysema. Eur Respir J 2007; 30: 914-921.

241 Agusti AG, Barbera JA, Roca J, et al. Hypoxic pulmonary vasoconstriction and gas exchange during exercise in chronic obstructive pulmonary disease. Chest 1990; 97: 268-275.

242 Barbera JA, Roger N, Roca J, et al. Worsening of pulmonary gas exchange with nitric oxide inhalation in chronic obstructive pulmonary disease. Lancet 1996; 347: 436-440.

243 Morrell NW, Higham MA, Phillips PG, et al. Pilot study of losartan for pulmonary hypertension in chronic obstructive pulmonary disease. Respir Res 2005; 6: 88-95.

244 Saadjian AY, Philip-Joet FF, Vestri R, et al. Long-term treatment of chronic obstructive lung disease by nifedipine: an 18-month haemodynamic study. Eur Respir J 1988; 1: 716-720.

245 Ghofrani HA, Wiedemann R, Rose F, et al. Sildenafil for treatment of lung fibrosis and pulmonary hypertension: a randomised controlled trial. Lancet 2002; 360: 895-900.
246 Olschewski $\mathrm{H}$, Ghofrani $\mathrm{HA}$, Walmrath $\mathrm{D}$, et al. Inhaled prostacyclin and iloprost in severe pulmonary hypertension secondary to lung fibrosis. Am J Respir Crit Care Med 1999; 160: 600-607.

247 Alp S, Skrygan M, Schmidt WE, et al. Sildenafil improves hemodynamic parameters in COPD-an investigation of six patients. Pulm Pharmacol Ther 2006; 19: 386-390.

248 Collard HR, Anstrom KJ, Schwarz MI, et al. Sildenafil improves walk distance in idiopathic pulmonary fibrosis. Chest 2007; 131: 897-899.

249 Gunther A, Enke B, Markart P, et al. Safety and tolerability of bosentan in idiopathic pulmonary fibrosis: an open label study. Eur Respir J 2007; 29: 713-719.

250 Madden BP, Allenby M, Loke TK, et al. A potential role for sildenafil in the management of pulmonary hypertension in patients with parenchymal lung disease. Vascul Pharmacol 2006; 44: 372-376

251 Rietema H, Holverda S, Bogaard HJ, et al. Sildenafil treatment in COPD does not affect stroke volume or exercise capacity. Eur Respir J 2008; 31: 759-764.

252 Torbicki A, Perrier A, Konstantinides S, et al. Guidelines on the diagnosis and management of acute pulmonary embolism: The Task Force for the Diagnosis and Management of Acute Pulmonary Embolism of the European Society of Cardiology (ESC). Eur Heart J 2008; 29: 2276-2315.

253 Rubin LJ, Hoeper MM, Klepetko W, et al. Current and future management of chronic thromboembolic pulmonary hypertension: from diagnosis to treatment responses. Proc Am Thorac Soc 2006; 3: 601-607.

254 Bonderman D, Wilkens H, Wakounig S, et al. Risk factors for chronic thromboembolic pulmonary hypertension. Eur Respir J 2009; 33: 325-331.

255 Bresser P, Fedullo PF, Auger WR, et al. Continuous intravenous epoprostenol for chronic thromboembolic pulmonary hypertension. Eur Respir J 2004; 23: 595-600.

256 Nagaya N, Sasaki N, Ando M, et al. Prostacyclin therapy before pulmonary thromboendarterectomy in patients with chronic thromboembolic pulmonary hypertension. Chest 2003; 123: 338-343.

257 Hoeper MM, Kramm T, Wilkens H, et al. Bosentan therapy for inoperable chronic thromboembolic pulmonary hypertension. Chest 2005; 128: 2363-2367.

258 Hughes R, George P, Parameshwar J, et al. Bosentan in inoperable chronic thromboembolic pulmonary hypertension. Thorax 2005; 60: 707.

259 Bonderman D, Nowotny R, Skoro-Sajer N, et al. Bosentan therapy for inoperable chronic thromboembolic pulmonary hypertension. Chest 2005; 128: 2599-2603.

260 Reichenberger F, Voswinckel R, Enke B, et al. Long-term treatment with sildenafil in chronic thromboembolic pulmonary hypertension. Eur Respir J 2007; 30: 922-927.

261 Jais X, D'Armini AM, Jansa P, et al. Bosentan for treatment of inoperable chronic thromboembolic pulmonary hypertension: BENEFiT (Bosentan Effects in iNopErable Forms of chronIc Thromboembolic pulmonary hypertension), a randomized, placebo-controlled trial. J Am Coll Cardiol 2008; 52: $2127-2134$. 